U.S. Geological Survey Natural Hazards Science StrategyPromoting the Safety, Security, and Economic Well-Being of the Nation

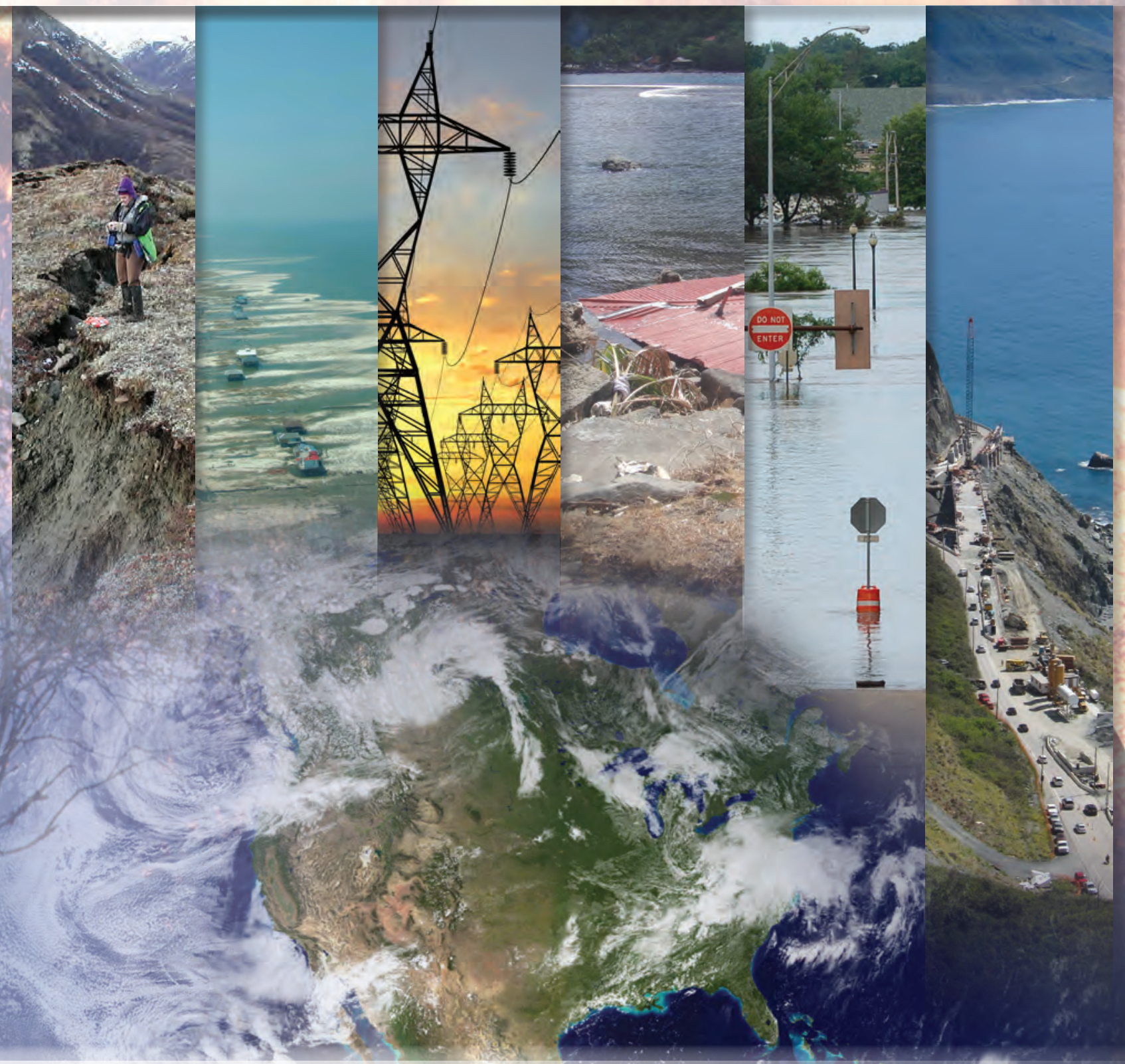

Circular 1383-F

U.S. Department of the Interior U.S. Geological Survey 


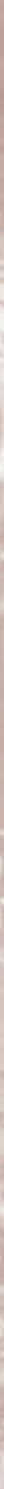

Cover. Clockwise left to right:

The Denali Fault, Alaska, displaced the ground surface by more than 6 meters on November 4, 2002, in a M 7.9 earthquake. The U.S. Geological Survey (USGS) monitors and studies earthquakes in the United States and around the world, providing warnings and other information to support mitigation and response. Photograph by Peter Haeussler, USGS.

Hurricane Katrina damaged and destroyed houses on Dauphin Island, Alabama, August 31, 2005. The USGS assesses coastal hazard vulnerability, including the severe beach erosion shown here. Photograph by USGS.

Electric power grids are vulnerable to changing space-weather conditions. The USGS maintains a network of magnetic observatories that are essential for real-time, space-weather situational awareness.

A roof moved into the ocean in Fagasa, American Samoa, during the tsunami that hit the island on Sept. 29, 2009. USGS researchers work to increase the understanding of tsunami processes and provide the National Oceanic and Atmospheric Administration (NOAA) with real-time earthquake information to create tsunami warnings. Photograph by Bruce Jaffe, USGS.

June 2008 flood at Cedar Rapids, lowa. USGS streamgages and on-site observations by USGS field staff provide critical data to flood forecasts made by NOAA. Photograph by Don Becker, USGS.

Landslides threaten human activities and a marine sanctuary along the coastline at Big Sur, California. The USGS works with the California Department of Transportation to understand landslide issues along this part of the California coast. Photograph by Mark Reid, USGS.

The Blue Marble. Image by NASA Goddard Space Flight Center.

Background. Front cover: Grass fire in eastern Washington, 2000. The USGS contributes data and information to national efforts to understand the causes and consequences of wildland fires. Photograph by Gary Wilson, Natural Resources Conservation Service, U.S. Department of Agriculture.

Back cover: Eruption of Okmok Volcano, Aleutian Islands, Alaska, Aug. 2, 2008. The USGS monitors volcanoes and provides warnings to the National Weather Service, the Federal Aviation Administration, and the airline industry because even remote eruptions can affect aviation worldwide. Photograph by Janet Schaefer, Alaska Division of Geological and Geophysical Surveys. 


\section{U.S. Geological Survey Natural Hazards Science Strategy-Promoting the Safety, Security, and Economic Well-Being of the Nation}

By Robert R. Holmes, Jr., Lucile M. Jones, Jeffery C. Eidenshink, Jonathan W. Godt, Stephen H. Kirby, Jeffrey J. Love, Christina A. Neal, Nathaniel G. Plant, Michael L. Plunkett, Craig S. Weaver, Anne Wein, and Suzanne C. Perry

Circular 1383-F 


\section{U.S. Department of the Interior \\ KEN SALAZAR, Secretary \\ U.S. Geological Survey \\ Marcia K. McNutt, Director}

U.S. Geological Survey, Reston, Virginia: 2013

For more information on the USGS - the Federal source for science about the Earth, its natural and living resources, natural hazards, and the environment, visit http://www.usgs.gov or call 1-888-ASK-USGS.

For an overview of USGS information products, including maps, imagery, and publications, visit http://www.usgs.gov/pubprod

Any use of trade, product, or firm names is for descriptive purposes only and does not imply endorsement by the U.S. Government.

Although this report is in the public domain, permission must be secured from the individual copyright owners to reproduce any copyrighted materials contained within this report.

Suggested citation:

Holmes, R.R., Jr., Jones, L.M., Eidenshink, J.C., Godt, J.W., Kirby, S.H., Love, J.J., Neal, C.A., Plant, N.G., Plunkett, M.L., Weaver, C.S., Wein, Anne, and Perry, S.C., 2013, U.S. Geological Survey natural hazards science strategyPromoting the safety, security, and economic well-being of the Nation: U.S. Geological Survey Circular 1383-F, 79 p. 


\section{Foreword}

In 2007, the U.S. Geological Survey (USGS) published a Bureau Science Strategy Facing Tomorrow's Challenges - U.S. Geological Survey Science in the Decade 2007-2017. It provided a view of the future, establishing science goals that reflected the USGS's fundamental mission in areas of societal impact such as energy and minerals, climate and land use change, ecosystems, natural hazards, environmental health, and water. Intended to inform long-term program planning, the strategy emphasizes how USGS science can make substantial contributions to the well-being of the Nation and the world.

In 2010, I realigned the USGS management and budget structure, changing it from a structure associated with scientific disciplines — Geography, Geology, Biology and Hydrology — to an issue-based organization along the lines of the Science Strategy. My aim was to align our management structure with our mission, our science priorities, our metrics for success, and our budget. An added benefit was that the USGS immediately appeared relevant to more Americans, and it became easier for those outside the agency to navigate our organizational structure to find where within the USGS they would find the solution to their problem. External partners rarely approached us with a problem in "geology," but they might need help with an issue in climate change or energy research.

The new organization is focused on seven science mission areas:

- Climate and Land Use Change

- Core Science Systems

- Ecosystems

- Energy and Minerals

- Environmental Health

- Natural Hazards

- Water

The scope of each of these new mission areas is broader than the science directions outlined in the USGS Science Strategy and together cover the scope of USGS science activities.

In 2010, I also commissioned seven Science Strategy Planning Teams (SSPTs) to draft science strategies for each USGS mission area. Although the existing Bureau Science Strategy could be a starting point for this exercise, the SSPTs had to go well beyond the scope of the existing document. What is of value and enduring from the work of the programs that existed under the former science disciplines needed to be reframed and reinterpreted under the new organization of the science mission areas. In addition, new opportunities for research directions have emerged in the five years since the Bureau Science Strategy was drafted, and exciting possibilities for cooperating and collaborating in new ways are enabled by the new mission focus of the organization.

Scientists from across the Bureau were selected for these SSPTs for their experience in strategic planning, broad range of experience and expertise, and knowledge of stakeholder needs and relationships. Each SSPT was charged with developing a long-term (10-year) science strategy that encompasses the portfolio of USGS science in the respective mission area. Each science strategy will reinforce others because scientific knowledge inherently has significance to multiple issues. Leadership of the USGS and the Department of the Interior will use the science vision and priorities developed in these strategies for program guidance, implementation planning, accountability reporting, and resource allocation. These strategies will guide science and technology investment and workforce and human capital strategies. They will inform our partners regarding opportunities for communication, collaboration, and coordination.

The USGS has taken a significant step toward demonstrating that we are ready to collaborate on the most pressing natural science issues of our day and the future. I believe a leadership aligned to support these issue-based science directions and equipped with the guidance provided in these new science strategies in the capable hands of our scientists will create a new era for USGS of which we can all be proud.

Marcia McNutt

Director 


\section{Contents}

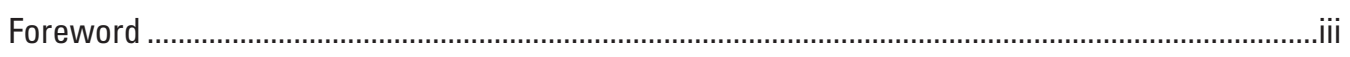

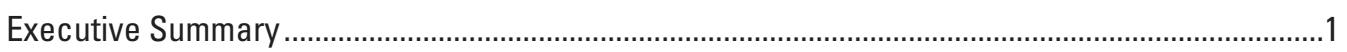

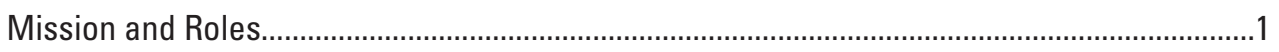

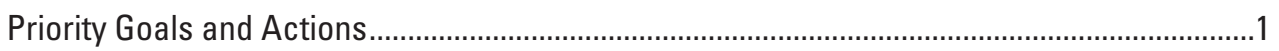

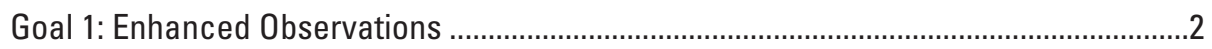

Core Responsibilities that Must be Sustained ........................................................

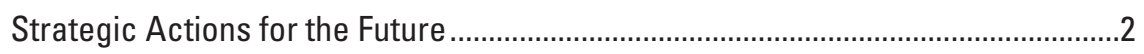

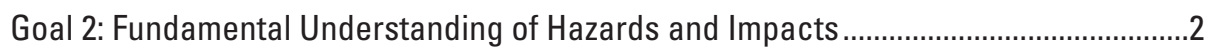

Core Responsibilities that Must be Sustained ......................................................

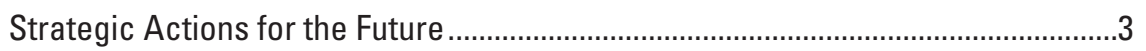

Goal 3: Improved Assessment Products and Services ....................................................

Core Responsibilities that Must be Sustained ..............................................................

Strategic Actions for the Future ................................................................................

Goal 4: Effective Situational Awareness.....................................................................

Core Responsibilities that Must be Sustained ..........................................................

Strategic Actions for the Future .................................................................................

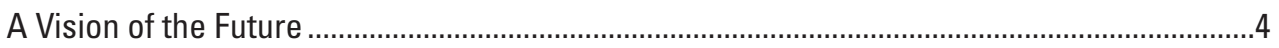

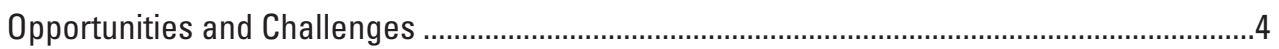

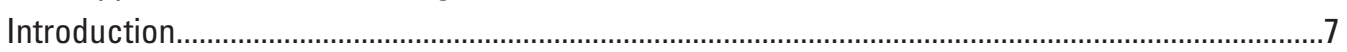

Mission Statement.

The USGS Role in Hazard Science .....................................................................................

Natural Hazards Science Strategy Planning Process.............................................................

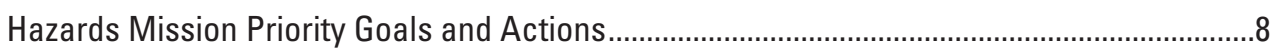

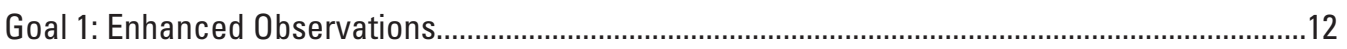

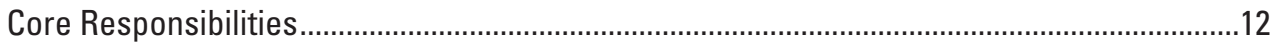

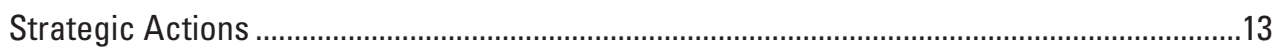

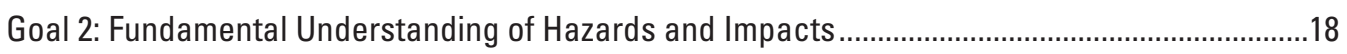

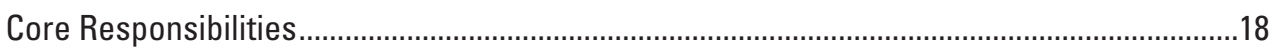

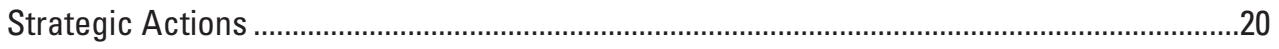

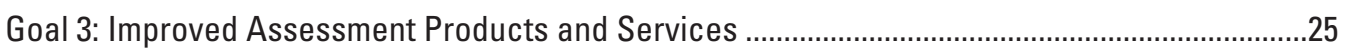

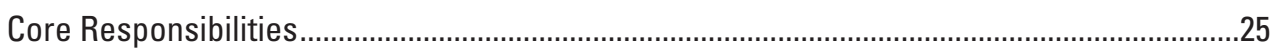

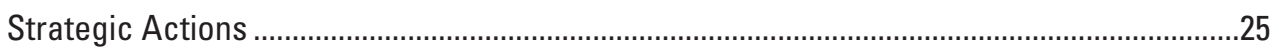

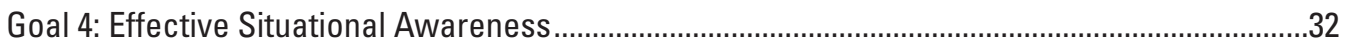

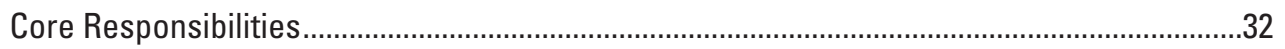

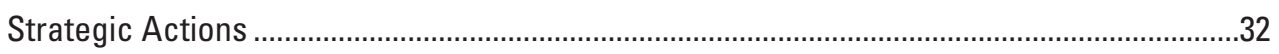

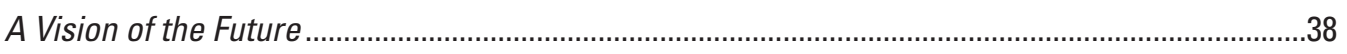

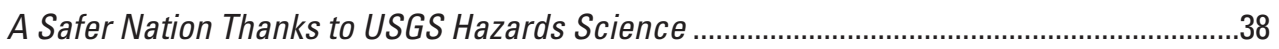


A Vision of USGS Hazard Science Successes of the Future ...................................................38

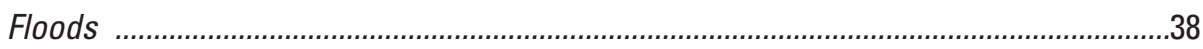

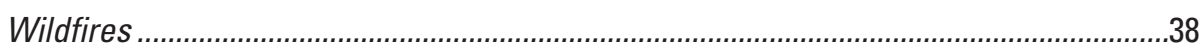

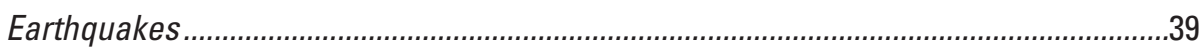

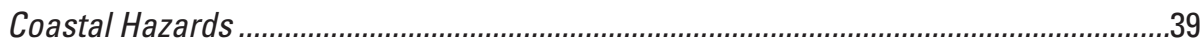

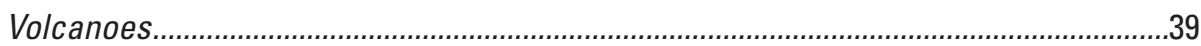

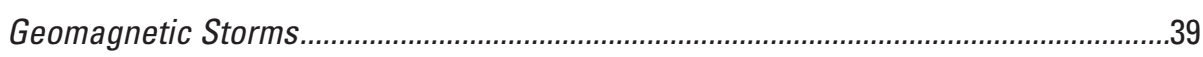

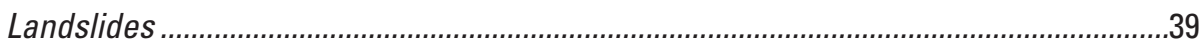

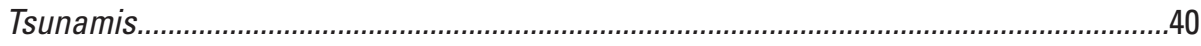

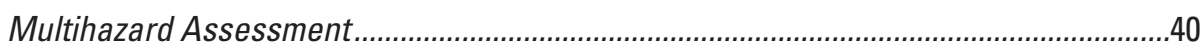

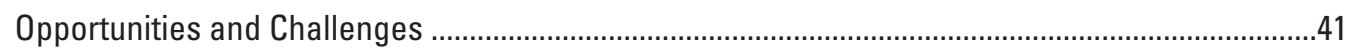

Planning and Interconnections Across the USGS Mission Areas .............................................48

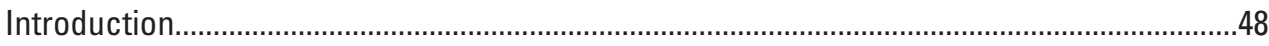

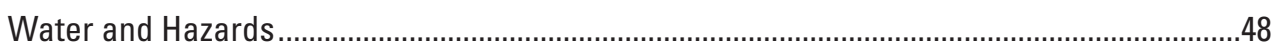

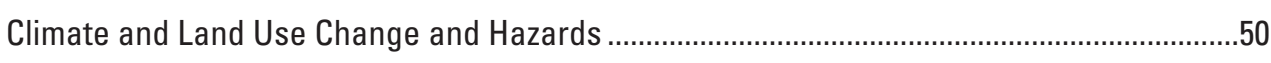

Energy and Minerals and Hazards...................................................................................

Environmental Health and Hazards .................................................................................51

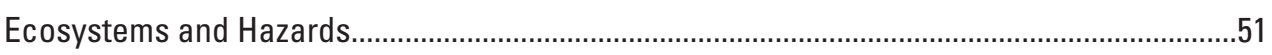

Core Science Systems and Hazards ...........................................................................52

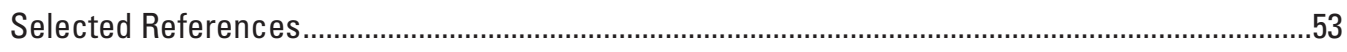

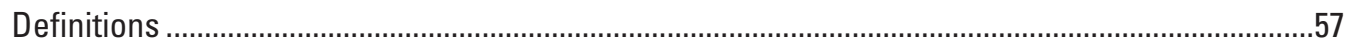

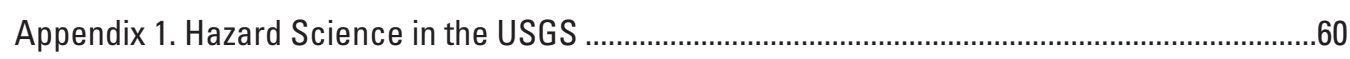

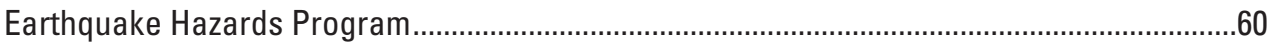

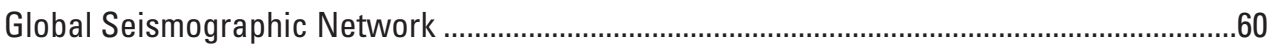

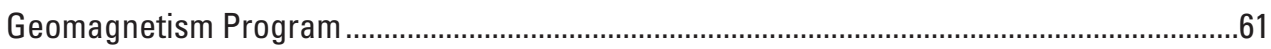

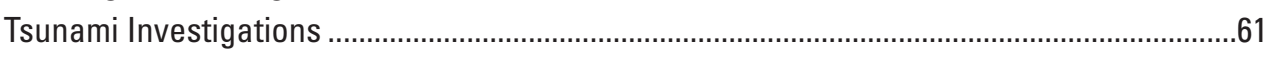

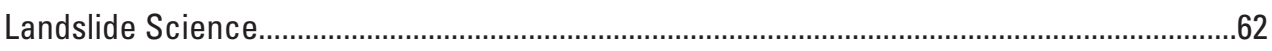

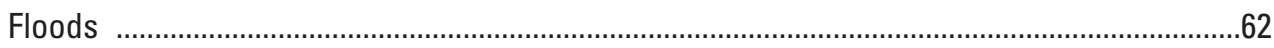

Hazard, Vulnerability, and Risk Study, and Decision Support ................................................63

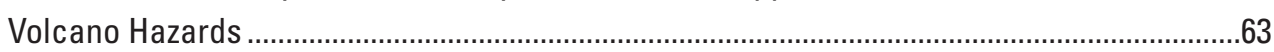

Appendix 2. The Domestic Value of USGS International Efforts in Hazard Science ........................65

Appendix 3. Hazards Science Strategy Planning Team: Composition, Charge,
Philosophy, and Process............................................................................................66

Selection Approach and Criteria for Strategic Actions ...........................................................68

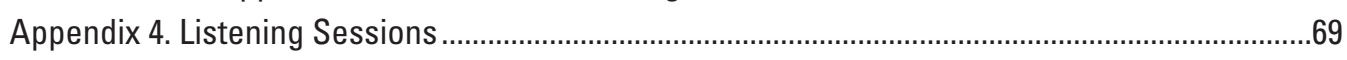

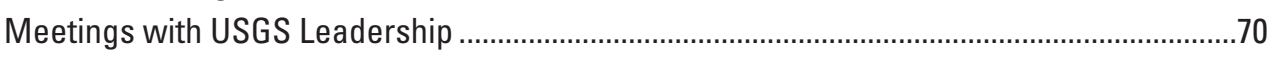

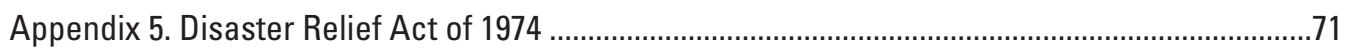




\section{Figures}

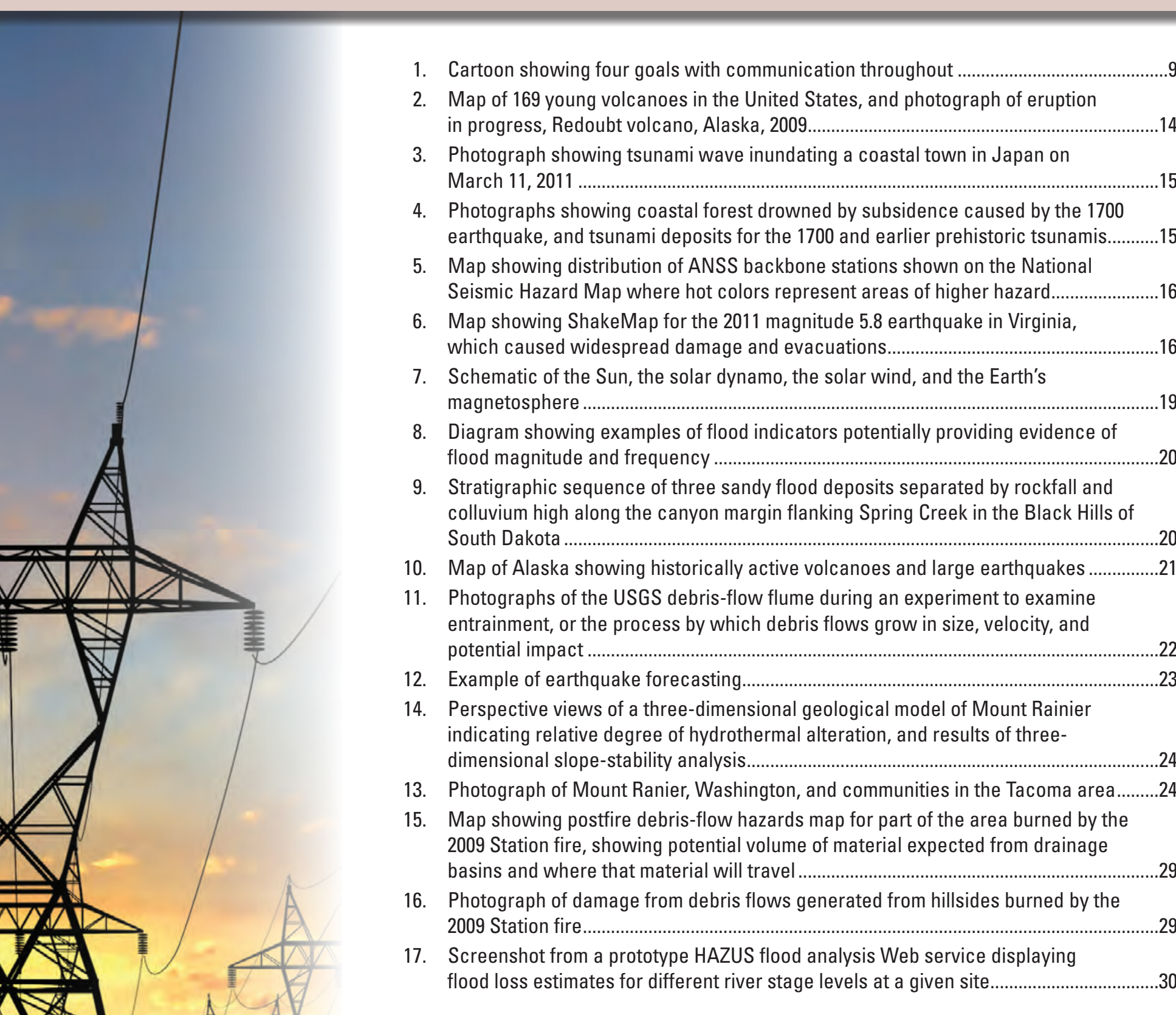


18. Map showing recent damaging hurricanes assessed by the USGS include Ivan (landfall near Gulf Shores, Alabama, on Sept. 16, 2004), Katrina (landfall at Plaquemines Parish, Louisiana, on Aug. 29, 2005), and Ike (landfall near Galveston, Texas, on Sept. 13, 2008).

19. Before and after photographs of Hurricane lke coastal impacts .....................................31

20. Map showing assessment of inundation potential near Galveston, Texas for Hurricane lke.

21. Photograph of Rapid Deployment Streamgage installed on the Minnesota River at Granite Falls, Minnesota. .34

22. Landsat 5 satellite image of the Wallow North Fire in east-central Arizona..

23. Screenshot of the U.S. Geological Survey's Volcano Hazards Program Web page.

24. Photograph of the public views Mount St. Helens from Johnston Ridge on October 1, 2004

25. Photograph of explosive activity at Mount St. Helens, October 1, 2004.........................37

26. Model of an atmospheric river storm

27. Lidar image revealing an intricate pattern of surface ruptures along the Borrego fault following the April 4, 2010, El Mayor-Cucapah earthquake (M 7.2) in Baja California, Mexico.

28. InSAR interferogram of Mount Peulik, a stratovolcano located about 550 kilometers southwest of Anchorage, Alaska

29. Image of 10-day burn probability perimeters derived from the FSPro analysis.

30. Photographs of Kilauea, the largest stationary source of $\mathrm{SO}_{2}$ in the United States

31. Photograph of installation of the Deadhorse, Prudhoe Bay, Alaska observatory, January 2010

32. Photograph of the island of Kasatochi, before and after eruption in 2008 ......................49

1-1. Map showing locations of USGS geomagnetic observatories. .61

1-2. Panoramic view of the San Juan, Puerto Rico geomagnetic observatory....

1-3. Pie diagram showing approximate U.S. Geological Survey appropriated and reimbursable hazard funding levels 


\section{Tables}

1. USGS assessment products in current use

2. Examples of USGS Products for warnings and situational awareness ...........................33

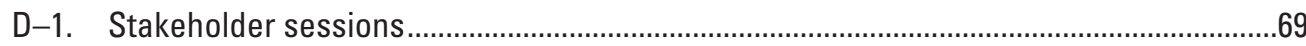

\section{Highlights}

Role of USGS in Federal Government. 10

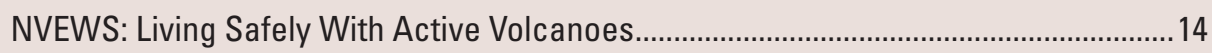

A Tale of Two Giant Earthquakes and Their Tsunamis ................................................... 15

U.S. National Seismic Hazard Maps: From USGS Science to a More

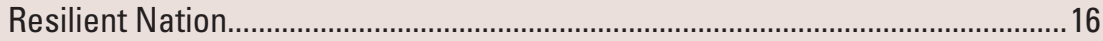

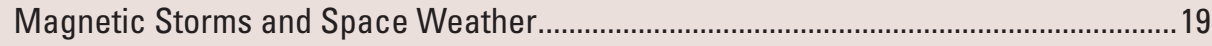

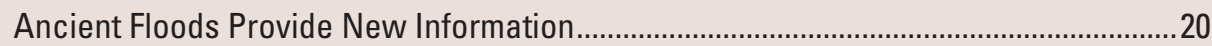

Alaska: A Geohazards Natural Laboratory for the Nation ..............................................21

Examining the Controls on Debris-Flow Initiation, Mobility, and Magnitude...................22

Today's Chance of an Earthquake: Real-Time Forecasts from the Advanced National Seismic System ...................................................................23

Using Aerogeophysical Mapping and 3D Analysis to Define Collapse-Prone

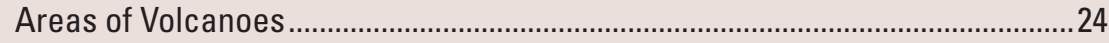

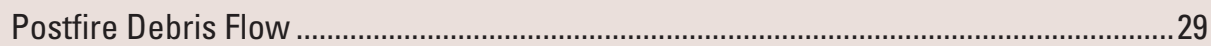

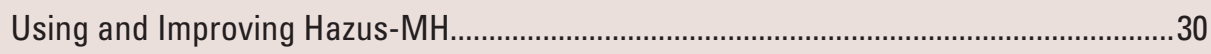

U.S. Geological Survey Role in Assessing Hurricane Impacts .........................................

Value of Rapid Deployment Streamgages For Floods...................................................34

Imagery for Emergency Response: the USGS Hazards Data Distribution System ..........35

USGS Hazard Web Pages: Popular and Highly Rated ...................................................36

Continuing Lessons in Managing Volcano Hazards: Mount St. Helens,

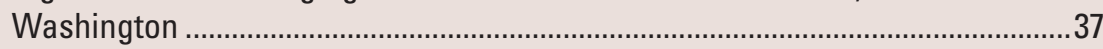

MHDP Scenarios for Building Networks and Doing Research..................................... 42

Lidar and InSAR: Powerful Tools for Assessments and Forecasts ..................................43

LANDFIRE: Geospatial Information for Strategic and Tactical Wildfire Planning........... 44

Volcanic Gas and Human Health: New Partnerships to Address

Emerging Hazards

Magnetic Orientation for Directional Drilling........................................................... 48

Hazardous Events and Ecosystem Dynamics .................................................................4 


\section{Abbreviations}

$\begin{array}{ll}\text { ANSS } & \text { Advanced National Seismic System } \\ \text { CDC } & \text { Centers for Disease Control and Prevention } \\ \text { CSS } & \text { Core Science Systems } \\ \text { DHS } & \text { Department of Homeland Security } \\ \text { EROS } & \text { Earth Resources Observation and Science Center } \\ \text { FEMA } & \text { Federal Emergency Management Agency } \\ \text { GPS } & \text { global positioning satellites } \\ \text { GSN } & \text { Global Seismic Network } \\ \text { H-SSPT } & \text { Natural Hazards Science Strategy Planning Team } \\ \text { HDDS } & \text { Hazards Data Distribution System } \\ \text { HREC } & \text { Hazard Response Executive Committee } \\ \text { MHDP } & \text { Multi-Hazards Demonstration Project } \\ \text { NASA } & \text { National Aeronautics and Space Administration } \\ \text { NEHRP } & \text { National Earthquake Hazard Reduction Program } \\ \text { NEIC } & \text { National Earthquake Information Center } \\ \text { NHMA } & \text { Natural Hazards Mission Area } \\ \text { NISAC } & \text { National Infrastructure Simulation and Analysis Center } \\ \text { NOAA } & \text { National Oceanic and Aeronautics Administration } \\ \text { NSF } & \text { National Science Foundation } \\ \text { NSIP } & \text { National Streamflow Information System } \\ \text { NVEWS } & \text { National Volcano Early Warning System } \\ \text { SAFRR } & \text { Science Application for Risk Reduction Project } \\ \text { USACE } & \text { Army Corps of Engineers } \\ \text { USAID } & \text { United States Agency for International Development } \\ \text { USFS } & \text { United States Forest Service } \\ \text { USGS } & \text { United States Geological Survey } \\ \text { WMA } & \text { Water Mission Area } \\ & \\ \text { Her }\end{array}$



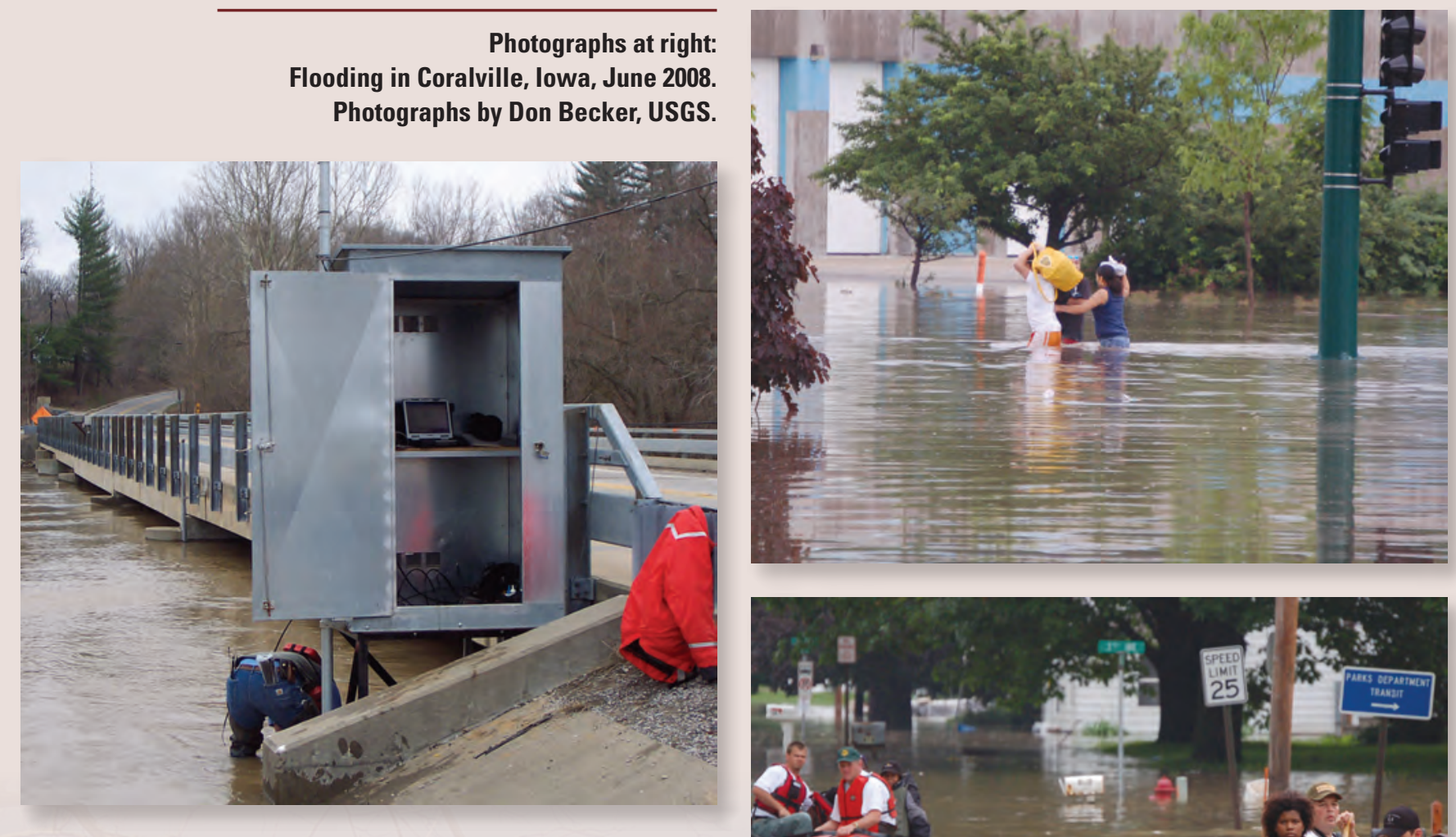

Top: Hydrographer repairing instrumentation on the Big Muddy River at Murphysboro, Illinois.

Bottom: Hydrographer determining outside stage for the Skillet Fork near Wayne City, Illinois. Photographs by Robert Holmes, USGS.

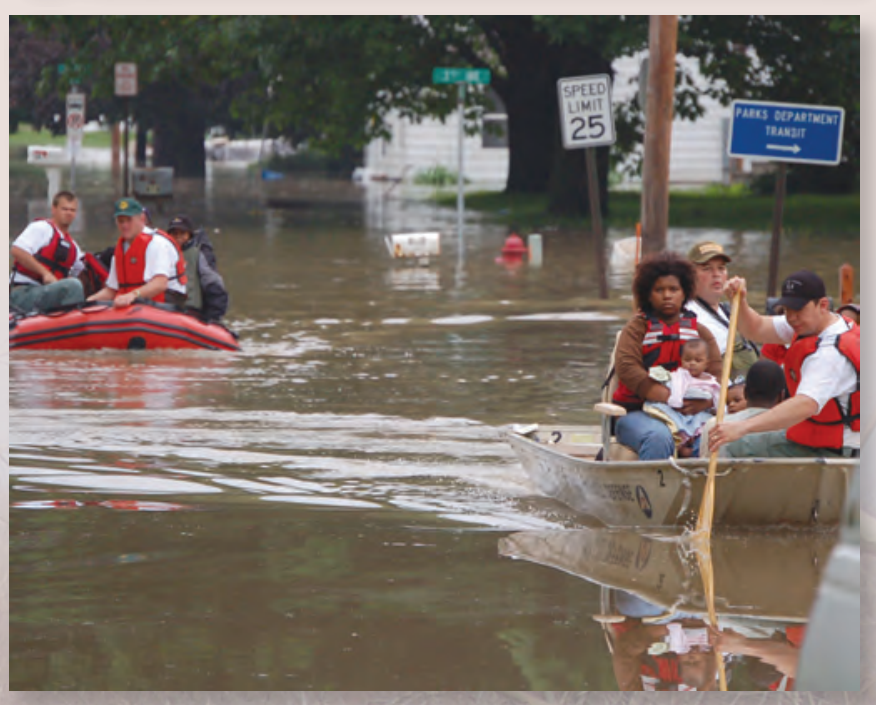




\title{
U.S. Geological Survey Natural Hazards Science Strategy-Promoting the Safety, Security, and Economic Well-Being of the Nation
}

\author{
By Robert R. Holmes, Jr., Lucile M. Jones, Jeffery C. Eidenshink, Jonathan W. Godt, Stephen H. Kirby,
} Jeffrey J. Love, Christina A. Neal, Nathaniel G. Plant, Michael L. Plunkett, Craig S. Weaver, Anne Wein, and Suzanne C. Perry

\section{Executive Summary}

\section{Mission and Roles}

The mission of the U.S. Geological Survey (USGS) in natural hazards is to develop and apply hazard science to help protect the safety, security, and economic well-being of the Nation. The costs and consequences of natural hazards can be enormous, and each year more people and infrastructure are at risk. USGS scientific research - founded on detailed observations and improved understanding of the responsible physical processes - can help to understand and reduce natural hazard risks and to make and effectively communicate reliable statements about hazard characteristics, such as frequency, magnitude, extent, onset, consequences, and where possible, the time of future events.

To accomplish its broad hazard mission, the USGS maintains an expert workforce of scientists and technicians in the earth sciences, hydrology, biology, geography, social and behavioral sciences, and other fields, and engages cooperatively with numerous agencies, research institutions, and organizations in the public and private sectors, across the Nation and around the world. The scientific expertise required to accomplish the USGS mission in natural hazards includes a wide range of disciplines that this report refers to, in aggregate, as hazard science.

In October 2010, the Natural Hazards Science Strategy Planning Team (H-SSPT) was charged with developing a long-term (10-year) Science Strategy for the USGS mission in natural hazards. This report fulfills that charge, with a document hereinafter referred to as the Strategy, to provide scientific observations, analyses, and research that are critical for the Nation to become more resilient to natural hazards. Science provides the information that decisionmakers need to determine whether risk management activities are worthwhile. Moreover, as the agency with the perspective of geologic time, the USGS is uniquely positioned to extend the collective experience of society to prepare for events outside current memory.
The USGS has critical statutory and nonstatutory roles regarding floods, earthquakes, tsunamis, landslides, coastal erosion, volcanic eruptions, wildfires, and magnetic storms - the hazards considered in this plan. There are numerous other hazards of societal importance that are considered either only peripherally or not at all in this Strategy because they are either in another of the USGS strategic science plans (such as drought) or not in the overall mission of the USGS (such as tornados).

\section{Priority Goals and Actions}

The USGS conducts hazard research to inform a broad range of planning and response activities at individual, local, State, national, and international levels. A sustainable society requires a responsive government to reduce the loss of life and disruption caused by natural hazards. People who are potentially affected by natural hazards need robust assessments to prepare for hazardous events, and they need information about updated hazards for situational awareness during times of crisis. To meet these needs, scientists, in turn, require fundamental understanding of natural processes and observations of natural events. Thus, the H-SSPT developed four overarching and interrelated goals regarding observations, understanding, assessments, and situational awareness. To accomplish each goal, this Strategy identifies core responsibilities and strategic actions. Core responsibilities are activities that the USGS must continue in order to uphold its mission. In many cases, these are mandated activities that help to protect lives and assets, or strengths developed as a consequence of long-standing national need. Strategic actions are high-value, priority efforts that go beyond the core responsibilities and will reduce uncertainties about hazards, improve communication, and thus enhance the ability to provide accurate, effective assessments and situational awareness. 
We provide a prioritization philosophy, to be applied through the collaborative efforts of the USGS Executive Leadership Team, Program Coordinators, and Science Centers, to accomplish prioritization effectively. For each goal, this Strategy identifies key strategic actions that were synthesized from hundreds of suggestions provided by USGS hazards stakeholders within the past year (2011). Given the spectrum of hazards under consideration in this report, along with the broad administrative controls for funding USGS hazards science, this report does not prioritize the strategic actions.

The first and highest priority is to maintain the basic and applied research, observations, and communication efforts such as assessments and warnings that form the core responsibilities. These are areas of USGS activity that must be safeguarded in times of decreased funding. Given sufficient funding to support the core responsibilities, the strategic actions indicate areas of advancement that will have greatest impact on improved understanding and on the efficacy of assessments and situational awareness.

The H-SSPT recommends that strategic actions be prioritized based on the degree to which the strategic action does the following:

- Helps meet USGS core responsibilities (particularly statutory responsibilities).

- In a larger context, helps the Federal Government to meet its responsibilities in the hazards arena.

- Is important for risk reduction, protecting human health, the economy, or national security.

- Addresses a large gap in hazards science understanding and reduces uncertainty.

- Enhances areas where the USGS has a unique role and expertise.

- Holds a high potential for investment return in the form of improved assessments and awareness.

\section{Goal 1: Enhanced Observations}

The USGS acquires comprehensive observations important to natural hazards to improve fundamental understanding, assessments, and situational awareness.

\section{Core Responsibilities that Must be Sustained}

- Operate monitoring networks for earthquakes, streamflow, volcanic activity and geomagnetic storms, and produce datasets of observations and near-real-time products.

- Conduct surveys, such as geological mapping and acquisition of geophysical data, to enable a better understanding of hazardous processes including sources and impacts.
- Collect the ephemeral data during hazardous events that will support future research to reduce loss.

- Develop long-term chronologies, with associated magnitudes, of hazardous events from both historical and paleohazard studies.

- Distribute this information to the wide range of users through a variety of data portals.

\section{Strategic Actions for the Future}

- Enhance the existing monitoring networks to provide reliable operation, ensure full interoperability with other agencies that rely on uninterrupted data flow from the USGS, and improve early warning.

- Improve the use of monitoring information through better near-real-time delivery, new tools for use of data, and the merger of existing, critical datasets.

- Take advantage of rapidly changing technology, recognizing that the ability to monitor effectively depends on the technology used and the ability to adapt to changes.

- Improve overall data quality standards governing quality assurance, metadata, additions, curation, and timeliness.

- Expand observations of geologic setting, including geological mapping and geophysical data acquisition, as these observations are essential to understanding the frequency, physical mechanisms, and impacts of events.

- Improve data collection during and after hazardous events to protect public safety and gather critical, ephemeral information.

- Use geological and historical methods to expand hazard chronology and magnitude distribution studies needed to define probabilities of occurrence.

\section{Goal 2: Fundamental Understanding of Hazards and Impacts}

The USGS advances and applies fundamental understanding of natural hazards to improve assessments and situational awareness.

\section{Core Responsibilities that Must be Sustained}

- Increase understanding of the underlying physical processes that produce the hazard and determine where and under what conditions hazards occur. 
- Uphold the tradition of innovation in instrumentation, measurement and experimental techniques.

- Foster USGS scientific expertise to provide expert advice as needed in crisis and noncrisis situations.

- Publish results with peer review and distribute to appropriate audiences through relevant mechanisms.

- Support innovation and creativity in the conduct of our science.

\section{Strategic Actions for the Future}

- Promote targeted research on physical hazard initiation processes, because limited understanding about these processes limits the ability to make accurate predictions.

- Promote research on extreme events, which are the rare, potentially catastrophic events with the greatest societal consequences.

- Promote research about natural hazard vulnerability, risk estimation, and communication.

- Encourage interchange of ideas in research about the role of fluids in physical processes, because this broad topic of investigation is essential to understanding a multitude of hazards phenomena.

- Promote research in the triggering and interaction of multiple hazard processes, which frequently happen in nature and have distinct probabilities of occurrence and potential impacts.

\section{Goal 3: Improved Assessment Products and Services}

The USGS develops assessments of natural hazards, vulnerability and risk to inform decisions that can mitigate adverse consequences.

\section{Core Responsibilities that Must be Sustained}

- Create hazard assessments used to inform decision making, based on fundamental understanding of natural hazards.

- Evaluate the assessments using observations made at national and regional scales and over long time periods to capture significant and infrequent events.

- Develop new assessment tools to improve the scientific foundation of assessments as new understanding evolves.
- Inform the public about natural hazards to promote risk-wise behavior by publishing assessments and providing assessment tools using USGS scientific information.

\section{Strategic Actions for the Future}

- Improve the formulation of assessments, in particular, by ensuring there is a process to update assessments with the most current understanding, methodology, and observations.

- Create and distribute effective multimedia assessments developed through partnerships with users, social and behavioral researchers, and educators.

- Develop multihazard assessments to compare the relative risk of multiple hazards or assess the combined risk of multiple hazards.

- Balance investments in hazard, vulnerability and risk assessment to ensure that the USGS improves the accuracy, resolution, and timeliness of hazard assessments while engaging with other entities who make use of the hazard information.

- Develop event and disaster scenarios and other strategic assessments to incorporate research results into decision-making processes.

- Evaluate the accuracy, use, validity and effectiveness of assessments, working with social and behavioral scientists and assessment users, in order to improve future assessments and demonstrate the value of USGS assessments.

\section{Goal 4: Effective Situational Awareness}

The USGS provides situational awareness to improve emergency response, inform the public, and minimize societal disruption.

\section{Core Responsibilities that Must be Sustained}

- Collect the data and conduct analyses to inform warnings by the USGS or others of impending crises.

- Issue warnings and advisories of impending potential hazardous events and their termination.

- Provide timely information to other agencies, emergency managers, the media, and the public about hazardous events as they occur.

- Invest appropriate resources in hazard education during crisis as well as noncrisis times. 


\section{Strategic Actions for the Future}

- Develop and provide training for the next generation of tools for rapid event detection and response, which will require targeted partnerships to define the products and delivery mechanisms that most effectively put USGS information into the hands of decisionmakers.

- Improve data systems critical to situational awareness responsibilities, a need that includes making monitoring networks that are more robust, expanding monitoring coverage as needed, and delivering information in usable formats.

- Implement 24x7 operations for critical USGS monitoring efforts in order to maximize USGS ability to inform partner agencies, respond to hazards, and deliver expertise when it is needed.

- Improve provision of scientific expertise for decisions and assessments during rapidly changing situations. This necessitates training of scientific staff in media response.

- Improve internal hazards coordination, which is conducted across the Bureau and over many regions and includes data, research, and geospatial support activities.

- Evaluate warning and response products to improve their accuracy, timeliness, and communication, and demonstrate the value of the USGS hazard investment in observations and fundamental understanding.

- Involve the whole community in the evaluation of the response products so as to increase the reach of the products.

\section{A Vision of the Future}

If these core responsibilities are upheld, and these strategic actions are taken, the USGS will move closer to the H-SSPT vision of the future, where the Nation will be more resilient because of USGS hazards science. That vision includes a USGS that does the following:
- Operates a robust, comprehensive network of instruments that monitor hazardous conditions.

- Leads the Nation in hazards science because of its diverse, expert staff.

- Creates easily understood assessments that are routinely used to reduce risk.

- Employs newly developed software tools that bring together data and understanding to better manage natural disasters and shares these tools with emergency managers.

\section{Opportunities and Challenges}

Although this Strategy addresses the scientific needs and opportunities of the USGS mission in natural hazards, the newly formed USGS Natural Hazards Mission Area (NHMA) can address important programmatic and policy issues that fall outside this report's structure of four goals, with associated core responsibilities and action items. Under its umbrella, the NHMA can help to accomplish the following:

- Maintain USGS leadership in hazard science through effective workforce planning.

- Address neglected and emerging natural hazard problems and ensure that hazards lacking programs in the USGS have proper advocacy, support, and input.

- Coordinate and facilitate international, interagency, and cross-Mission Area collaborations that are essential to fulfillment of the USGS mission in natural hazards and are crucial during hazard crises.

- Collaboratively develop hazard communication products that engage the public's interest in natural disasters to boost public awareness of USGS hazards efforts and risk-wise behavior.

- Engage hazard expertise when it can assist with human-caused events such as the Deepwater Horizon oil spill and provide critical evaluations of predictions.

Hurricane Isaac leaves flooded homes in his wake near the community of Braithwaite, Louisiana, Sept. 4, 2012. Photograph by Brady Couvillion, USGS.

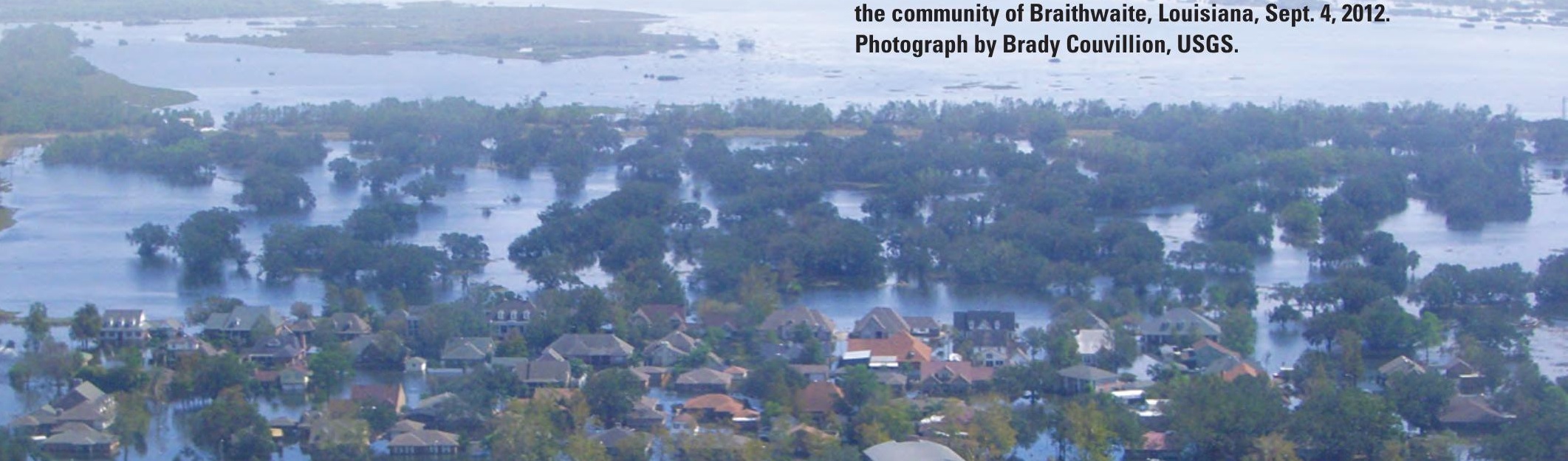




\section{USGS Hazard Science Makes a Difference}

\section{U.S. Geological Survey (USGS) hazard programs have a long history of science, service, and products that reduce the impacts of hazardous events:}

\section{Trans-Alaska [0il] Pipeline}

The USGS contributed design inputs to the Trans-Alaska [Oil] Pipeline that help to ensure the pipeline's thermal stability and resistance to strong ground motion and fault offsets during earthquakes. The pipeline design has resulted in successful thermal performance_-avoiding surrounding permafrost melting — since it was completed in 1977; and demonstrated successful mechanical performance during the 2002 M7.9 Denali earthquake, which ruptured the Denali Fault right under the pipeline,. Both cases demonstrate the value of science-based hazard intervention and mitigation (Fuis and Wald, 2003; available at $h t t p: / / p u b s . u s g s . g o v / f s / 2003 / f s 014-03 /$.

\section{USGS Provides Critical Data During 2011 Floods}

The Mississippi River Basin experienced "epic" flooding as a result of sustained rainfall in the upper part of the Basin through late spring and early summer 2011. For the first time since 1937, the Birds Point/New Madrid floodway was operated to reduce upstream flooding. Boat-mounted hydroacoustic instruments deployed by USGS scientists were used to determine the flow rates coming through the floodway for operational decisions by the U.S. Army Corps of Engineers, as well as detailed three-dimensional water velocity vectors, which were measured in the nearby Mississippi River before and after activation of the floodway to ensure that commercial barge traffic could move safely along the river.

\section{Working Group on California Earthquake Probabilities: Uniform California Earthquake Rupture Forecast}

Since 1988, the USGS has led the science of time-dependent earthquake forecasting. The USGS works closely with the California Earthquake Authority to assess insurance rates by calculating the probability of damaging earthquakes throughout the State. USGS scientists, working with colleagues in the California Geological Survey, the Southern California Earthquake Center, and others continually seek ways to evaluate and develop the best available science for probabilistic forecasts, which provide a bridge between cutting-edge research and a practical application for public safety. This work continues to set trends in hazard assessments in the United States and around the world (http://www.wgcep.org/).

\section{The Vital USGS Streamgage Network and Online Web Interface}

The USGS has a network of some 7,800 near-real-time streamgages and more than 4,000 of these form a major backbone of the National Weather Service's (NWS) flood forecasting operation, as evidenced by the following quote from a NWS hydrologist from the Southeastern United States: "The USGS work has been and continues to be crucial to the NWS ability to provide accurate river forecasts and warnings to inform State agencies, Dam Operators, Emergency Operations Centers, Emergency Managers and the public across Georgia and Florida" (Joel Lanier, Senior Service Hydrologist, NWS Tallahassee, Florida, written commun., 2011; http://waterdata.usgs.gov/nwis/rt).

\section{Reducing Global Volcanic Risk}

The Volcano Disaster Assistance Program (VDAP) is a global volcanic risk mitigation activity cofunded by the U.S. Agency for International Development and the USGS. VDAP volcanologists work with local scientists to provide training, equipment, and consultation in order to build capacity and minimize loss. Since 1986, VDAP has responded to dozens of volcanic crises around the world, saving thousands of lives and returning with valuable lessons to reduce risk in the United States. One of the most important success stories was the accurate forecast of the cataclysmic 1991 eruption of Mount Pinatubo in the Philippines. VDAP's rapid response to the initial unrest and timely warning of the impending eruption led to a successful evacuation of Clark Air Base, its valuable aircraft, and thousands of residents from densely populated, nearby communities (http://vulcan.wr.usgs.gov/Vdap/framework.html, http://vulcan.wr.usgs.gov/Vdap/framework.html, http://pubs.usgs. gov/fs/1997/fs113-97/, and http://pubs.usgs.gov/fs064-97/.

\section{Coastal Processes}

In collaboration with the National Oceanic and Atmospheric Administration (NOAA) and the U.S. Army Corps of Engineers (USACE), the USGS is predicting the likely interactions between storm forcing (for example, surge and waves) and coastal topography (beaches, berms, and dunes) during hurricanes in near-real-time. This information provides a powerful shortterm tool to emergency responders and communities to identify areas of greatest likely damage. 


\section{USGS Hazard Science Makes a Difference-Continued}

Volcanic Ash Hazards, Impacts, and Preparing the Nation for Ash-Fall Events

Drifting ash clouds and ash fall from volcanic eruptions can have far reaching impacts. USGS scientists have worked closely with NOAA, university, and international partners to understand and explain the effects of volcanic ash on people, infrastructure, and ecosystems. A new USGS ash cloud dispersion and ash fall forecast tool, Ash3D, will help warn downwind communities and infrastructure of expected ash fall severity. In addition, USGS leadership, in improving the complex global system of ash-cloud warnings for aviation, has made significant contributions to safe and efficient air travel in the United States and around the world (http://volcanoes.usgs.gov/ash/index.html; and Neal and Guffanti, 2010, http://pubs. usgs.gov/fs/2010/3116/.

\section{Geomagnetism Leadership}

The USGS provides international leadership in obtaining integrated real-time domestic and global geomagnetic-field monitoring, as well as leadership in the development and production of geomagnetic-storm intensity indices. USGS and Intermagnet observatories are critical ground-based assets in coordinated monitoring of space weather, which can have very damaging impacts to the infrastructure and activities of our modern, technologically based society. The same observatories also support forecasts and warnings provided by NOAA, the U.S. Air Force, and space-weather agencies in Europe and Japan (Love and others, 2008, http://pubs.usgs.gov/fs/2007/3092/; and Love and Finn, 2011, http://dx.doi. org/10.1029/2011SW000684).

\section{Living with Landslides}

Landslides occur in all 50 states and cause fatalities and damage nearly every year. The Landslide Handbook —A Guide to Understanding Landslides, published in collaboration with the Geological Survey of Canada, is a valuable guide for landslide hazard education. The richly illustrated guidebook discusses the nature of landslides, why and where they occur, potential impacts, and what can be done to mitigate these impacts. It has been translated into Mandarin Chinese, Spanish, Portuguese, and Japanese with support from the World Bank, China Geological Survey, and Japan Landslide Society. It received the 2011 Geological Society of America Burwell Jr. Award (Highland and Bobrowsky, 2008, http://pubs.usgs.gov/ circ/1325/1.

\section{Contributions to Burned Area Emergency Response}

After a wildfire there potentially are major impacts to water quality, endangered species, cultural resources, and the threat of introduction or spread of invasive species. In many areas, wildfires also increase the likelihood of floods and debris flows for the next several storm seasons. USGS burn severity characterizations, derived from satellite imagery, have become a primary tool used by Department of Interior and United States Forest Service Burned Area Emergency Response Teams to assess the impacts of a wildfire and rapidly develop a mitigation plan to protect communities, water, and ecosystems from subsequent harmful impacts.

\section{Community Exposure to Tsunami Hazards for Emergency Managers}

USGS investigations of the variations in community exposure to tsunami hazards in Oregon, Washington and Hawai i have been put to many and varied uses: education materials, comprehensive land use and mitigation planning, tabletop and functional exercises, vulnerability assessment workshops, mapping prioritization, and recommendations for national policy on tsunami preparedness. The wide use owes credit to agency partnerships, user engagement, varied communication methods, and guidance from social and behavioral science research, which provided both community vulnerability attributes and insight into how to frame the information for decisionmakers (Oregon: Wood, 2007, http://pubs. usgs.gov/ sir/2007/5283/; Washington: Wood and Soulard, 2008, http://pubs.usgs.gov/sir/2008/5004/; Hawai i: Wood and others, 2007, http://pubs.usgs.gov/sir/2007/5208/.

\section{A Scenario that Inspires Earthquake Preparedness}

A southern San Andreas earthquake scenario developed by the USGS Multi-Hazards Demonstration Project became the basis of the Great Southern California ShakeOut, comprising the largest-ever statewide exercise of emergency responders ("Golden Guardian," led by the Office of Homeland Security), and the largest public drill ever attempted in the United States, with more than 5 million participants. Exercise planners heavily used the scenario, with help from USGS scientists, who customized scenario results for individual counties and cities. The USGS also supplied inspiration and organization for the inaugural ShakeOut drill, which has now spawned annual events in many states and countries. 


\section{Introduction}

\section{Mission Statement}

The mission of the USGS in Natural Hazards is to develop and apply hazard science to help protect the safety, security, and economic well-being of the Nation. A sustainable society requires a responsive government to reduce the loss of life and disruption caused by natural hazards. The USGS role is to make and effectively communicate reliable statements about hazard characteristics such as frequency, magnitude, extent, speed of onset, consequences, and where possible the time of future hazardous events, derived from a growing understanding of the physical processes responsible for the hazards. The mission spans a wide range of hazards, and therefore, the needed science covers a wide range of disciplines in the natural, social and behavioral sciences that this report refers to, in aggregate as, hazard science. Bold terms indicate first usage of words that are explained in the Definitions section.

Scientific analysis and research are critical as the Nation strives to be more resilient to hazardous events and natural disasters. The natural processes leading to events that are potentially hazardous to human society are ongoing and only hazardous when their effects exceed the range that is expected or planned for. As the agency with the perspective of geologic time, the USGS is uniquely positioned to extend the collective experience of society to include events over that much greater time scale. The science also provides information that decisionmakers need to determine what risk is acceptable and what risk reduction activities are feasible. Decisions include land-use planning - such as not building in floodplains or on landslides - ground stabilization, protective structures, building code requirements, insurance, personal and societal preparedness, and recovery planning. Society cannot prepare effectively if it does not know what to plan for. USGS hazard science provides that information and strives to communicate it effectively.

Hazard science comprises several interlocking components: observations, fundamental understanding, assessments, forecasts, warnings, and crisis and disaster response. The components are linked and overlapping; progress within one component supports and contributes to progress in other components. The USGS Hazards Mission Science Strategy identifies goals and strategic actions that will lead to more accurate, higher resolution, and timely hazard assessments and warnings of natural hazards based on sound fundamental understanding and supported by robust observations. Effective hazard assessments and warnings will have an increased impact on hazard planning, preparedness, and response decisions and will result in reduced hazard vulnerability. Attaining these goals will continue the existing long-term, hazards-related efforts by the USGS that have helped to minimize disastrous impacts from events, large and small. For example:
- During the 2011 Mississippi River flood, according to the U.S. Army Corps of Engineers, USGS streamflow data, water-quality data, and data communication efforts were critically important in preventing an estimated $\$ 108$ billion in flood damages.

- After recent wildfires in the southwest, interpretations of USGS remote-sensing data were used to map fire severity, which, in turn, enabled USGS scientists to map seasonal probabilities of debris flows. Results were shared with local officials before the arrival of storms that could have triggered debris flows, providing time to make decisions about land management and public safety.

- Each day, USGS volcano monitoring and activity notices help airlines fly confidently on efficient, ash-free air routes, minimizing costly disruption and promoting aviation safety.

Only some of the many natural processes that can impact human society are included within the hazards mission of the USGS: coastal processes from severe storms including hurricanes, earthquakes, floods, geomagnetic storms, landslides, subsidence, tsunamis, volcanic eruptions, and wildfires. Some hazards, like tornados, are not included because the physical science - in this case, meteorology - is not within the purview of the USGS. Hurricanes are included to the extent that the USGS studies the impacts of hurricanes on coastal processes. In other cases, such as glacial and other cryosphere-related hazards, the science lies within the broad scope of USGS science, but the USGS no longer has a sustainable program in the area, and existing capacity lies in another part of the USGS, in this case Climate and Land Use Change. Other hazards were excluded because the physical processes are the realm of a different USGS mission. For instance, it is clear that drought can be an extreme hazard to human society. However, drought is almost synonymous with water availability and the science needed to address drought is a core capability of the Water mission.

\section{The USGS Role in Hazard Science}

Among the many State and Federal agencies with hazard science and service mandates, the USGS plays a prominent role in protecting the Nation from hazards by providing impartial, scientifically sound information. More specifically, the USGS has critical statutory and nonstatutory roles over a wide range of natural hazards. The Disaster Relief Act of 1974 (appendix 5) gives the USGS statutory responsibility for warnings of geologic hazards, including "earthquakes, volcanic eruptions and ash clouds, landslides, mudflows, subsidence, faulting and fissuring of the ground surface and glacier-related processes." (quote from Federal Register Note, appendix 5). 
For many hazards, other Federal agencies have substantial and often lead roles. Thus, for some hazards, the USGS is the lead Federal agency with delegated statutory responsibilities over a range of roles; whereas for other hazards, the USGS provides expertise and critical monitoring data to support the statutory responsibilities of other Federal agencies.

To accomplish this broad hazard science and service mission, the USGS maintains an expert workforce of scientists and technicians in the earth sciences, hydrology, biology, geography, social and behavioral sciences, and other fields. (Appendix 2 provides information on hazard science within the USGS.) The USGS engages cooperatively with numerous agencies, research institutions, and organizations, in the public and private sectors, with stakeholders across the Nation and around the world. The extent, spectrum, and complexity of USGS partnerships are broad.

To protect the Nation, the USGS conducts science over a wide span of locales and timeframes. Because of commonalities among hazards worldwide, USGS hazard science for the United States often is critically informed by, and informative to, hazardous events in other countries. Even in countries with long written histories - and in some cases active monitoring programs - historical and instrumental records provide limited information about hazards that occur on geologic, not human, time scales. Thus, some recent catastrophic events were unanticipated largely because events like these have not occurred during the period of human documentation. The USGS conducts geological investigations of rare giant events as a way to expand knowledge beyond the human record and as a way to help anticipate such events.

\section{Natural Hazards Science Strategy Planning Process}

In October 2010, the USGS reorganized its structure around various missions, guided by the strategy outlined in "Facing Tomorrow's Challenges-U.S. Geological Survey Science in the Decade 2007-2011" (USGS Circular 1309; U.S. Geological Survey, 2007). The USGS mission in natural hazards is administratively under the Natural Hazards Mission Area, which serves to guide hazards science efforts throughout the USGS and to promote collaborations with numerous outside stakeholders.

The Natural Hazards Science Strategy Planning Team (H-SSPT) was then selected and charged with developing a long-term (10-year) science strategy (hereinafter called the Strategy) for the mission of the USGS in natural hazards. This Strategy is the fulfillment of that charge and will be used to guide implementation plans to be developed by the programs and regions. USGS and DOI leadership will use this report's goals, actions, and articulation of priorities to develop a decadal roadmap for meeting the USGS mission in natural hazards.

The H-SSPT used Circular 1309 as a springboard and focus on how best to plan and carry out the natural hazards responsibilities and conducted months of discussions with stakeholders inside and outside the USGS. The team identified four cross-hazard goals required to meet mission responsibilities and the highest priority strategic actions needed to meet those goals. The specificity of the strategic actions is intended to lie between the long-range vision of Circular 1309 and the details of the annual and 5-year plans of the various USGS Programs and Projects. (The goals and strategic actions are listed in the Hazards Mission Goals and Actions section.)

Staffing of the H-SSPT, the charge to the H-SSPT, and the process used in the development of this Strategy are in appendix 3. The extensive "listening sessions" and information exchanges within many of the USGS offices and among USGS partners and stakeholders, including professional societies, other Federal agencies, and selected State and academic entities, are in appendix 4. Especially noteworthy in this effort was the extensive number of public contacts, within and outside the USGS and ranging geographically from Alaska to Florida.

\section{Hazards Mission Priority Goals and Actions}

The USGS conducts hazard science so that it can be used to inform the public and decisionmakers at all levels as they seek to promote public safety, reduce losses, and improve resilience to natural hazards. These decisionmakers need scientific assessments of the hazard, vulnerability, and risk to prepare for a potential hazardous event; and they need warnings and information for situational awareness during events. To create these assessments and warnings, scientists require a fundamental understanding of the natural processes and observations of the natural events. In other words, to protect the safety, security, and economic well-being of the Nation, the USGS needs to observe and understand hazards and use this information to create assessments, provide warnings, and inform or generate plans for anticipating and responding to hazardous events. Thus, this report identifies these four activities as the goals required to fulfill the USGS mission: observations, understanding, assessments, and situational awareness.

All four goals are linked. The required inputs for all assessments are observations and analyses using conceptual, statistical, or numerical models that capture the fundamental understanding of hazard processes. These models characterize the expected existence, intensity, or likelihood of occurrence of a particular hazard or its consequences. These are formulated into assessments that inform decisions about mitigation and response activities. Products for situational awareness combine the results of assessments, observations, and understanding.

As an example of this linkage, consider the National Seismic Hazard Maps, the flagship product of the USGS Earthquake Program. These maps express the probability that a certain level of ground shaking will be experienced at every location in the United States over some time frame. To create these maps, the USGS works with its partners in the States to 
gather observations of the rate of earthquake occurrence across the Nation, map the active faults and analyze the information about the faults to estimate their rates of motion. They must also gather information about how shaking decreases as it travels away from the fault, and how other factors may affect the levels of shaking. Observations are analyzed with a fundamental understanding of the earthquake process to create an assessment of the hazard that is then used in the building code to determine what level of seismic resistance is required in different areas. The same seismic monitoring system that provided the information to make that map also provides information about new earthquakes within minutes of occurrence that is then used by the public and emergency managers for situational awareness as they prepare for and respond to those events. The long-term assessment is modified with knowledge about how one earthquake makes another earthquake more likely and the observation of the occurrence of a new event to create a short-term assessment that includes the possibility of aftershocks.

The four-goal framework of this report is not the only way that these activities might be grouped. In this report, assessments and situational awareness differ primarily by the time frames in which they are used. Certainly, "hazard assessments" can describe products used in the long term (such as a 100-year flood plain or a ground shaking probability map) and in a short-term crisis situation (such as a flood forecast or earthquake clustering probabilities). However, the team created a separate goal for situational awareness because the demands of a crisis require special short-term products that use monitoring systems (such as river stage or near-real-time earthquake location maps) and expert advice. Similarly, the boundary between observations and the analysis of the observations to increase fundamental understanding can be fuzzy; as is the difference between developing the science to create an assessment, the creation of the assessment, and channeling the assessment uncertainties back into new research that adds to fundamental understanding.

The H-SSPT considered a separate goal for communication but decided communication is so critical it should be built into all goals. Also, a separate goal might cause scientists to conclude that communication was someone else's job. Instead, aspects of communication can be found throughout and are pronounced in assessments and situational awareness, where the actions emphasize that the information created for users must include the users in the evolution of products to better serve their needs.

A particular challenge was how to address the need for information about vulnerability and risk, not just hazard. Hazard is the physical process that is independent of the impacts on humans. Vulnerability studies draw on physical science, engineering, and social and behavioral sciences to determine what aspects of human society are vulnerable to damaging processes. Risk assessment combines the hazard with vulnerability to evaluate the probability of losses. Thus, risk assessment requires the physical sciences that are a core hazard mission strength to be combined with engineering and

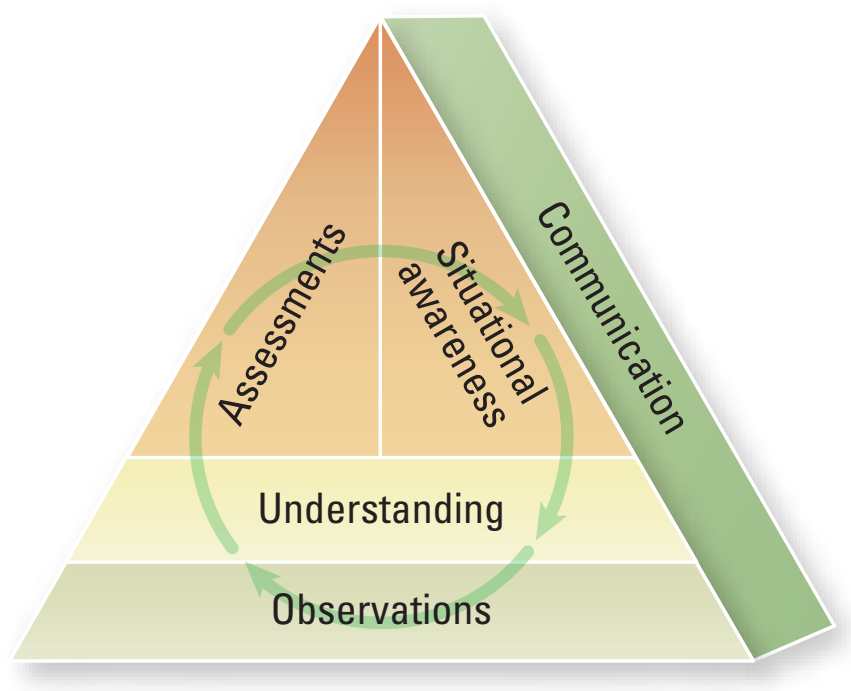

Figure 1. Four goals with communication throughout. This graphic conceptualizes the four goals of this Strategy. Assessments and situational awareness require understanding and observations. Communication is essential to all efforts.

social and behavioral sciences that reside in different parts of the USGS, or are completely external. A message from many stakeholders was for the USGS to take a larger role in ensuring that hazards information results in accurate risk assessments that have broader use in the community. Recognizing that many aspects of vulnerability and risk analysis can be done by others or in partnership with others, this report treats risk as an integral part of hazards science and includes the research and development of risk assessments as one of the many types of assessment that are needed.

Below, a section is devoted to each goal. After defining the goal, we describe the core responsibilities that must be sustained to fulfill the USGS mission. The report then identifies key strategic actions to make progress in each goal. These were selected from hundreds of potential strategic actions identified by USGS hazards stakeholders and reported to the H-SSPT over the past year.

If an action is in this report, the team considers it important. Given the spectrum of hazards under consideration in this report, along with the broad administrative controls for funding USGS hazards science, no prioritization of the strategic actions in this report is given. The H-SSPT, instead, provides a prioritization philosophy, which when applied through the collaborative efforts of the USGS Executive Leadership Team, Program Coordinators, and Science Centers, will lead to effective prioritization. The highest priority should be given to maintaining basic and applied research, including observations that maintain our core responsibilities for which the USGS has either a statutory responsibility or is a strength that has developed as a consequence of long-standing national need. These are areas of USGS activity that must be safeguarded in times of decreased funding. Given sufficient funding to support the 


\section{Role of USGS in Federal Government}

Millions of people worldwide look to the U.S. Geological Survey (USGS) for rapid, reliable hazard information, either directly or through its partners. Many agencies across the Federal Government work together to provide critical information regarding natural hazards before, during, and after hazardous events. The list includes but is not limited to the USGS, the National Oceanic and Atmospheric Administration (NOAA), the Centers for Disease Control and Prevention (CDC) and the Department of Homeland Security (DHS). The USGS has a unique leadership role for many natural hazards based on its long-standing monitoring programs, scientific expertise, and the authority of the Disaster Relief Act of 1974 (Public Law 93-288, see appendix 5), which gives the USGS the delegated Federal responsibility to provide notifications and warnings for geologic hazards, including earthquakes, volcanic eruptions, and landslides. For a number of other hazards, USGS capabilities support the statuatory responsibilities of partners, specifically:

- Data from USGS national and global seismic networks feed directly to the tsunami warning centers of NOAA.

- USGS streamgages and storm-surge monitors provide information for NOAA's flood and severe weather warnings, including those for hurricanes.

- Fourteen USGS geomagnetic observatories are used by NOAA and the U.S. Air Force to develop forecasts of geomagnetic storms caused by solar flares and other space weather.

- USGS geospatial information is used in response operations for wildfires and many other types of hazardous events, providing crucial coordination of remote sensing and other assets.

The USGS also is identified in these legislated mandates:

- The USGS is a partner in the congressionally established four-agency National Earthquake Hazards Reduction Program (NEHRP). First authorized in 1977, NEHRP strives to reduce the risks to life and property from future earthquakes in the United States. Last reauthorized in 2004, the NEHRP legislation identifies a number of responsibilities for the USGS within an umbrella statement that the USGS "shall conduct research and other activities necessary to characterize and identify earthquake hazards, assess earthquake risks, monitor seismic activity, and improve earthquake predictions."

- The USGS is a partner in the multiagency National Tsunami Hazard Mitigation Program, which is led by NOAA and includes both federal and state agencies. The Tsunami Warning and Education Act of 2006 (Public Law 109-424) establishes a Tsunami Forecasting and Warning Program and includes acknowledgement of the cooperative effort involving NOAA, USGS, and the National Science Foundation to provide rapid and reliable seismic information from international and domestic seismic networks.

The USGS currently (2011) co-leads the National Science and Technology Council's Subcommittee on Disaster Reduction (SDR), which supports the White House Office of Science and Technology Policy and is charged with establishing clear national goals for Federal science and technology investments in disaster reduction, promoting interagency cooperation for natural and technological hazards and disaster planning, facilitating interagency approaches to identification and assessment of risk and to disaster reduction, and advising the Administration about relevant resources and the work of SDR member agencies.

Within the USGS, the newly established Natural Hazards Mission Area (NHMA) has direct responsibility for six programs that were formerly in the Geologic Discipline. These include Coastal and Marine Geology, Earthquake Hazards, Geomagnetism, the Global Seismographic Network, Landslide Hazards, and Volcano Hazards. In addition, NHMA is responsible for coordinating and supporting the broader hazards vision of the USGS, including activities related to floods, hurricanes and severe storms, tsunamis, and wildfires. Many of the activities in those hazard areas are funded through programs in other mission areas. Finally, NHMA will take on responsibility for coordinating USGS response activities following disasters, potential disasters, and hazardous events. 
core responsibilities, the strategic actions indicate key areas of advancement that will have greatest impact on improved fundamental understanding and on the efficacy of natural hazard assessments and situational awareness. The H-SSPT recommends the prioritization of strategic actions be based on the degree to which the strategic action does the following:

- Helps meet USGS core responsibilities (particularly statutory responsibilities).

- In a larger context, helps the Federal Government to meet its responsibilities in the hazards arena.
- Is important for risk reduction, protecting human health, the economy, or national security.

- Addresses a large gap in hazards science understanding and reduces uncertainty.

- Enhances areas where the USGS has a unique role and expertise.

- Holds a high potential for investment return in the form of improved assessments and awareness.

Shorelines are highly variable environments characterized by a number of natural hazards, including tsunami, storm surge, high winds, coastal erosion, sea-level rise, and high wave overtopping. Building on eroding coasts increases vulnerability to these hazards. Aerial view looking northwest of Makapuu Beach Park (foreground) and Waimanalo Bay in the distance, southeast Oahu, Hawaì i. Photograph by Bradley Romine, University of Hawaì i at Manoa. 


\section{Goal 1: Enhanced Observations}

The USGS acquires comprehensive observations important to natural hazards to improve fundamental understanding, assessments, and situational awareness.

Understanding hazards begins with observations. Observations are crucial for fundamental understanding, for making assessments and warnings, and for the subsequent reduction of the impacts of hazards. The USGS observes hazardous events across a large range of spatial and temporal scales. Monitoring networks record continuously with sensors located across the landscape to create catalogs of events over time, providing data for scientific studies, assessments, and warnings, whereas surveys are discrete recordings, updated as required with improvements in technology or understanding. Bedrock and surficial geologic mapping help to determine the geological setting for a variety of hazards and provide key understanding of earthquake and tsunami hazard sources, ground shaking and landslide initiation, and the tectonic setting and long-term record of volcanism. Aeromagnetic, magnetotelluric, gravity and active-source seismic surveys provide unique constraints on subsurface geological structures and hazard sources. Longterm hazards chronologies are developed from historical and paleohazards studies to recognize individual events. All these kinds of observations are necessary to describe the hazard and assess the chance of future events. The community of users of USGS observation data is broad and varies from individual citizens to specialized research scientists. The agency must continually seek feedback and input from data user groups to maximize the benefit of these observations.

\section{Core Responsibilities}

To fulfill its mission and meet statutory responsibilities, the USGS, in collaboration with its many local, State, and Federal partners, must continue to do the following:

- Operate monitoring networks for earthquakes, streamflow, volcanic activity and geomagnetic storms, and produce datasets of observations and near-real-time products.

- Conduct surveys, such as geological mapping and acquisition of geophysical data, to enable a better understanding of hazardous processes including sources and impacts.

- Collect the ephemeral data during hazardous events that will support future research to reduce loss.

- Develop long-term chronologies, with associated magnitudes, of hazardous events from both historical and paleohazard studies.

- Distribute this information to the wide range of users through a variety of data portals.
Monitoring.-Monitoring takes many forms in the USGS, but the simplest is the development of basic observational datasets over time. Monitoring datasets typically consist of measurements at particular locations, and the longer the observations are made the more valuable the dataset. One of the distinguishing characteristics of USGS monitoring activities is the sustained ability to acquire, interpret, archive and disseminate data. The USGS runs large networks of instruments that are the primary source of information about earthquakes, volcanic activity, floods, and geomagnetic storms. Earthquake and volcano monitoring use networks of global positioning satellites (GPS) and arrays of other instruments to measure earth strain. Space weather requires real-time data streams, including those from geomagnetic observatories. In addition, USGS hazards programs deploy temporary arrays of instruments during times of crisis, when a disaster or hazardous event may be imminent, or immediately after an event has occurred, to capture ephemeral data that quickly will be lost. USGS monitoring network data detect volcanic unrest in advance of hazardous eruptions, detect and report hazardous events in near-real-time, and transmit data to other agencies. Several other agencies use USGS data for crucial infrastructure and public safety activities. For example, USGS streamflow data is used by the National Oceanic and Atmospheric Administration (NOAA) for flood warning and flood forecasts and by the U.S. Army Corps of Engineers for operation of the Mississippi River and Tributaries flood control system. NOAA also uses the USGS earthquake information for their tsunami warnings.

Information from monitoring networks serves three purposes.-First, it provides awareness of the current state of potentially hazardous processes and systems, second, it underpins short-term forecasts, and third, it motivates and supports targeted research of natural hazards. Remote-sensing data are routinely used to monitor for wildfire and volcanic hazards. All USGS monitoring involves considerable partnering and coordination. Some monitoring needed to fulfill the USGS mission in hazards, such as that required for floods, overlaps strongly with monitoring needed by other missions of the USGS such as water and climate change. In other cases, the overlap is with multiple hazards (such as earthquake data that provides information about volcanoes and tsunamis). Partners outside the USGS are critical to USGS activities and include Federal, State, and local agencies, international organizations and private firms, who often co-fund, supply data and partner in operation of the networks.

Surveys.-Surveys include such activities as geologic mapping and geophysical surveys, which are the framework for understanding hazardous processes. Bedrock geologic maps include interpretations from large-area geophysical surveys. Surficial geologic investigations examine stratigraphy and map Quaternary deposits where earthquake shaking, coastal 
erosion, landslides, flooding, volcanic eruptions, and tsunamis interact with human development and the natural environment. Modern geologic maps are digital and often include material properties such as density or seismic velocity as part of an integrated database. The USGS also has a long history of measuring in-situ stresses in boreholes, measurements that reflect the state of tectonic stress relevant to earthquake and volcano hazards. In the last two decades, the introduction of highresolution lidar and multibeam swath mapping has revolutionized the ability to unravel complicated landscapes, and hazard history, on land, offshore and along the Nation's coastlines.

Hazards chronology.-Whereas direct measurements are accurate, and historical records provide us with an understanding of the effects of hazards on society, paleostudies of events occurring over geological timescales are necessary for assessing rare but potentially catastrophic events. The short time available for most instrumental hazard observations almost ensures that rare, extreme events are missing in hazards assessments. Historical and paleo datasets are complementary, and complete chronologies must use them in combination in order to estimate event occurrence likelihood and size distribution. The USGS continues to conduct a large number of paleohazard and historical studies to document earthquakes, landslides, tsunamis, volcanic eruptions, and space-weather events. This is an effort critical to improved hazard assessments and warnings.

Ephemeral Data.-Ephemeral data are perishable and transient. That is, when hazardous events occur or threaten, there is a short time period when we can collect certain data. Observing what happens as events unfold can provide critical data about earth processes and what happens to society that cannot be obtained at any other time. High water marks from storm surge after a hurricane or tsunami, what a building does during strong earthquake shaking, ashfall following an eruption, liquefaction after an earthquake, and environmental changes due to an event are all examples of ephemeral data.

Distribution-A core responsibility is to distribute data from observations to appropriate users. USGS monitoring networks have a broad base of users who obtain information from the web, portable devices, and other methods. All of these data are used by the larger scientific community, industry and local government. For example, a network of GPS sensors, run by the earthquake program, is used by local surveyors as a baseline.

\section{Strategic Actions}

1. Enhance the existing monitoring networks. Monitoring systems need to be continually upgraded to ensure they operate reliably during significant events and are fully interoperable with other agencies that rely on uninterrupted data flow from the USGS, improving their use for situational awareness and issuance of warnings. Priorities include the following:

a. Maintain the existing national leadership and coordination of Advanced National Seismic System (ANSS), Global Seismic Network (GSN) and National Streamflow Information Program (NSIP) to ensure the networks do not devolve from national networks to disparate regional networks. Completing the ANSS, including the ground motion monitoring and building instrumentation components. Completing the upgrade to the Global Seismic Network to allow better detection and reporting of global seismicity, including potential tsunami generation.

b. Partner closely with the Water Mission Area to expand NSIP, in order to accomplish its purposes and goals as described in the program plan (http:// pubs.usgs.gov/of/1999/ofr99456/). Cooperating with the DOI and Water Mission Area to meet a DOI goal to secure 30 percent federal NSIP funding for the streamgaging network by 2016 .

c. Implement a multisensor volcano monitoring system as outlined in the National Volcano Early Warning System (NVEWS) Implementation Plan.

d. Improve geomagnetic monitoring by integrating and promoting near-real-time foreign geomagnetic feeds and supporting magnetic-observatory operations in the Pacific, at the South Pole, and internationally.

e. Expand operation and analysis of GPS sensors and data for geodetic monitoring with scientific partners.

f. Cooperate with the Water Mission Area to expand and formalize the use of storm-surge sensors for hurricanes and tsunamis, and rapid deployment gages for flooding and in the aftermath of major wildfire burns.

2. Improve the use of monitoring information. To ensure better use, the USGS needs to improve near-real-time delivery of data and develop new tools for use of these data, merge existing critical time series and establish clear paths to use these new data for analyzing hazardous events and processes. Priorities include the following:

a. Ensure real-time $(24 \times 7)$ operational continuity of all critical monitoring networks to provide assurance of real-time data dissemination to improve warnings and situational awareness.

b. Support coordinated and innovative multisensor monitoring of targeted natural hazard "laboratories," such as earthquake-fault systems and volcanoes.

c. Develop ways to merge disparate data streams and resulting analysis to provide a more complete situ- 
ational awareness product, particularly for earthquake, volcano and tsunami monitoring and warnings.

d. Establish a cross-hazard/cross-Mission Area working group to define the operational requirements for collection, processing, archiving, analysis, and timely distribution of remote-sensing information related to hazards and disasters.

e. Expand linkages with other monitoring networks, internally and externally, to enhance efficiency and interoperability. Explore whether partnerships (such as those developed by Core Science Systems) can make hazard data more readily discoverable and used. An example would be the current effort toward interoperability of hydrologic data by the Integrated Water Resources Science and Services (IWRSS) Consortium, of which USGS is a part. f. Continue innovative web distribution of hazard information, especially the development of a single portal for multiple hazards.

3. Take advantage of rapidly changing technology. Effective monitoring depends on the technology used and the ability to adapt to changes. The USGS should keep updated about new technology and mold and integrate these new technologies to enhance and improve fundamental understanding, assessments, and warnings. Priorities include the following:

a. Expand the acquisition, use, and analysis of current and future generations of geophysical-survey data and remote-sensing data for hazard monitoring and event response. Many hazard studies require highresolution surface morphology, which can be realized through lidar and multibeam swath bathymetry.

\section{NVEWS: Living Safely With Active Volcanoes}

The U.S. Geological Survey (USGS) Volcano Hazards Program (VHP) monitors the Nation's volcanoes, in order to warn and inform those in harm's way. VHP also develops testable models for how volcanoes work to improve hazard assessments and eruption forecasts. The combination of planning, monitoring, and forecasting can prevent an eruption from becoming a disaster. The National Volcano Early Warning System (NVEWS) is a bold, strategic vision that will modernize and improve VHP service to the Nation, through real-time monitoring, a $24 \times 7$ capacity to detect volcanic unrest and issue warnings, high-quality data for hazards analysis and research, an external grants program to engage the broader scientific community in VHP's mission, and more effective work with cooperators, emergency managers, and stakeholders, including the public. Importantly, the NVEWS plan ranks and prioritizes volcanoes for additional instrumentation based on their eruptive history, relative exposure of communities and infrastructure, and the status of existing monitoring networks. NVEWS already has improved interoperability among the five U.S. volcano observatories, enhanced high priority monitoring networks, and initiated planning to provide improved 24-hour seismic alerting capacity in cooperation with the National Earthquake Information Center. Full NVEWS implementation will require time and new resources. However, the program is designed to make incremental improvements as funding allows, and to redirect resources, if needed, during volcanic unrest. In concert with strong ongoing USGS research on volcanic processes and hazards, the NVEWS focus on vigilance, early warning, and preparedness will significantly reduce our national exposure to volcano hazards.
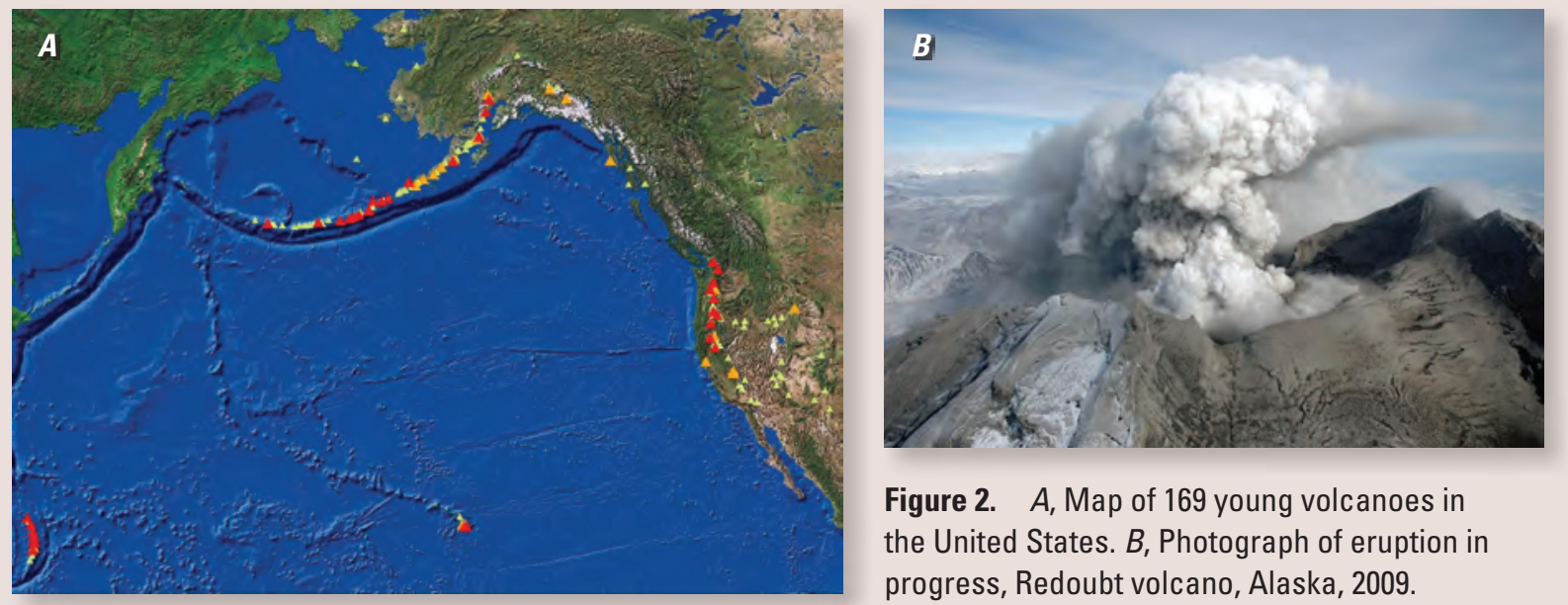

Figure 2. A, Map of 169 young volcanoes in the United States. $B$, Photograph of eruption in progress, Redoubt volcano, Alaska, 2009. 
b. Foster development of new technologies specific to particular hazards, such as those that are portable, smart, and cost effective systems. c. Promote cross-hazard communication among operational and technical development personnel concerning new opportunities arising from changing technology in instrument development, data acquisition, data transmission, data management, and data processing.

\section{A Tale of Two Giant Earthquakes and Their Tsunamis}

\section{March 2011, in Northern Japan}

This M9 earthquake and huge tsunami caused what Japan's Prime Minister called the worst disaster to strike Japan since World War II, with 15,000 dead or missing, economic losses approaching \$0.6 trillion, and a catastrophic nuclear accident. The tsunami waves also caused an estimated $\$ 120$ million in losses in the United States. Japanese design and construction standards for earthquake resistance are very high and this earthquake produced little structural damage. Japan was ready for this earthquake, but had underestimated the possible height of tsunami waves. Thus, tsunami mitigation measures in northeastern Japan provided inadequate protection, resulting in huge losses.

The Japanese catastrophe left many in the United States asking whether such earthquakes and tsunamis are possible here. In the Pacific Northwest, the answer is yes. Earthquakes of this magnitude and tsunamis with comparable run-up are expected along the Cascadia subduction zone. However, during the last decade, scientific discoveries led by the U.S. Geological Survey (USGS), and community preparations based on this new science, have greatly increased Cascadia's readiness.

\section{January 1700, Pacific Northwest U.S.}

As recently as 1975, the Cascadia subduction zone offshore of Washington, Oregon, and northern California was considered a quiet place with no known great earthquakes and few events recorded by modern seismic networks. By

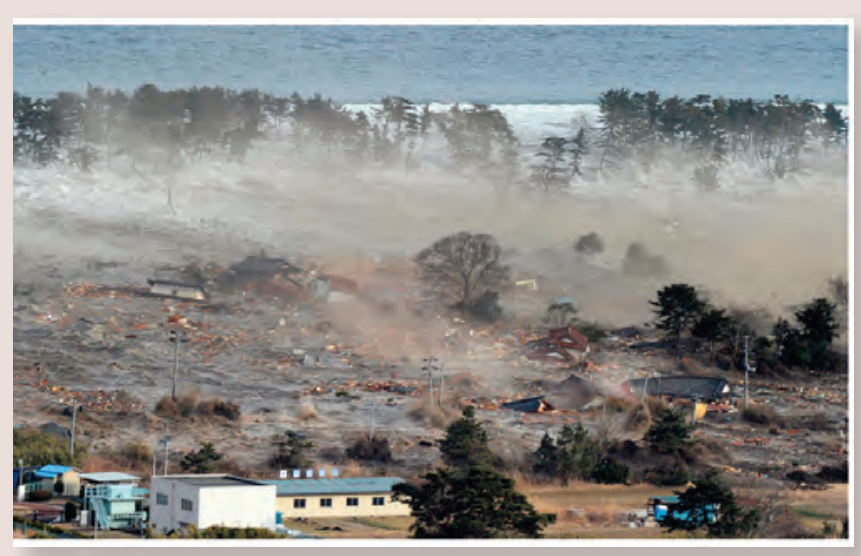

Figure 3. Tsunami wave inundating a coastal town in Japan on March 11, 2011.
1987, investigations pioneered by the USGS identified a chronology of seven M8 to M9 earthquakes and associated tsunamis over the last 3,500 years, showing that giant earthquakes have struck repeatedly. Tree ring dating showed the most recent event occurred between August 1699 and May 1700 . The date was pinpointed after some remarkable scientific sleuthing. Tsunami inundations at five Japanese coastal towns began at about midnight local time on January 27,1700 , yet no one in Japan felt the ground shake, suggesting a distant tsunami source. Computer modeling of tsunami wave travel showed that only a $\mathrm{M} \sim 9$ subduction earthquake in Cascadia on January 26, 1700, could have produced Japan's inundation patterns and timing of damage.

Fortunately, scientists have recognized the Cascadia hazard. The Cascadia chronology of giant prehistoric earthquakes and tsunamis is now the longest record in the world, with 20 events known over the past 10,000 years. This detailed record transformed Cascadia's hazard assessment and prompted continuing planning and preparedness that, so far, includes installation of tsunami warning sirens, creation of tsunami inundation maps, establishment of tsunami evacuation routes, scenarios, and considerable local training. However, the experience in Japan shows that low probability tsunamis with unexpectedly large waves cannot be ruled out in Cascadia, and that complacency or overconfidence about precautions can lead to losses of life and property.

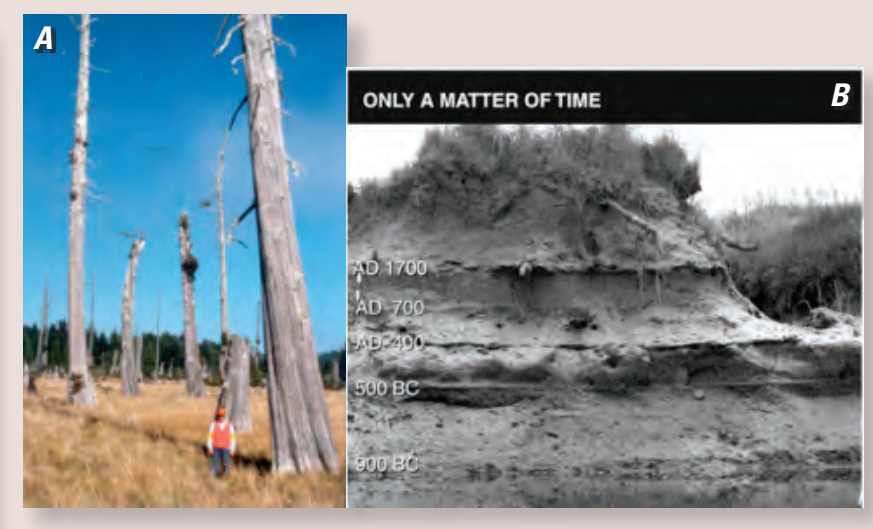

Figure 4. $\quad A$, Coastal forest drowned by subsidence caused by the 1700 earthquake. $B$, Tsunami deposits for the 1700 and earlier prehistoric tsunamis. 


\section{U.S. National Seismic Hazard Maps: From USGS Science to a More Resilient Nation}

The National Earthquake Hazard Reduction Program requires the U.S. Geological Survey (USGS) to assess the Nation's seismic hazards. The USGS assessment, known as the U.S. National Seismic Hazard Maps, is adopted by the Building Seismic Safety Council (BSSC) and incorporated as part of the seismic provisions in the country's model building codes. This is the only USGS hazard assessment that is developed nationally and incorporated into legal statutes. In addition, the National Seismic Hazard maps and their datasets underpin nearly all earthquake risk assessments done in the United States, inform insurance rate structures, and play a key role in other public policy decisions.

The USGS updates the maps about every 6 years, which ensures that the "best available science" moves into the periodic renewal of building codes and becomes public policy. Updating the National Maps is a major effort that involves many people and organizations. In a given update cycle, the USGS and its partners in academia and the private sector typically discuss new discoveries about the behavior of faults and potential seismic sources, consider improved estimates of seismic wave attenuation, new approaches for hazard calculations and better explanation of uncertainty. The thorough discussion of inputs is followed by extensive peer review. The USGS will begin the next update cycle in 2012, to deliver updated maps to the BSSC in 2013.

A key input to the USGS National Seismic Hazard Maps, which help engineers develop safer building practices for the country's earthquake-prone regions, is information from the Advanced National Seismic System (ANSS). To record and locate all earthquakes of magnitude 3.5 or greater in the lower 48 states, the ANSS includes a backbone network of the National Earthquake

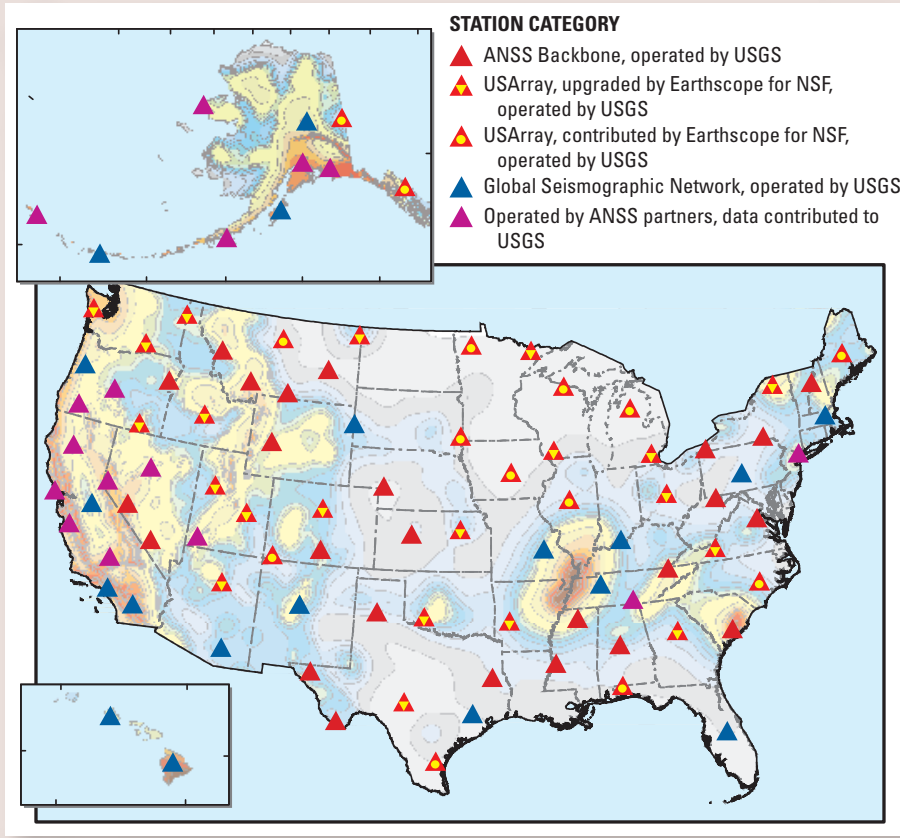

Figure 5. Distribution of ANSS backbone stations shown on the National Seismic Hazard Map where hot colors represent areas of higher hazard. High hazard areas exist in many parts of the nation.
Information Center, the National Strong Motion Project, and in areas of higher activity, 15 regional seismic networks operated by the USGS and its partners. Congress has charged the U.S. Geological Survey (USGS) to build ANSS to do the following:

- Continuously monitor earthquakes and other seismic disturbances throughout the United States, including earthquakes that may cause a tsunami or precede a volcanic eruption, with special focus on regions of moderate to high hazard and risk.

- Thoroughly measure strong earthquake shaking at ground sites and in buildings and critical structures. Focus is largely in urban areas and near major active fault zones.

- Automatically broadcast information when a significant earthquake occurs, for immediate assessment of its impact. ANSS has greatly improved the delivery of critical seismic data to National Oceanic and Atmospheric Administration's tsunami warning centers, for monitoring of the active volcanoes, and for situational awareness of emergency managers. In regions with sufficient seismic stations, within minutes that information includes a ShakeMap (fig. 6) showing the distribution of potentially damaging ground shaking.

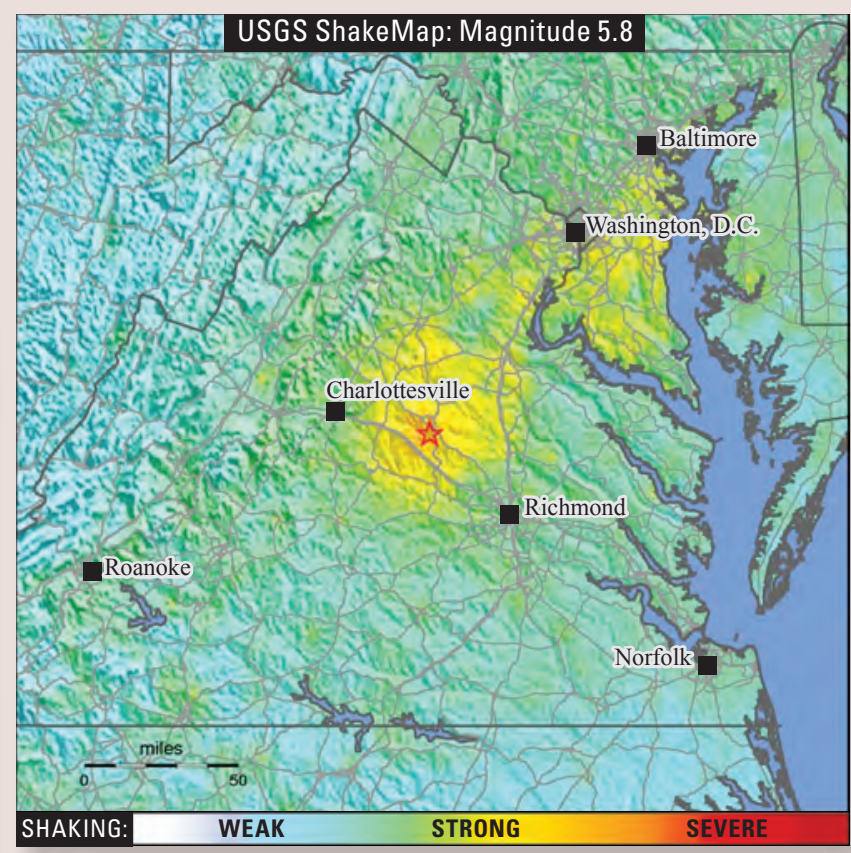

Figure 6. ShakeMap for the 2011 magnitude 5.8 earthquake in Virginia, which caused widespread damage and evacuations. The ShakeMap shows expected intensity of ground shaking and allows emergency managers to quickly assess location and severity of most likely damage. The ANSS system automatically generates ShakeMaps, usually within a few minutes after a large earthquake occurs, then updates the maps as more observations become available. When fully implemented, ANSS will produce ShakeMaps for all of the Nation's highest-at-risk areas. 
4. Improve overall data quality standards. For its data to be useful, the USGS must continue and expand data quality-assurance efforts. Priorities include the following:

a. Set quality-assurance and metadata standards and best practices for collecting long-term hazard data sets.

b. Ensure that both the USGS and the partners who help populate USGS databases collect all data to these standards.

c. Curate data for quality control and ensure that any updates are documented properly.

d. Provide for timely public display of data using web technology.

e. Provide adequate flexibility in standards enforcement so as not to interfere with monitoring for research purposes.

5. Expand earth framework observations. Natural hazards occur within geologic, hydrologic and ecologic frameworks. The characteristics of these frameworks are important in understanding the frequency, physical mechanisms and impacts of the events. Earth framework observations are needed on a periodic basis and often are most effectively and efficiently carried out in partnership with others, especially NSF-supported earth framework projects and surveys in other Mission Areas. Priorities include the following:

a. Bedrock geologic mapping, land and seafloor morphology, and other map-base coverage needed to support hazard assessments including those for coastal erosion, earthquakes, tsunamis, and volcanic eruptions.

b. Vegetation, land use, soil cover and other surficial geology along with the underlying geotechnical data which are a critical requirement for fundamental understanding of hazard processes along with the production of modern, reliable hazard maps.

c. Aeromagnetic and gravity surveys which need to be expanded across much of the Nation in support of a 3 -D view of earth structure, in order to understand ground shaking potential in urban areas, shallow magmatic plumbing systems, volcano-tectonic interactions, volcanic edifice collapse, and fault systems.

d. Coordination across Mission Areas. Many of the efforts require substantial cross-Mission-Area coordination and support in order to improve mapping and data quality, and to reduce redundancy and costs.

6. Improve data collection during and after hazardous events. The USGS should improve the scientific response during and immediately after hazardous events. Priorities include the capacity to accomplish the following: a. Stage and rapidly deploy instrumentation at the onset of a hazardous event.

b. Collect ephemeral data, such as high water marks, ash fall, damage to the built environment, landslide locations, and other data pertinent to response and recovery.

c. Fund and staff rapid deployment of expert field teams to collect data.

7. Expand hazard chronology and magnitude distribution studies. This action better defines probabilities of hazardous event occurrence by drawing on the historical and geologic records. This work links to Core Science Systems and Energy and Minerals by encouraging geologic studies aimed at establishing paleogeologic records and their geologic framework. Priorities include the following:

a. Paleoflood studies of river systems, in collaboration with the Water Mission Area, to determine the chronologies of flood peaks. Increased effort should be made for river systems east of the 100th meridian.

b. Paleo-landslide and wildfire chronology studies that will examine the link between climate change, landslide activity, and wildfire occurrence.

c. Paleo-earthquake studies to examine hazards in areas where hazardous events are poorly understood but where there is high vulnerability. Examples of such areas are the eastern and central United States, and areas with unusual ground motion response.

d. Paleo-investigations of strong earthquake ground motion effects, uplift and subsidence, and fault motions."

e. Geologic investigations of eruptive histories of high priority volcanoes, including bedrock mapping, tephrochronology, and related petrologic and magmatic system studies.

f. Field and modeling studies of earthquake tsunami sources in America's subduction zones and past tsunami wave runups along the Nations's shorelines.

g. Event chronologies in the marine environment developed with a new generation of high-resolution offshore surveys through sediment coring, seismic surveys and "acoustic trenching," and geophysical data collection.

h. Coordination in the Natural Hazards Mission Area to support new methods development through cross-hazards workshops and creation of a standing "Working Group for Paleo-Hazards."

i. Magnetic-storm chronologies and individual storm histories. 


\section{Goal 2: Fundamental Understanding of Hazards and Impacts}

The USGS advances and applies fundamental understanding of natural hazards to improve assessments and situational awareness.

Understanding the processes that produce hazards and risk is the framework that guides pursuit of all three other goals. Fundamental understanding provides not only guidance about what to observe and where to observe hazardous events, processes, and their sources, and to what accuracy, It also enables quantitative assessment of long-term hazards and risks, and provides a scientific basis for forecasts, warnings, and post-event information that go beyond short-term observations.

Observations of hazard processes and effects are interpreted using applied physics and chemistry, modern earthscience principles, experimental geoscience, and mathematics, including statistics. Using these tools, advances in hazard science at the USGS throughout the past decades have come from statistical analysis of data collected on hazardous events and from the testing and improvement of conceptual and quantitative theories of natural hazards processes in light of new observations.

Whereas the USGS has a leadership role in this arena, there are many efforts outside the agency, primarily within the academic community, that have similar interests and meaningful resources. Efforts to communicate and coordinate with the larger community should be a high priority.

\section{Core Responsibilities}

To fulfill its mission and meet statutory responsibilities, the USGS, in collaboration with its many local, State, and Federal partners, must continue to conduct sustained research targeted to societally relevant goals that can accomplish the following:

- Increase understanding of the underlying physical processes that produce the hazard and determine where and under what conditions hazards occur.

- Uphold the tradition of innovation in instrumentation, measurement and experimental techniques.

- Foster USGS scientific expertise to provide expert advice as needed in crisis and noncrisis situations.

- Publish results with peer review and distribute to appropriate audiences through relevant mechanisms.

- Support innovation and creativity in the conduct of our science.

Scientific research and technical development staff within the hazards mission of the USGS are supported through modern laboratory facilities, library and information-technology services, and, of course, funding to hire new staff and to promote the work of the staff. Most important, perhaps, is the culture within the USGS that encourages curiosity, the pursuit of new ideas, and the communication and publication of results and products that improve the ability to respond to hazards.

Hazard science research at the USGS encompasses the understanding of an impressive diversity of physical phenomena. In some ways, the fundamental scientific research undertaken within the various hazards projects are each distinctively different. But in other ways, there are important commonalities, in terms of the underlying physical processes, and methods scientists use to pursue their research. These themes of commonality represent opportunities for cross-hazard and cross-mission collaborative research, both within the USGS and externally. Common themes also are useful for identifying expertise gaps in the development of staffing plans.

Physical process expertise.-USGS research into natural processes leading to hazards have extensive commonalities of underlying physics. For example, classical continuum mechanics is important for understanding the behavior of solids and their brittle failure, plastic deformation, and fluid flow and turbulence that are relevant to research in such subjects as plate tectonics, streamflow, landslide initiation and movement, earthquake initiation and fault processes, and magmatic intrusion and volcanic eruptions. Understanding the behavior of mixtures of solid particles and fluids, and liquid-gas mixtures is important for research into coastal erosion, landslides, airborne volcanic ash, volcanic eruption dynamics, and riversediment, tsunami, and flood dynamics. Wave propagation is fundamental to the sciences of seismology, tsunamis, and geomagnetism. Process-based analysis often is conducted using analytical and numerical analysis methods.

Regional expertise and event-driven research.-When faced with a natural hazardous event that threatens people and communities, the Nation looks to the USGS to explain the hazard processes, impacts, and the fundamental science behind these insights. The credibility and depth of knowledge that USGS scientists possess about specific hazard sources on the landscape is unique and highly valued. To maintain this stature, the USGS must support detailed, long-term investigations by teams of scientists that become the Nation's resource for place-based hazard expertise. Similarly, to speak about hazardous processes and impacts with authority, these same scientists must where possible witness hazardous events and their aftermaths and pursue targeted research during and after hazardous events.

Data analysis. - USGS scientists use a variety of data analysis techniques. Statistical methods are used to analyze hazard chronologies and the spatial distribution of events. For example, the probability of earthquake mainshock occurrence often is modeled as a stationary process, whereas the probability of aftershocks is modeled in terms of transient temporal 
clustering. Particularly challenging is the analysis of extreme events, for which occurrence in time is rare but the hazardous effects can be devastating. The time evolution of hazardous processes can be studied through time-series analysis. These often are applied to continuous data streams acquired from earthquake, streamflow, volcano, and geomagnetic monitoring networks. Both statistical and time-series analysis methods are important for the development of new diagnostic tools used for near-real-time hazard monitoring and post-event assessment.

Vulnerability and risk analysis. - Research engineers and geographers, and social and behavioral scientists within the USGS pursue vulnerability and risk analysis by leveraging USGS hazard information. Hazard vulnerability and risk research is vital to providing feedback to hazard researchers, collaborating with experts to translate scientific information for decision making and supporting numerous agencies and consultants that conduct risk analyses for communities and sectors. Vulnerability and risk research needs to involve earth scientists. Partnerships are important for providing expertise from other USGS Mission Areas (regarding human health, ecosystem services, water quality and quantity, projected land use and cover change), other agencies, engineering expertise, social and behavioral scientists, and users. Collaborative research activity includes developing knowledge and tools to assess vulnerability and risk from hazard assessments; estimating environmental, social, and economic consequences of multiple hazard scenarios; and investigating causes of damages, losses, and impacts of rare and large events worldwide.

Innovative instruments, measurements, and experiment techniques.-Scientists, engineers, and technicians within the USGS pursue important innovative measurement, instrument development, and experimental work in support of scientific understanding and hazards monitoring and warnings, and

\section{Magnetic Storms and Space Weather}

Magnetic storms begin in space but can have serious consequences on Earth. They are caused by the dynamic interaction of the solar wind with the magnetosphere, defined by the extent of the Earth's magnetic field in space, and the ionosphere, the electrically conducting part of the Earth's atmosphere. The largest storm of the 20th century occurred on March 13-14, 1989. This storm induced electric currents in the Earth's crust that found their way through ground connections into the high-voltage Canadian Hydro-Québec power grid, causing transformer failure and resulting in the loss of electric power to more than 6 million people. The same storm also damaged and disrupted the operation of satellites and it severely disrupted GPS systems and over-the-horizon radio communication systems used by the U.S. military. The storm of March 1989, large though it was, pales in comparison to that of September 1859, when the largest storm in recorded history occurred. If such a storm were to occur today, the economic impact to the United States because of disrupted technological systems could exceed \$1 trillion (Baker and others, 2008). Indeed, it is on, or just above, the surface of the Earth that the practical effects of space weather are realized. Therefore, ground-based sensor networks play an important role in space-weather monitoring and magnetic observatories operated by the U.S. Geological Survey are an integral part of the National Space Weather Program, a partnership that includes the National Oceanic and Atmospheric Administration, the National Aeronautics and Space Administration, the National Science Foundation, and the U.S. Air Force.

Figure 7. Schematic of the Sun, the solar dynamo, the solar wind, and the Earth's magnetosphere.

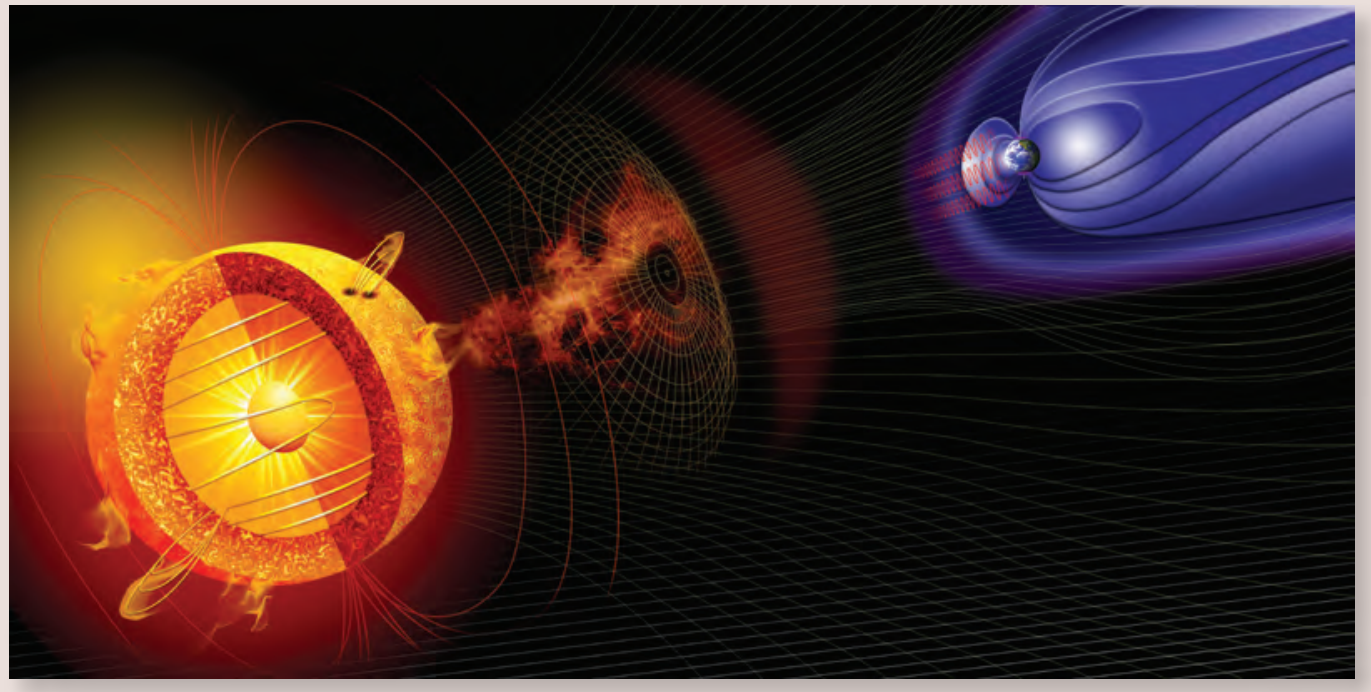


these activities have led to important improvements in hazard monitoring and warning capability. Many of the equipment innovations often have been in collaboration with the private sector. Priority areas for the USGS and its partners include the following:

- Advances in monitoring of land-surface deformation with GPS and Interferometric Synthetic Aperture Radar (InSAR).

- Applying new mapping technologies to ensure data products characterizing wildland fuels and burn severity are current and high quality.

- Field-scale experiments of debris flows.

- Innovative monitoring of landslide hydrology and movement.

- Innovations and improvements of seismic monitors and reporting.

- Enhanced space-weather analysis techniques.
- Application of Doppler radar to characterize volcanic ash clouds.

- Development of acoustic Doppler instruments to rapidly measure streamflow and provide detailed threedimensional velocity profiles.

- Advanced laboratory experiments of subsurface geologic processes, including fault friction and permeability and volcanic eruption dynamics.

- Research and applied science on riverine and coastal erosion hazards.

\section{Strategic Actions}

The USGS must support the fundamental research that will improve the quality and timeliness of assessment and warning products. The following are frontier research areas that are critical for future improvements and advances.

\section{Ancient Floods Provide New Information}

How big? How often? These are key questions confronting scientists, engineers and public policy officials facing hazards posed by riverine flooding. The U.S. Geological Survey streamflow measurement program helps to answer these questions by measuring the magnitude and frequency of high flows on many of the Nation's streams and rivers. At some places, measurements extend more than 100 years, and many of these long duration records allow reasonable estimation for floods that have not happened in the memories of many communities. In some instances, the observed flood record is insufficient, because measurements are absent, time spans are too short, the records do not show consistent patterns, or because operators of critical structures like dams and nuclear facilities need estimates that include exceptionally rare floods.

Scientists and engineers can look back in time with an approach called paleoflood hydrology, which finds and interprets flood indicators, the physical evidence floods leave in their wake, then makes quantitative inferences about unobserved or unmeasured floods. Flood indicators include physical effects on vegetation and various types of geologic evidence, with the best data from layered deposits in areas of slack water. Some paleoflood records, such as those in Black Hills, South Dakota, extend back thousands of years, far exceeding any stream measurement record. Resulting inferences include timing, magnitude, and frequency of individual floods at specific sites or for specific rivers. Findings from paleoflood studies inform flood hazard assessments, as well as understanding of the linkages between climate, land use, and flood frequency.

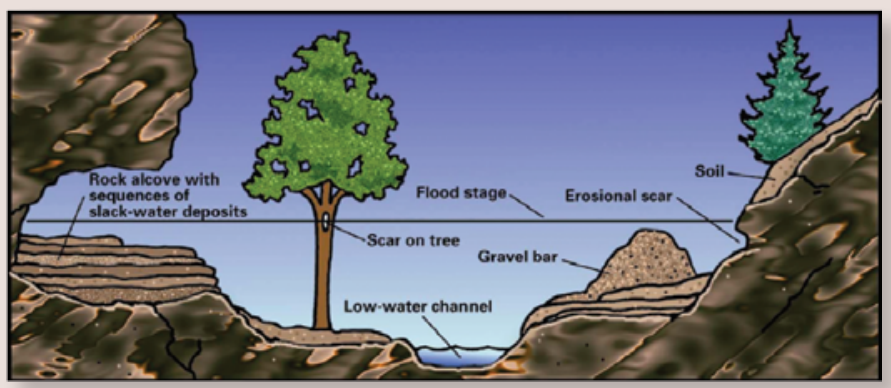

Figure 8. Examples of flood indicators potentially providing evidence of flood magnitude and frequency.
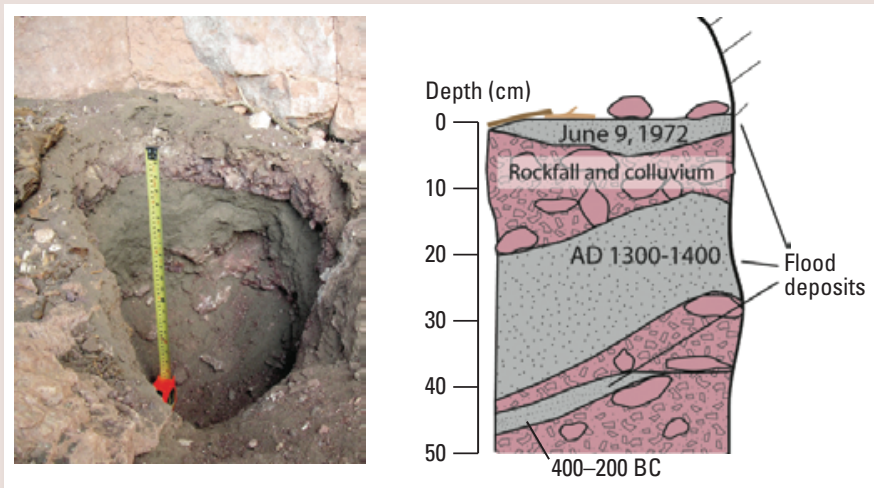

Figure 9. Stratigraphic sequence of three sandy flood deposits separated by rockfall and colluvium high along the canyon margin flanking Spring Creek in the Black Hills of South Dakota. The uppermost deposit was left by the devastating flood of June 9, 1972 that affected the central eastern Black Hills. Underlying coarser and thicker deposits indicate an even larger flood radiocarbon dated to AD 1300-1400. 
1. Promote targeted research on physical hazard initiation processes. Predictions of many hazards, including earthquakes, tsunamis, volcanic eruptions, landslides, and magnetic storms, are limited because of the lack of understanding of the physical process leading to their initiation. Important research questions include the following:

a. What controls the onset, duration, style and magnitude of a hazardous event?

b. How well do observations reflect the physical processes of hazard initiation?

c. What new observations are needed to discriminate between alternative models?

2. Promote research on extreme events. Most hazard assessment deals with the problem of predicting the probability of rare, extreme events from limited information on occurrence based on the instrumental and historical observations of smaller, more frequent events. This requires analysis of Quaternary geological, ice-core, paleo, and historical records of hazardous events to extend and increase the content of the observational record, such that extreme events are included. The extension of the records will reduce uncertainty in the underlying probability distribution and provide empirical information to assess the potential and magnitude of the infrequent large events. Important research questions include the following:

a. To what extent can rare events, such as large earthquakes or magnetic storms, be described as being random?

b. How should scientists characterize the frequency of occurrence and extent of hazards, such as floods, hurricanes, and wildfires, especially when considering nonstationarity caused by climate fluctuations?

c. What are the impacts of extreme events as portrayed in physically realistic scenarios?

d. What are the occurrences of extreme events in unstudied areas with high risk (for example, earthquakes in the central United States)?

3. Promote research about natural hazard vulnerability, risk estimation, and communication. USGS focus and investment in vulnerability and risk assessments varies across hazards depending on statutory requirements, maturity of the science, and need. Important research questions to be addressed include how to accomplish the following:

\section{Alaska: A Geohazards Natural Laboratory for the Nation}

Remote Alaska offers an unparalleled setting in which to study natural hazards that threaten our Nation and the World. Frequent large earthquakes, volcanic unrest, floods, landslides, fire, coastal retreat, and tsunami in Alaska can be examined to test and improve forecasts of hazards in more populated areas. Alaska has one of the highest rates of seismicity and great earthquakes worldwide. Five of these generated local tsunamis with wave heights greater than 10 meters. The 1946 tsunami sent destructive waves across the Pacific Basin as far as Antarctica and the great earthquake of 1964 resulted in tsunami fatalities in Oregon, California, and Hawai i as well as Alaska. In the last 10,000 years, 90 volcanoes have erupted, generating 8 of the planet's 25 largest Holocene eruptions. Flooding due to ice-dam failure, ice-jams, and heavy snowmelt have produced some of the largest flood events on record. In addition to threatening communities in Alaska, these hazards endanger one of the world's largest fisheries, critical oil and gas infrastructure, and north-Pacific shipping on which our Nation depends. This geologically active region of hazard superlatives also presents a tremendous opportunity. Leveraging new and existing partnerships, international interest in regional hazard studies, and a National Science Foundation initiative in Alaska over the next decade, the USGS can make fundamental progress in broadly applicable hazard science by investing in Alaska, the Last Frontier.

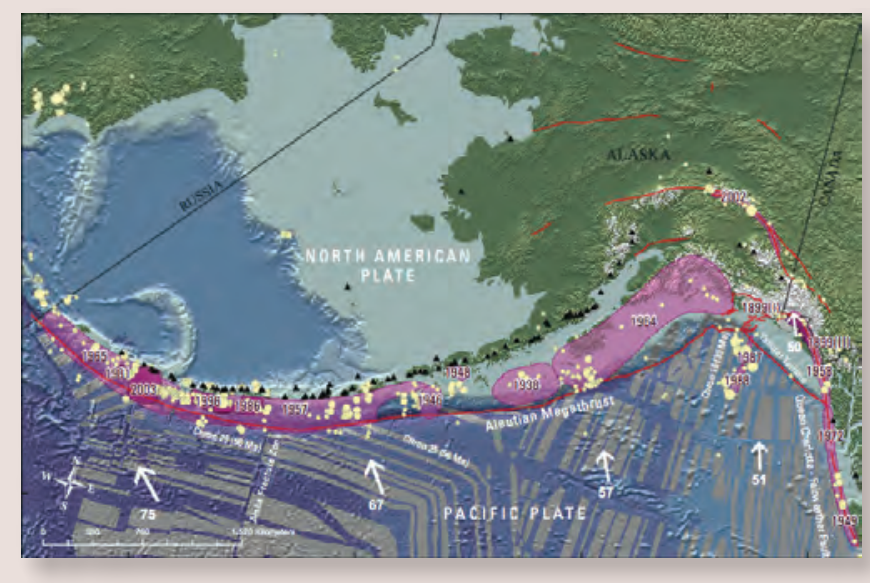

Figure 10. Map of Alaska showing historically active volcanoes (filled black triangles) and large earthquakes (yellow dots scaled by magnitude). Approximate areas of great subduction earthquake rupture are shown in pink with year of occurrence. Gray stripes: magnetic anomalies indicative of incoming Pacific Plate age. Red lines: major active faults. White arrows show directions of relative plate motion with rates in $\mathrm{mm} /$ year. Map by Peter Haeussler, USGS. 
a. Formulate results of physical science research into information useful to vulnerability and risk analyses.

b. Estimate the environmental, economic, and social consequences including cascading impacts associated with hazardous events.

c. Estimate natural hazard vulnerability, risk, and resilience.

d. Most effectively communicate vulnerability and risk to encourage appropriate actions.

4. Encourage interchange of ideas in research about the role of fluids in physical processes. Some of the most important issues in a multitude of hazards phenomena, and in other Mission Areas, involve geological and geophysical fluid flows. Important research questions are wide-ranging and include the following:

a. Role of multiphase fluids in magmatic systems and volcanic processes. b. Multidimensional hydraulic modeling of river and flood processes and their measurement technology.

c. Subsurface hydrology interactions with volcanic, earthquake, landslide and subsidence processes.

d. Coastal processes, including hurricane and tsunami runup and inundation.

e. Role of fluids along faults in the initiation of earthquakes.

f. Terrain-following flows such as debris, tsunami and pyroclastic flows.

\section{Promote research in the triggering and interaction} of multiple hazard processes. Each hazard is governed by physical processes that can trigger other hazards and amplify effects. For example, earthquakes trigger landslides that can set off tsunamis or cause liquefaction that destroys more buildings. The USGS should expand the research into the nature of the triggering and interaction of

\section{Examining the Controls on Debris-Flow Initiation, Mobility, and Magnitude}

Debris flows are fast-moving landslides that cause death and destruction every year. However, precise prediction of when or where debris flows will occur, and how large they will grow, is currently (2011) beyond our understanding. Scientific study of debris flows has been hampered by their unpredictable timing, location and magnitude, which make systematic observation and measurement of these events difficult and dangerous. To increase scientific understanding despite these realities, the U.S. Geological Survey (USGS), in cooperation with the U.S. Forest Service, constructed a unique experimental facility near Eugene, Oregon, for studying debris flows in a controlled environment. The USGS debris-flow flume, operated by the Cascade Volcano Observatory, offers unmatched opportunities to examine the physical processes of and controls on landslide and debris flow initiation, mobility and magnitude. Experimental work performed at the flume has fundamentally advanced the understanding of debris-flow and landslide process mechanics, motivating the development and improvement of hazard assessment and forecasting tools such as assessment of debris flow hazard from volcanoes.

Figure 11. Photographs of the USGS debris-flow flume during an experiment to examine entrainment, or the process by which debris flows grow in size, velocity, and potential impact.

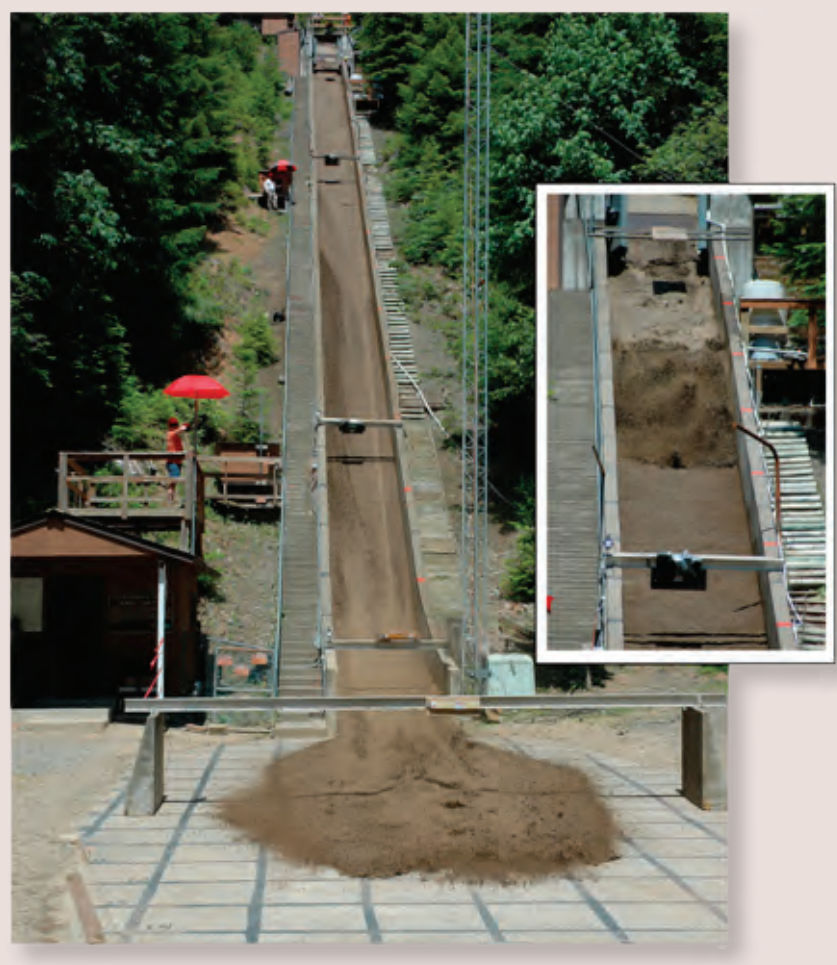
The flume is about 95 meters long and is inclined at 31 degrees. Flow discharges at about 10 meters per second onto the concrete run-out pad, where a 1-meter grid provides scale. Inset photo shows the agitated flow front encountering bed sediment about 20 meters downslope from the flume headgate. 
multiple hazards. Important research questions include the following:

a. What is the interaction of different hazards?

b. What parts of the Nation are most vulnerable to triggered hazards?

c. How are the probabilities, uncertainties, and potential impacts of triggered hazards best defined and depicted?

d. What controls the distribution, size, and impacts of landslides induced by earthquakes?

e. What controls the location, frequency, and magnitude of tsunamigenic landslides?

f. How does storm surge affect coastal erosion?

\footnotetext{
The La Conchita Landslide, Ventura County, California that was reactivated in 2005, killing 10 people. Photograph by Mark Reid, U.S. Geological Survey.
}

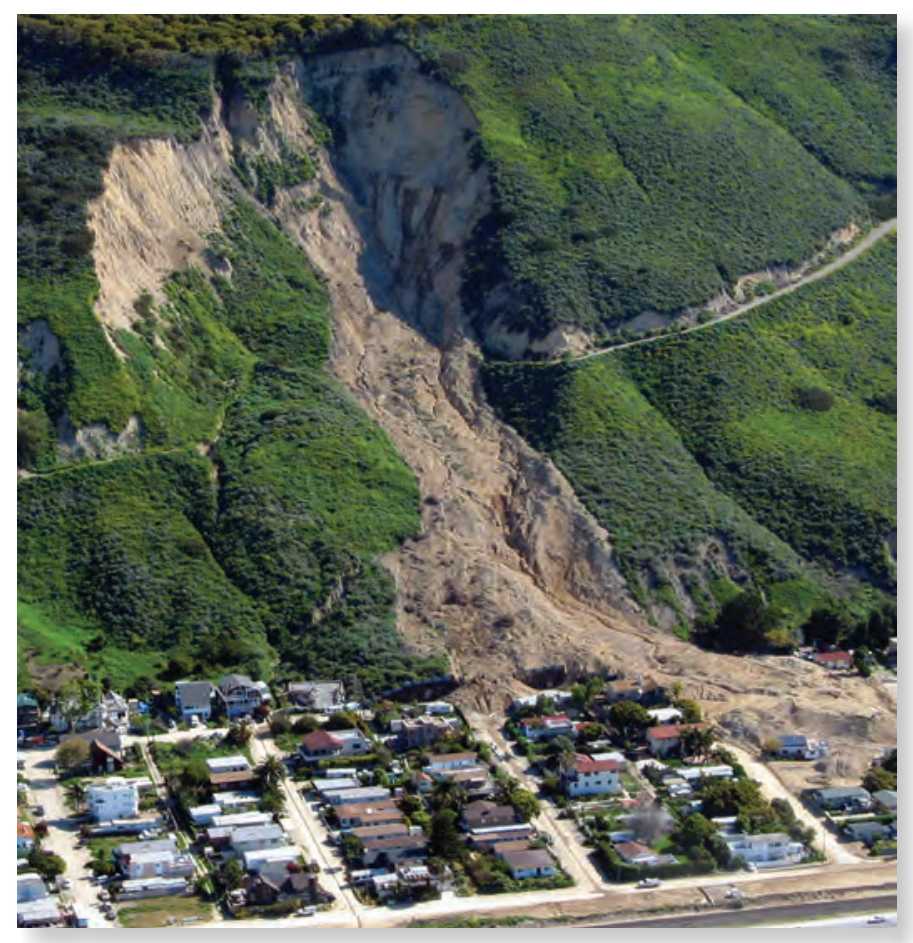

\section{Today's Chance of an Earthquake: Real-Time Forecasts from the Advanced National Seismic System}

Earthquake prediction, the ability to forecast that there is a high probability of a large earthquake in a limited area and time, has been an elusive goal because none of the studies of small earthquakes, geodetic measurements, geo-electric signals, geochemistry, nor any other data have revealed reliable patterns that precede damaging earthquakes. However, scientists have recognized one useful pattern in time and space - that earthquakes cluster. In other words, each earthquake makes another earthquake more likely. In most cases the resulting, triggered events are smaller than the first event and scientists call them aftershocks. But the pattern is more general and can be used to predict an increase in the probability of earthquakes over greater distances and larger magnitudes than an aftershock sequence. Although the probabilities of a larger event are small-around 5 percent in a week-they represent a many-fold increase compared to the probability before the cluster began. This capability has been exploited to create an operational earthquake forecasting system that calculates changes in earthquake probability over a region and publishes the results in near-real-time online. Such a system can only exist in areas with high-performance monitoring networks, the best of the Advance National Seismic System.

Real-time earthquake forecasts require all four of the goals in this Strategy: monitoring uses fundamental understanding to create assessments for better situational awareness.
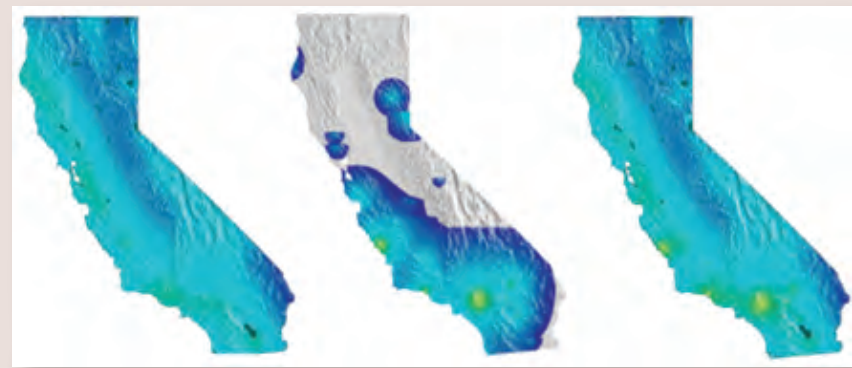

Figure 12. Example of earthquake forecasting. These maps show the probability of reaching or exceeding shaking intensity that can cause damage (MMI VI) in the 24 hours after May 25, 2003, 2:07 a.m., PDT. The left frame is the background hazard based on the 1996 USGS hazard maps for California. The center frame is the time-dependent hazard that exceeds the background from several events including 2003 San Simeon, 1992/1999 Landers/Hector Mine: 1994 Northridge; and 1989 Loma Prieta. The right frame is the combination of these two contributions, representing the total forecast of the likelihood of ground shaking in the next 24-hr period. 


\section{Using Aerogeophysical Mapping and 3D Analysis to Define Collapse-Prone Areas of Volcanoes}

Massive avalanches of rock and debris can result from the collapse of the flank of a volcano. The chance of flank collapse may increase when hot fluids weaken and alter the rocks of the volcano edifice. At Mount Rainier volcano (fig. 13), near the city and suburbs of Tacoma in the State of Washington, past collapses of hydrothermally altered rocks have generated debris flows that have traveled long distances. Future occurrences of collapse and consequent debris flows threaten areas that are now (2011) densely populated. To better understand this threat, the USGS has combined detailed geologic mapping with geophysical data to create a three-dimensional model of rock strength at Mt. Rainier. This model is critical for accurate assessment of the stability of the volcano edifice and provides a means to estimate collapse volume, an important constraint on debris-flow travel distance and hazard. Such analyses provide a means to improve hazard assessments for the surrounding region.

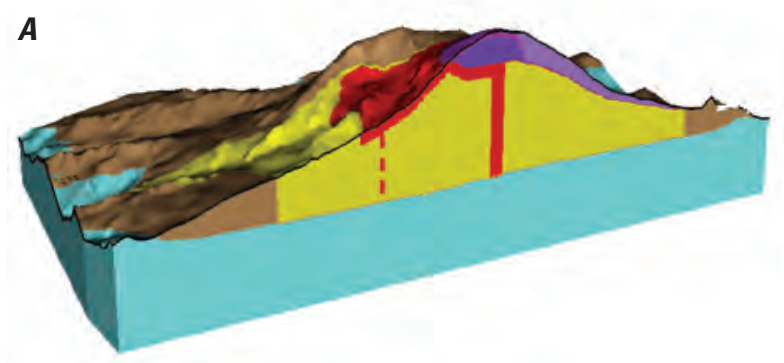

\section{EXPLANATION}

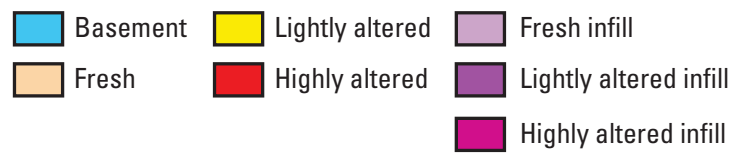

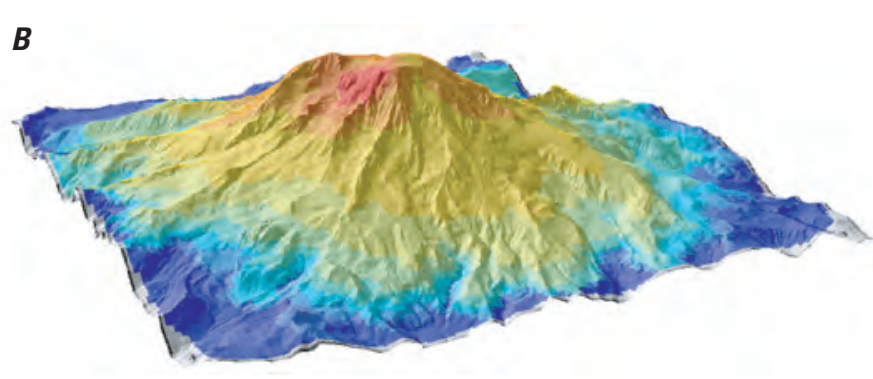

EXPLANATION

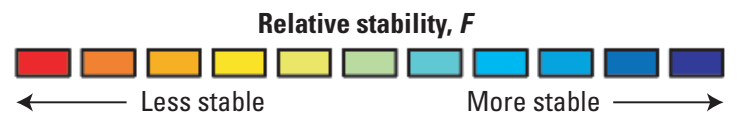

Figure 14. Perspective views of $A$, three-dimensional geological model of Mount Rainier indicating relative degree of hydrothermal alteration, and $B$, results of three-dimensional slope-stability analysis. Relative degree of alteration was used as a proxy for rock strength in the stability analysis. Relatively stable areas are shown in cool colors and relatively less stable areas are show in in warm colors.

San Andreas fault zone, Carrizo Plains, central California. Photograph by R.E. Wallace, USGS. 


\section{Goal 3: Improved Assessment Products and Services}

The USGS develops assessments of natural hazards, vulnerability and risk to inform decisions that can mitigate adverse consequences.

Assessments are a practical tool for decisionmakers to increase risk-wise behavior and a primary way that the USGS can communicate hazard science. Assessments can address natural hazards, vulnerability, and risk.

Natural hazard assessments identify what is known and what is uncertain about past, ongoing, or future hazardous events. Hazard assessments can describe recurrence intervals and probabilities of occurrence, speed of onset, magnitude, duration and spatial extent. For some hazards, assessments can provide information (for example, maps) to answer specific questions that are often constrained by time-frame (for example, what is the probability of a hazardous event in the next 100 years or in the next 5 minutes?), and location (for example, is location A less exposed to hazards than location B?). Society benefits from hazard assessment by using them to understand and minimize vulnerabilities, and risks, and enhance resilience to natural hazards. Vulnerability assessments estimate the susceptibility of the population, the built environment, economic activity, and ecosystems to damage and disruption from natural hazardous events. Vulnerability assessments may include maps of the exposure of populations, businesses, infrastructure, and valuable resources to hazards. Vulnerability assessments include characterizations of damages, disruptions, and economic losses to specific hazard scenarios. Risk assessments combine hazard and vulnerability assessments to describe the nature and likelihood of possible future hazardous events.

\section{Core Responsibilities}

To fulfill its mission and statutory responsibilities, the USGS, in collaboration with its many local, State, and Federal partners, must continue to do the following:

- Create hazard assessments used to support decision making, based on fundamental understanding of natural hazards.

- Evaluate the assessments using observations made at national and regional scales and over long time periods to capture significant and infrequent events.

- Develop new assessment tools to improve the scientific foundation of assessments as new understanding evolves.

- Inform the public about natural hazards to promote risk-wise behavior by publishing assessments and providing assessment tools using USGS scientific information.
Assessments produced by the USGS support statutory requirements for earthquake and tsunami, volcano, and flood hazards (table 1). For example, the USGS Earthquake Program has the most visible assessment role under obligations of the National Earthquake Hazard Reduction Program (NEHRP). The goal of NEHRP in the USGS is to mitigate earthquake losses that can occur in many parts of the Nation by providing earth science data and assessments essential for land-use planning, engineering design, and emergency-preparedness decisions. National seismic hazard maps are the basis for seismic provisions in model building codes adopted throughout the United States. Urban earthquake hazard maps are used by some states in their earthquake regulations and guidelines. Other assessments fill critical gaps in the Nation's hazard assessment and response activities or are in development for future potential uses. Table 1 highlights the current and upcoming USGS assessment products and their uses for each hazard. Dependencies between assessments exist such that one hazard assessment may feed another (for example, debris flow assessments use fire assessments) and vulnerability and risk assessments are contingent on hazard assessments.

The USGS has a national and institutional obligation to communicate its hazard assessments to those who can use them to plan for, respond to, and recover from hazardous events. An institutional obligation requires the USGS to publish hazard assessments that rely on accepted scientific principles. Developing tools to utilize the assessments appropriately and ensure their accessibility satisfies statutory and nonstatutory obligations to help protect the safety, health, and wealth of the Nation.

\section{Strategic Actions}

\section{Improve the formulation and scope of assessments.} Priorities include the following:

a. Implement a robust process to incorporate new data and scientific understanding more rapidly to update and improve assessment resolution, accuracy, and timeliness.

b. Develop probabilistic approaches and quantification of uncertainties where possible.

c. Identify knowledge gaps to guide investments in observation and research.

d. Incorporate secondary effects (for example basin amplification of seismic shaking, post-eruption lahars from volcanoes, landslides from earthquakes, water-quality impacts from hazardous events) to provide more comprehensive estimation of consequences of events. 
Table 1. USGS assessment products in current use.

$[R$, used in research and development sometimes with prototype users; L, used in legislative or regulatory mandated function; U, produced routinely and sent outside the U.S. Geological Survey for hazard management; UCERF, Uniform California Earthquake Rupture Forecast; FEMA, Federal Emergency Management Agency; NOAA, National Oceanic and Atmospheric Administration; NASA, National Aeronautic and Space Administration; NWS, National Weather Service; NTHMP, National Tsunami Hazard Mitigation Program; WUI, wildlife-urban interface; SAFRR, Science Application for Risk Reduction Project]

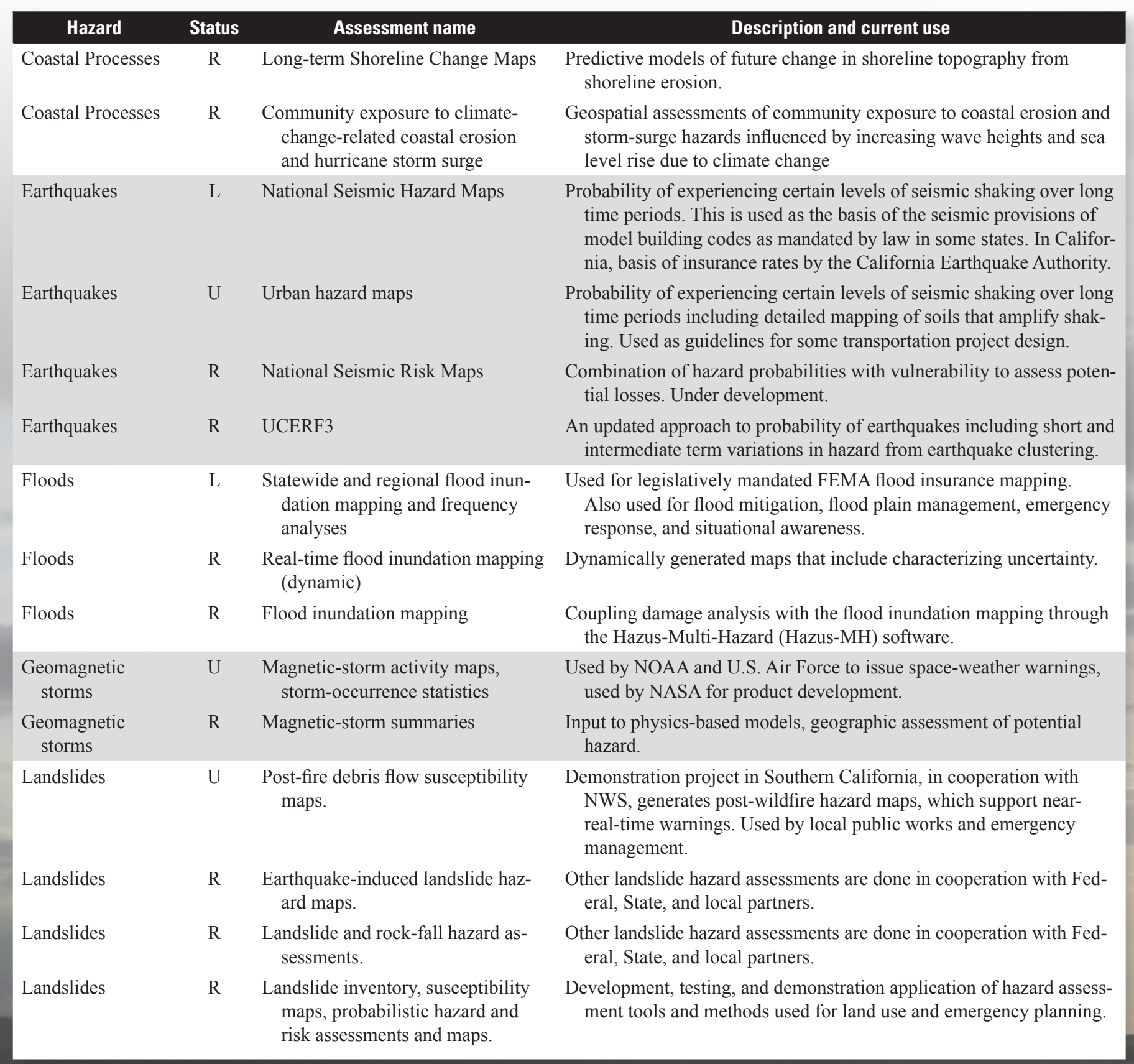


Table 1. USGS assessment products in current use.-Continued

$[R$, used in research and development sometimes with prototype users; L, used in legislative or regulatory mandated function; U, produced routinely and sent outside the U.S. Geological Survey for hazard management; UCERF, Uniform California Earthquake Rupture Forecast; FEMA, Federal Emergency Management Agency; NOAA, National Oceanic and Atmospheric Administration; NASA, National Aeronautic and Space Administration; NWS, National Weather Service; NTHMP, National Tsunami Hazard Mitigation Program; WUI, wildlife-urban interface; SAFRR, Science Application for Risk Reduction Project]

\begin{tabular}{|c|c|c|c|}
\hline Hazard & Status & Assessment name & Description and current use \\
\hline Tsunamis & $\mathrm{L}$ & $\begin{array}{l}\text { USGS tsunami source input data } \\
\text { for NTHMP tsunami inundation } \\
\text { assessments }\end{array}$ & $\begin{array}{l}\text { Inundation assessments are used by others to plan evacuation routes, } \\
\text { locate warning sirens, and to identify especially vulnerable facili- } \\
\text { ties. Also used by FEMA to set rates in National Flood Insurance } \\
\text { Program. }\end{array}$ \\
\hline Tsunamis & $\mathrm{R}$ & Tsunami inundation scenarios & $\begin{array}{l}\text { Based on the most credible earthquake tsunami sources and tsunami } \\
\text { wave-field modeling. Facilitate assessment of coastline inundations } \\
\text { in demonstration projects. }\end{array}$ \\
\hline Tsunamis & $\mathrm{R}$ & Pedestrian evacuation modeling & $\begin{array}{l}\text { Geospatial modeling to determine pedestrian travel times out of } \\
\text { tsunami-prone areas. Used by State and local emergency managers } \\
\text { to guide education efforts and to identify potential sites for vertical- } \\
\text { evacuation strategies. }\end{array}$ \\
\hline Volcanoes & $\mathrm{R}$ & Risk Assessments & $\begin{array}{l}\text { Combination or hazard and vulnerability to assess potential losses car- } \\
\text { ried out on a few volcanoes. }\end{array}$ \\
\hline Volcanoes & $\mathrm{R}$ & Probabilisitic hazard assessments & Probabilistic tephra-fall assessment for critical facilities. \\
\hline Volcanoes & $\mathrm{R}$ & $\begin{array}{l}\text { Ash cloud dispersion and ash fall } \\
\text { forecast maps }\end{array}$ & $\begin{array}{l}\text { Graphical and text products indicating areas to be impacted by ash } \\
\text { clouds and ash fall. }\end{array}$ \\
\hline Wildfires & $\mathrm{U}$ & Fire Danger Forecast & $\begin{array}{l}\text { 7-day forecast of fire probability, prepared routinely for the conter- } \\
\text { minous Unites States; used by Federal, State, and local fire danger } \\
\text { forecasters and resource managers. }\end{array}$ \\
\hline Wildfires & $\mathrm{U}$ & Burn severity maps & $\begin{array}{l}\text { Characterization of burn severity for Burned Area Emergency Reha- } \\
\text { bilitation (BAER) and debris flow susceptibility. }\end{array}$ \\
\hline Multiple hazards & $\mathrm{R}$ & $\begin{array}{l}\text { Multihazard scenarios for earth- } \\
\text { quakes, winter storms, wildfires, } \\
\text { and tsunamis. }\end{array}$ & $\begin{array}{l}\text { Southern California Multi-Hazards Demonstration Project (now } \\
\text { SAFRR Project) collaboratively creates scenario hazard and vulner- } \\
\text { ability assessments that have been used by FEMA, other Federal, } \\
\text { State, regional, and local entities for exercises and to revise disaster } \\
\text { plans. }\end{array}$ \\
\hline
\end{tabular}


e. Develop a consistent methodology for urban areas where hazard holds special importance because of the density of people, buildings, or infrastructure that are at risk. This includes adapting the hazard assessment to provide information relevant to building codes (for example, seismic hazard maps) across the Nation.

f. Develop a consistent visual and electronic file format for all USGS flood inundation map products.

g. Cooperate with other mission areas to expand vulnerability assessments to include environmental health and ecosystem services and to project vulnerability and risk assessments into the future under climate and land use change.

2. Improve assessment distribution. Delivering assessments according to user needs and by multiple media will improve the uptake of the information and use in decisions. Priorities include the following:

a. Include known and potential users in the design and creation of assessment products to align better with user needs.

b. Use social and behavioral research to guide presentation of hazard information and mediums of dissemination, paying particular attention to the communication of uncertainty.

c. Develop alliances to create and provide educational materials that include interactive hazards education and training in use of assessments.

d. Provide tools and training for people to create their own assessments.

3. Develop multihazard assessments. Currently most assessments are single hazard. Users often need to compare the relative risk or assess the combined risk of multiple hazards within a geographical region. Priorities include the following:

a. Develop tools to compare multiple hazards, across a variety of temporal and spatial scales.

b. Create visualizations of multiple hazard assessments.

c. Integrate information about multiple hazards and impacts on the built environment to better inform urban decisionmakers.

4. Balance hazard and vulnerability and risk assessment. The need for USGS hazard research to improve the accuracy, resolution, and timeliness of assessments that focus on the physical characteristics of hazards must be balanced against the need to engage and collaborate with other agencies, engineers, social and behavioral scientists, planners, and emergency managers in the use of the information. Knowledge of vulnerability and risk enables earth scientists to relate to decisionmaker concerns before, during, and after hazardous events. Priorities include the following:

a. Identify relevant partnerships that improve and expand the usefulness of hazard assessments and support partners' needs without overextending USGS resources.

b. Pursue the translation of hazard assessments into decision-support methods and tools in those cases where the observational base and level of hazard understanding is mature and effort is likely to have significant societal benefit.

c. Develop and demonstrate the application of hazard understanding to vulnerability and risk assessment in collaboration with partners who are responsible for (i) maintaining the relevant social data and (ii) maintaining the integration of hazard assessments with these social data.

5. Develop event and disaster scenarios and other strategic assessments. Scenarios of potential disasters and certain hazardous events have proven to be particularly useful in helping users understand the results of research and incorporate the information in their decision making. The USGS should, as appropriate, expand the range of hazard, vulnerability and risk assessments and tabletop exercises in partnership with current and potential users to meet their needs in advance of hazardous events. The expansion should include scenario tools and processes for use during post-event recovery. These scenarios and strategic assessments can and should include events that lead to crises and widespread destruction, but also can include general levels of disruption to the infrastructure and activities of modern civilization.

6. Evaluate assessments. The USGS needs to actively evaluate the accuracy, use, validity, and impact of assessments to demonstrate improvements from research investments, as well as to demonstrate the effectiveness of the assessments to inform risk reduction and resilience decisions. Depending on the scope of the hazard program, the evaluations could be nationwide, regionally with partners, or as prototype studies and demonstration projects. Priorities include the following:

a. Where possible and appropriate, the USGS should solicit feedback on the efficacy of targeted assessments from partner agencies, such as DOI Bureaus, that rely on USGS hazard assessments. DOI lands provide opportunities to understand the role that hazard assessments play in reducing human and ecosystem vulnerability. 


\section{Postfire Debris Flow}

In 2009, the Station wildfire, the largest fire in the history of Los Angeles County, California, burned more than 251 square miles of the Angeles National Forest. Numerous mountain front communities were affected by the fire, and then, with the coming of winter storms, the same communities faced a new risk. Now these communities were potentially in the paths of debris flows. Debris flows are fast-moving, destructive landslides; they cause deaths and property damage annually. Wildfires can significantly increase the likelihood of debris flows, which can be generated by rainstorms over the burned area. In response to the urgent need for timely debris flow hazard information, the U.S. Geological Survey (USGS) rapidly performed a hazard assessment to estimate potential debris-flow probabilities, volumes, and inundated areas for the Station fire burned area (fig. 15).These assessments were then used by the National Weather Service Forecast Offices in Southern California to issue warnings of debris flow potential during storms. Before the onset of winter rains, reports and maps from this assessment also went out to the public, the U.S. Forest Service, and Los Angeles City and County emergency-response, public-works, and flood-control agencies. Concurrently, the USGS Multi-Hazards Demonstration Project mounted an extensive public-information campaign to disseminate debris flow hazard information. The information provided by the USGS was widely used to prioritize data-collection, hazard-mitigation, and warning efforts, and for emergency-response planning.

Figure 15. Postfire debris-flow hazards map for part of the area burned by the 2009 Station fire, showing potential volume of material expected from drainage basins and where that material will travel.

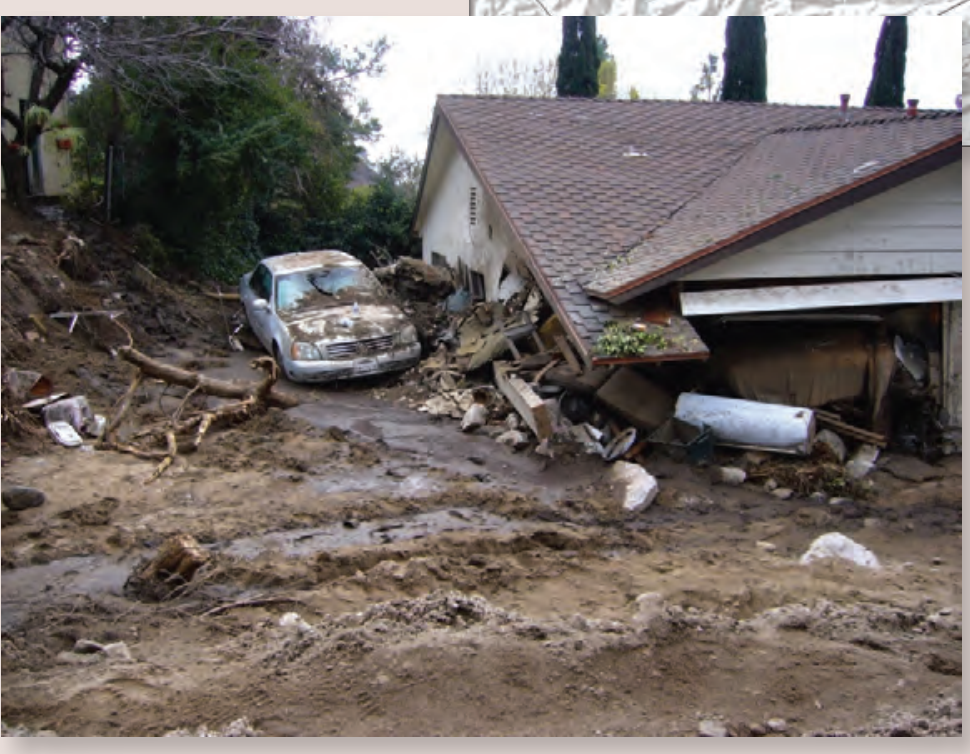

Figure 16. Damage from debris flows generated from hillsides burned by the 2009 Station fire. 
b. Work with social and behavioral scientists to evaluate user satisfaction, effectiveness of risk communication, accuracy of interpretation, understanding of uncertainty, and appropriateness of response to disseminated hazard maps and scenarios, and develop a repository of "lessons learned."

\section{Using and Improving Hazus-MH}

The Federal Emergency Management Agency (FEMA) developed a standardized methodology, the software package called Hazus-Multi-Hazard (Hazus-MH), to provide a nationally consistent tool to estimate potential losses from earthquake, flood, and wind events. Selected USGS hazard assessment products (for example, USGS ShakeMap data) are used in Hazus-MH.

USGS scientific studies have employed Hazus-MH in scenarios and risk analyses. For example, the USGS ShakeOut earthquake scenario used Hazus-MH to estimate certain building damage and output losses, and the ARkStorm scenario made use of Hazus-MH building inventory and employed Hazus-MH algorithms to estimate flood and wind damages and economic output losses. The USGS Land Use Portfolio Model uses Hazus-MH to estimate building damage for scenario-based risk and return analyses. The USGS National Seismic Hazard Mapping Project generates earthquake risk maps by combining probabilistic hazard curves with Hazus-MH building fragility curves.

Concurrently, USGS has identified and undertaken activities to improve the usability of Hazus-MH. A tool called the HazusMH Data Extractor (Beta v1.0) extracts damage and loss-estimate data from a Hazus-MH earthquake or flood estimation to a geodatabase for future use. USGS also is working on approaches to run Hazus-MH in batch mode.

In cooperation with FEMA, the USGS Flood Inundation Mapping Initiative, incorporated Hazus-MH inundation polygons and depth grids and is developing a web-based application of Hazus-MH software. This application will allow local emergency response personnel and municipal planners to view flood inundation extent and loss estimates for each flood stage of a USGS gage station without requiring an analyst to run Hazus-MH.

\section{HAZUS Map Viewer Prototype for Iowa City}

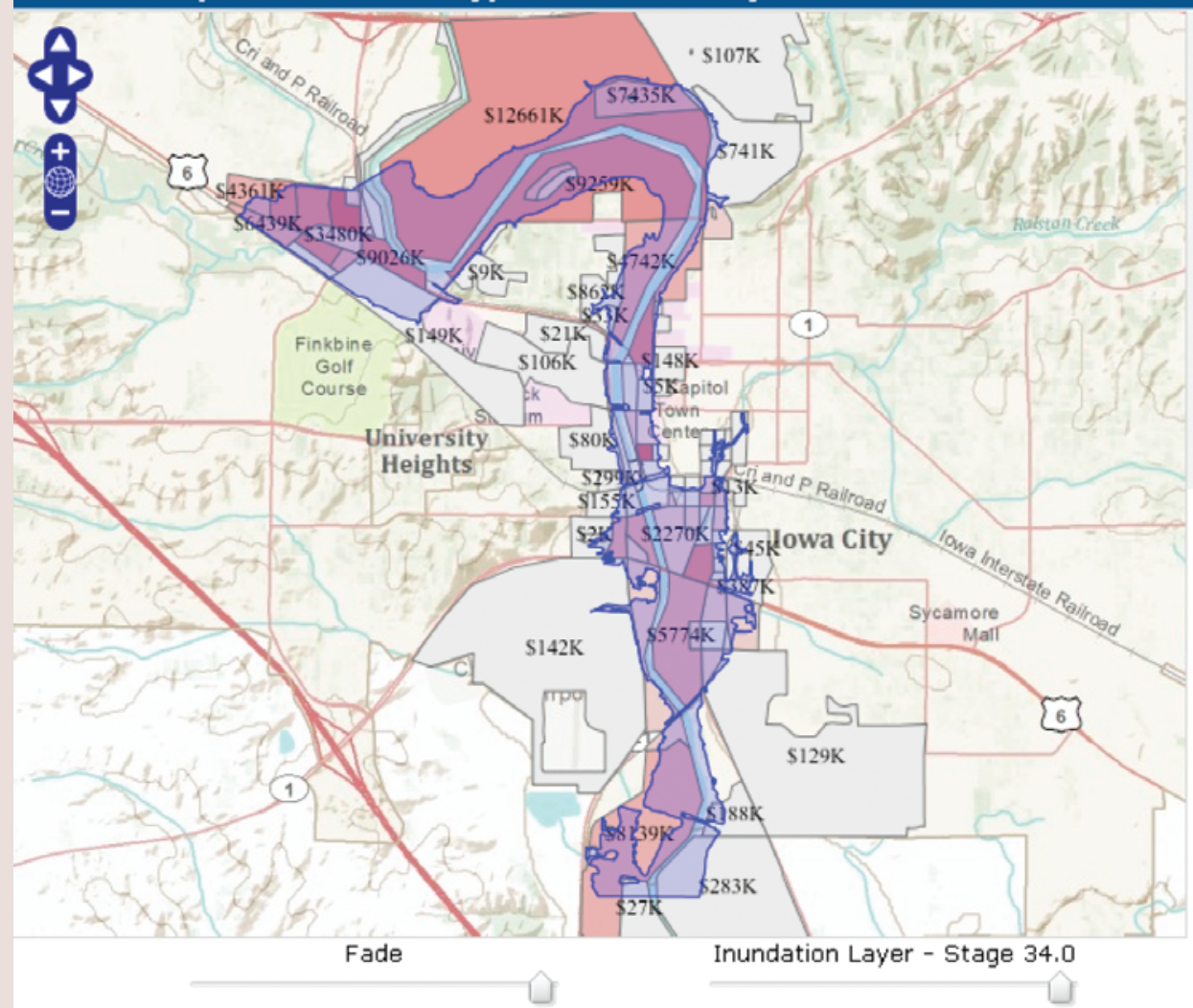

Map Layers

$\checkmark$ HAZUS Loss Data by Census Block

HAZUS Loss Data by Census Block General Building Stock Loss $\vee$

\begin{tabular}{ll}
\hline All & $\checkmark$ \\
\hline All & $\checkmark$ \\
\hline
\end{tabular}

\section{FEMA MEEAS,}

Quick Assessment report

Figure 17. Screenshot from a prototype HAZUS flood analysis Web service displaying flood loss estimates for different river stage levels at a given site. The USGS, FEMA, and NOAA/NWS are evaluating this technology for possible deployment under the Integrated Water Resources Science and Services (IWRSS) Consortium. 
c. Use scenario process to provide a forum for testing how assessments are used, including long-term planning and crisis response. d. Work with user communities to improve assessments based on these evaluations and to support the Whole Community approach promoted by FEMA.

\section{U.S. Geological Survey Role in Assessing Hurricane Impacts}

The U.S. Geological Survey (USGS) and its collaborators (including the National Aeronautics and Space Administration, the U.S. Army Corps of Engineers, and university researchers) conduct sustained investigations of coastal hazards associated with major hurricane landfall.

USGS hurricane research and response activities include collection of storm-surge water levels, aerial photography, and laser altimetry surveys of pre- and post-storm beach conditions.

These efforts document the nature, magnitude, and variability of coastal changes such as beach erosion, overwash deposition, island breaching and destruction of infrastructure. Predictive models and assessments of severe storm impacts are developed and evaluated, and probabilistic assessments are distributed to the public, local, State, and Federal agencies. The assessments and observations provide information needed to understand, prepare for, and respond to coastal disasters.

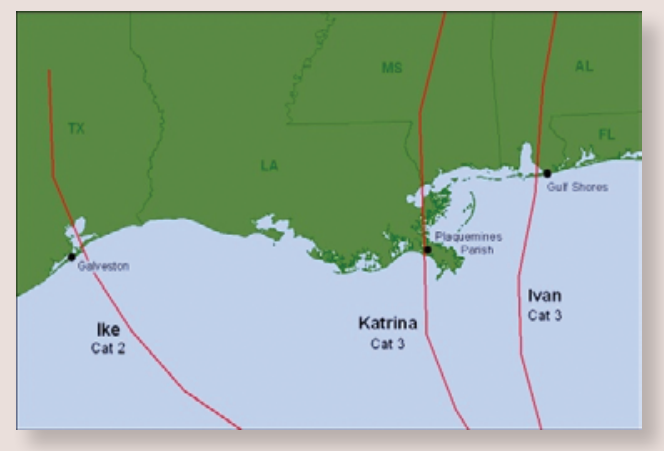

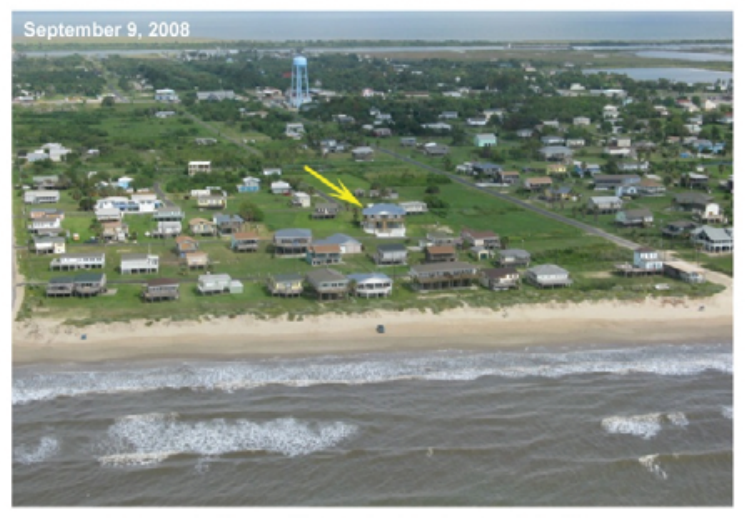

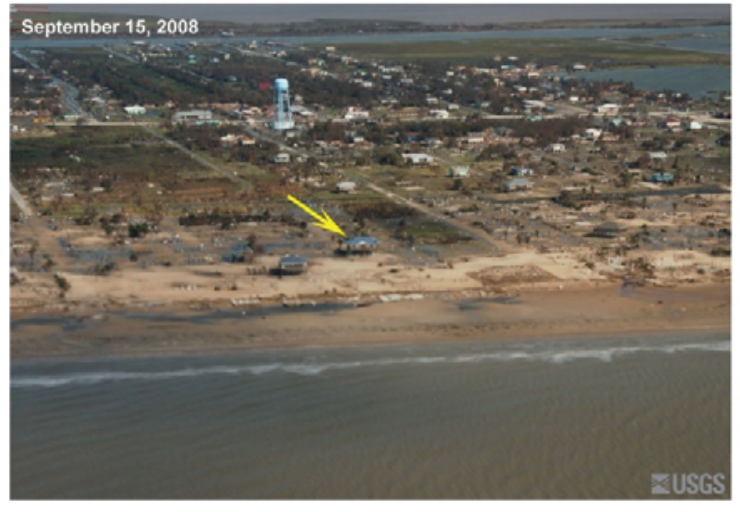

Figure 19. Before and after photographs of Hurricane Ike coastal impacts.
Figure 18. Recent damaging hurricanes assessed by the USGS include Ivan (landfall near Gulf Shores, Alabama, on Sept. 16, 2004), Katrina (landfall at Plaquemines Parish, Louisiana, on Aug. 29, 2005), and Ike (landfall near Galveston, Texas, on Sept. 13, 2008).

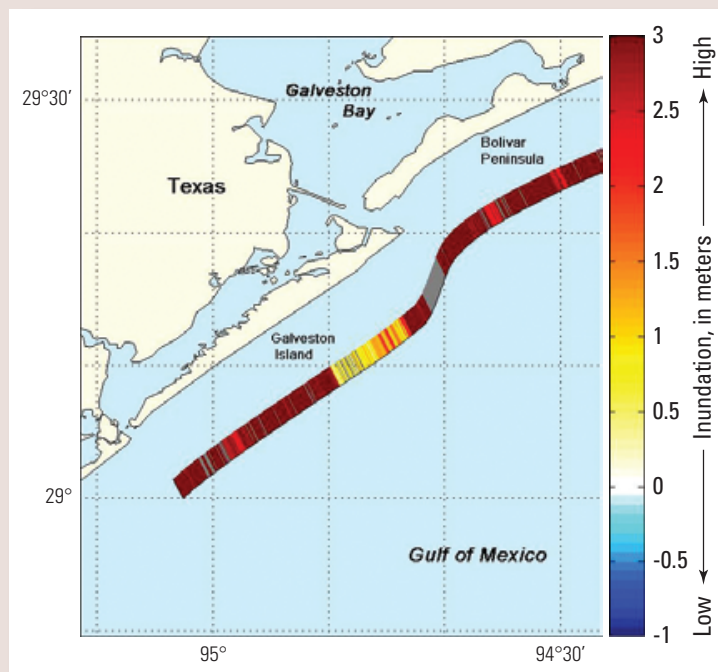

Figure 20. Assessment of inundation potential near Galveston, Texas for Hurricane Ike. Severe inundation (red colors) and coastal change were expected where surge exceeded the elevations of the dunes (East and others, 2008; http://pubs.usgs. gov/of/2008/1365/. 


\section{Goal 4: Effective Situational Awareness}

The USGS provides situational awareness to improve emergency response, inform the public, and minimize social disruption.

The role of the USGS during natural hazardous events, disasters and times of potential disasters varies considerably between the hazards. The Disaster Relief Act of 1974 gives the USGS statutory responsibility to issue alerts about geologic hazards, including "earthquakes, volcanic eruptions and ash clouds, landslides, mudflows, subsidence, faulting and fissuring of the ground surface and glacier-related processes" (quote from Federal Register Note, appendix 5). Different warnings can be issued and vary between these hazards. In addition, the USGS plays a critical role, supplying data and information to other Federal agencies that have the forecasting and alert responsibilities for floods, volcanic ash clouds, tsunamis, geomagnetic storms, and wildfires. For floods, geomagnetic storms, and tsunamis, the USGS supplies data in near-realtime to NOAA. Also, during the aftermath of a hazardous event, the USGS rapidly deploys interpretive geospatial products.

Accurate near-real-time information, and effective forecasts and warnings are crucial tools to provide situational awareness and reduce losses that surround hazardous events. For some hazards, it is valuable to provide information about how the hazards are evolving (for example, changes in status in the magnitude of a magnetic storm), when a hazard has ceased, and when the situation is all-clear (the hazardous event has ceased). All of this is important to prevent needless disruption and cost. The situational awareness role means USGS hazards science becomes the face of the USGS during a hazardous event. The societal benefit of this role is enormous and will necessarily require substantial attention to the broad community that relies on this aspect of the USGS. A deliberate effort to communicate with this community of users for the purpose of improving our products and services will be necessary to maximize the societal benefit of our situational awareness efforts.

It takes considerable effort and resources to develop and maintain robust alert capabilities. As much or more than any other component in the USGS hazards mission, forecasting must always be looking to the latest technologies, hardware and software solutions to keep its networks and data delivery systems functional and valuable. The types of information and the time frames when information is needed vary with the hazard (table 2) and with the phase in the hazard mitigation cycle.

Networks of USGS monitoring sites are critical elements in efforts to provide early warning and forecasts of hazardous events, and also serve a vital role during response and recovery efforts. Rapid public availability of consistent, quality-assured data must remain a hallmark of USGS operations and the systems that process, deliver, and archive that data must be robust. Goal 1 is necessary for Goal 4.

\section{Core Responsibilities}

To fulfill its mission and meet statutory responsibilities, the USGS, in collaboration with its many local, State, and Federal partners, must continue to do the following:

- Collect the data and conduct analyses to inform warnings by the USGS or others of impending crises.

- Issue warnings and advisories of impending potential hazardous events and their termination.

- Provide timely information to other agencies, emergency managers, the media, and the public about hazardous events as they occur.

- Invest appropriate resources in hazard education during crisis as well as noncrisis times.

In addition to warnings, the USGS informs the public and first responders with near-real-time information to improve their situational awareness. This is a rapidly evolving area with several new products that have found eager users in the emergency management arena. The current warning and informational products, and some of the users, are listed in table 2. The processing and dissemination systems are managed primarily within programs under the Hazards Mission Area and geospatial products from the Core Science Systems. These products are used to protect life and property and the Hazards Mission must continue to produce these products.

Implementation of new technologies typically is limited by resources and priorities, not capability. The kind, type, and frequency of data and scientific analysis that the USGS can provide for response activities depends on many variables including site density and the reliability and accuracy of equipment in its monitoring networks, how quickly the raw data are transmitted and converted to usable information, and whether effective, rehearsed procedure and coordination are in place to process and disseminate the resulting information.

\section{Strategic Actions}

1. Develop and provide training for the next generation of tools for rapid event detection and response. As new understanding is developed through research, new tools and products should be developed to inform and advise the public, partner agencies, and the emergency-response community during hazardous events. This will require targeted partnerships to define the products and activities needed for planning, response, and recovery efforts and the delivery mechanism that will most effectively get USGS information into the hands of decisionmakers. Priorities include the following: 


\section{Table 2. Examples of USGS Products for warnings and situational awareness.}

$[\geq$, greater than or equal to; USAID, U.S. Agency for International Development; FEMA, Federal Emergency Management Agency; NOAA, National Oceanic and Atmospheric Administration; NASA, National Aeronautic and Space Administration; FAA, Federal Aviation Administration; NWS, National Weather Service; DOD, Department of Defense]

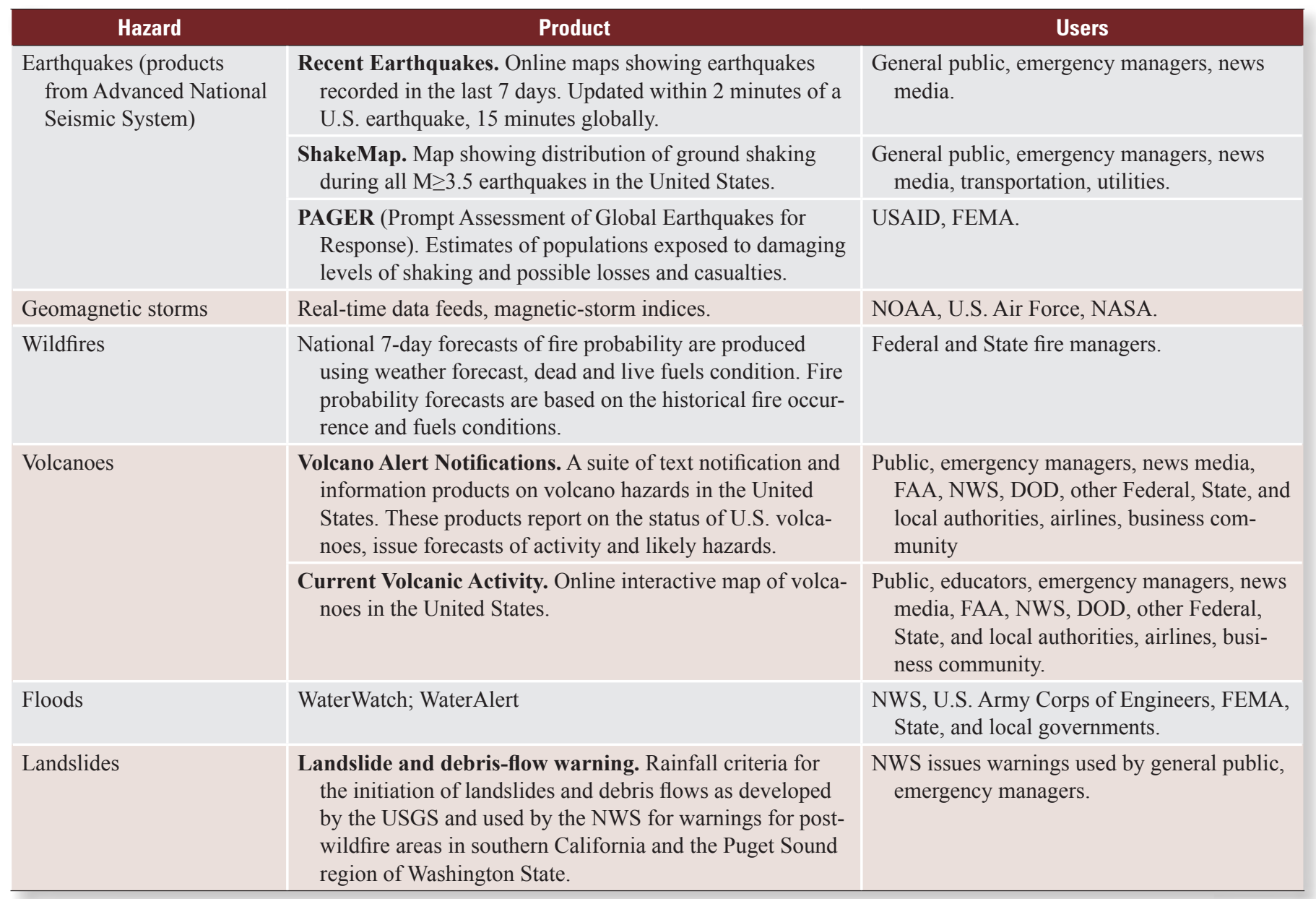

a. Data, nowcasts, forecasts, and interpretive geospatial products.

b. Operational alarm systems to detect volcanic unrest and eruptions.

c. Earthquake early warnings and operational forecasting of earthquake sequences.

d. Databases and decision-support systems for wildfire management, in partnership with the U.S. Forest Service.

e. State-of-the-art, near-real-time dynamic flood inundation maps and applications to meet a host of needs ranging from flood response and mitigation to damand levee-break simulations.

f. Landslide situational awareness capabilities akin to those in the other USGS statutory hazards, volcanoes and earthquakes. g. Coordinated ground and space-based real-time magnetic-storm activity predictions.

2. Improve data systems critical to situational awareness responsibilities. To serve this role, monitoring networks must become more robust and, in some cases, expanded to increase data density or to include areas not currently (2011) covered. Information also must be delivered in formats that are useful to a broad range of users including partner agencies, fellow scientists, emergency managers, and the general public. Priorities include the following:

a. Monitoring equipment meets reliability and accuracy standards.

b. Equipment maintenance and replacement schedules are adequate to ensure network readiness.

c. Networks provide adequate spatial and temporal data density. 
d. Appropriate levels of redundancy in sensors and telemetry are available in critical locations.

e. Systems (hardware and software) that convert field sensor data into an understandable product are reliable and timely.

f. Human resources are available and effectively staged.

g. Maintenance and enhancement of data portals and web-based distribution systems.

3. Implement $24 \times 7$ operation for critical USGS monitoring efforts. In order to maximize USGS ability to inform partner agencies, respond to hazards, and deliver scientific expertise in a timely fashion, $24 \times 7$ operational capability must be established for appropriate hazards. For example, interagency efficiencies can be realized if the streamgage program becomes a true $24 \times 7$ network health monitoring and response operation. New $24 \times 7$ capability might be in partnership with other agencies such as NOAA when the forecast and response role is a shared responsibility, or may be a stand-alone USGS operation for hazards that fall completely within the USGS mission. Activities to accomplish this could include the following: a. Initiate a formal study to determine which hazards require $24 \times 7$ operations and how best to accomplish them, recognizing the need for resources including staff.

b. Where feasible, establish a partnership with the existing $24 \times 7$ operation at the National Earthquake Information Center (NEIC) to support continuous operations and network health monitoring.

4. Improve application of scientific expertise during hazardous events. In the coming decade, emphasis must be placed on facilitating rapid access to USGS expertise, products, and services by ensuring that programs, facilities, and personnel can accomplish the following:

a. Provide expert information for public safety (such as flood stage information or aftershock rates). USGS experts should work closely with FEMA and State emergency managers to provide the science to inform decision making during crisis response.

b. Make timely assessments of rapidly changing hazard situations to inform tactical response and strategic recovery decisions.

\section{Value of Rapid Deployment Streamgages For Floods}

Even with 7,800 streamgages in the U.S. Geological Survey (USGS) network nationwide, stream stage and streamflow data are needed during floods at locations that are ungaged. The gages have crucial value for flood control reservoir operation, flood forecasting, flood fight operations, road closure, and emergency management, including evacuations. To meet the need for more gages during floods, USGS developed, built, and maintains a cache of rapid deployment streamgages (RDG) that can be installed to collect and transmit near-real-time data within hours to days at critical locations.

During the 2011 floods in the central United States, many RDGs were deployed to meet many needs. In Louisiana, RDGs were deployed in the Morganza floodway to provide near-real-time data to the U.S. Army Corps of Engineers and other stakeholders, including State and local governments to monitor water levels in the floodway after activation. This enabled U.S. Army Corps of Engineers officials to correlate the amount of water allowed into the floodway with water levels at various locations of the floodway. In Mississippi, an RDG was deployed along the Mississippi River for the Yazoo Levee District to monitor water levels near remote facilities. In Montana, North Dakota, and South Dakota RDGs were deployed in the Missouri River, Red River, and Souris River to provide the U.S. Army Corps of Engineers and the U.S. Bureau of Reclamation near-real-time stage and streamflow data to assist with dam operation decisions.

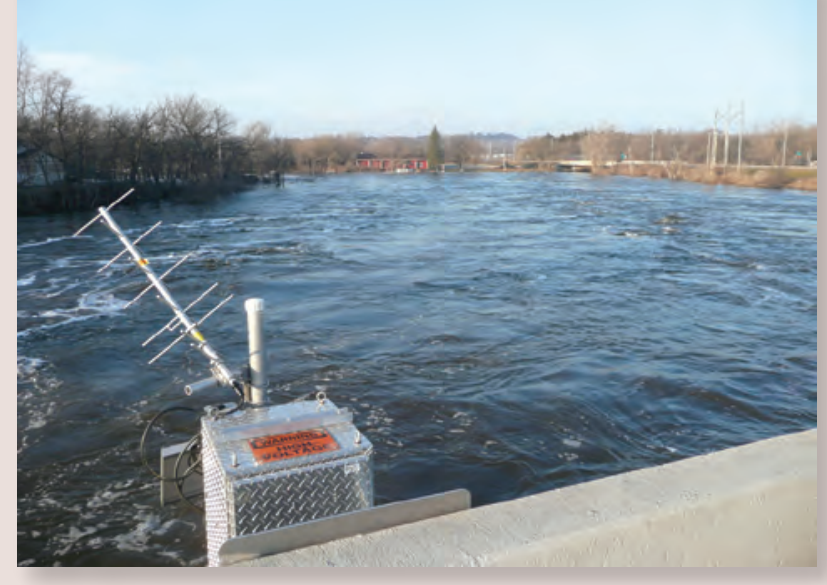

Figure 21. Rapid Deployment Streamgage installed on the Minnesota River at Granite Falls, Minnesota. Photograph by Josh Ayers, USGS. 
c. Improve the integration of geospatial response capabilities into USGS hazards science.

d. Fund and staff rapid deployment of expert field teams to interface with local responders. The effort would work across the USGS Mission Areas and begin by assessing USGS readiness for a catastrophic event. The USGS would develop strategies to deal with high probability hazardous events and high risk, low probability events.

e. Provide training and experience in media response during hazardous events, disasters, and potential disasters to a wider range of qualified hazard scientists and, as appropriate, enhance coordination of the USGS media response at USGS offices in different media markets.

5. Improve internal hazards coordination. Centralization of USGS hazard activities is not desirable or practical; however, improved coordination of these activities would produce efficiencies and synergies. Response to disas- ters and potential disasters is coordinated by the Hazard Response Executive Committee. This coordination cuts across missions and regions and includes the hazards science data and research, in addition to many geospatial activities. Priorities include the following:

a. Identify and build working relationships among USGS experts and across Mission Areas to tap during disaster response and recovery.

b. Engage the broader USGS community in a discussion to identify what roles different parts of the USGS will play during hazardous events.

c. Coordinate learning from national and international disasters and identify and promote hazard research that can best inform USGS operations during crises.

d. Conduct Mission-Area-led catastrophic event exercises to help Science Centers plan a robust interdisciplinary response and to determine how the Mission

\section{Imagery for Emergency Response: the USGS Hazards Data Distribution System}

When emergencies occur, first responders and disaster response teams need access to aerial photography and satellite imagery that is acquired within hours of the event. The U.S. Geological Survey (USGS) Hazards Data Distribution System (HDDS) provides quick and easy access to imagery and geospatial data for emergency response and recovery operations. HDDS provides data access and delivery services through both graphic and traditional, directory-based interfaces that allow emergency response personnel to select and obtain pre-event baseline and post-event emergency response imagery. Comparison of before-event images with after-event images is a powerful tool for situational awareness, and among other information enables decisionmakers to identify where impacts may be most severe and where access may be limited. To further assist emergency personnel who do not have time for lengthy data searches, the HDDS serves as a consolidated storage and pointof-entry system for access to the USGS-hosted datasets related to emergency response.

According to recent (early 2011) system statistics, the HDDS serves some 135 terabytes of data representing more than 4.5 million files and more than 640 baseline and disaster events.

In 2011 alone, HDDS servers have distributed more than 14 terabytes $(490,000$ files) of information to the disaster response community.

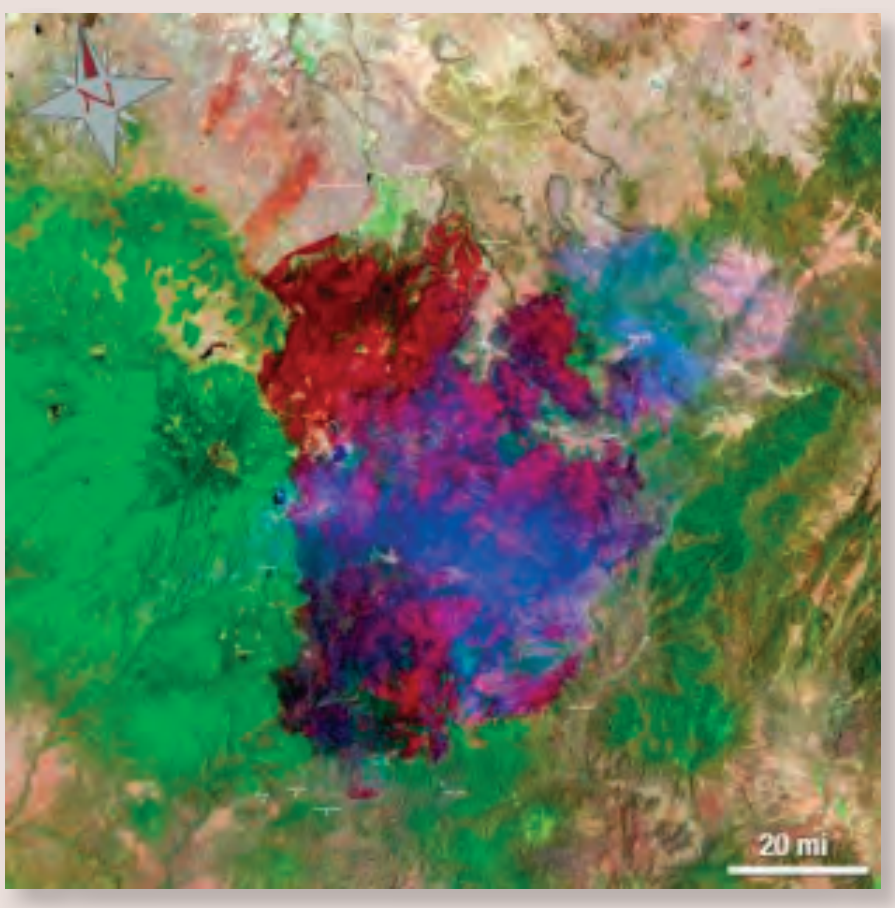

Figure 22. This Landsat 5 satellite image of the Wallow North Fire in east-central Arizona was taken on June 15, 2011. This false-colored image uses a 7-, 4-, 2-band combination and shows the burn scare in red, the ongoing fire in bright red. Vegetation is green, smoke is blue and bare ground is tan. 
Area and other Executive Leadership will support USGS response.

e. Coordinate the use of geospatial data during crises to meet the needs of internal and external users in partnership with the Core Science System Mission Area.

6. Evaluate warning and response products. Rigorous evaluation of situational awareness products will lead to better communication and more effective products. Evaluations also can demonstrate the value of the USGS hazard investment in observations and fundamental understanding. Priorities include the following:

a. Partner with social and behavioral expertise to assess and improve the accuracy, timeliness, and effectiveness of educational and situational awareness products for warnings and response decisions.

\section{USGS Hazard Web Pages: Popular and Highly Rated}

U.S. Geological Survey (USGS) Hazard Web pages get tens of millions of page views each month and offer a vast range of information, from characterizing hazardous events, to issuing crisis alerts and loss estimates, to earth science education. These pages are popular with the media and the curious public and are invaluable to scientists, emergency managers, first responders, and public utilities in the crucial early minutes and days during a hazard crisis or as a disaster unfolds. In quiet times, the Web pages also serve as a source of basic hazard education and information that assists the Nation - and in some cases the world - to prepare for hazardous events.

\section{USGS Earthquake Hazards}

Web pages of the National Earthquake Information Center and the Earthquake Hazards Program (EHP) provide timely information about worldwide earthquake occurrence, seismic intensities, and strong-motion impacts. These web pages have user hit rates that are the highest in the USGS and Department of the Interior (DOI) $(9,982,114$ visits and 30,302,461 page views in the month following the March 2011 Japan earthquake), are frequently cited, and received the highest 5-star-level Community Ratings for DOI sites (Data.gov).

\section{USGS Volcano Hazards Program}

Volcano Hazards Program (VHP) Web pages are popular to national and international audiences, including the aviation industry, providing up-to-date information about ongoing volcanic activity and alerts, hazards, and background information about U.S. volcanoes. VHP Web pages receive in excess of 15 million page views per month. During the last major eruption in the United States, the 2009 eruption of Redoubt Volcano in Alaska, the Alaska Volcano Observatory Web site received 28 million page views in just the month of March.

\section{USGS Flood Program}

The WaterWatch Web pages display maps, graphs, and tables that describe real-time, recent, and past streamflow conditions for the United States. A user can find information at scales from national to watershed. For the period of significant flooding in the United States from March to August, 2011, more than 730,000 unique users made some 5 million page requests.

\section{USGS Geomagnetism}

The Web site of the USGS Geomagnetism Program provides data and information about geomagnetic activity measured at ground-based observatories. The site receives over 6,000 page views per day, and this traffic can increase dramatically during magnetic storms. In preparation for the up-and-coming solar maximum, Program staff are developing geomagnetic-activity indices of use for diagnosing the changing conditions of near-Earth space weather.

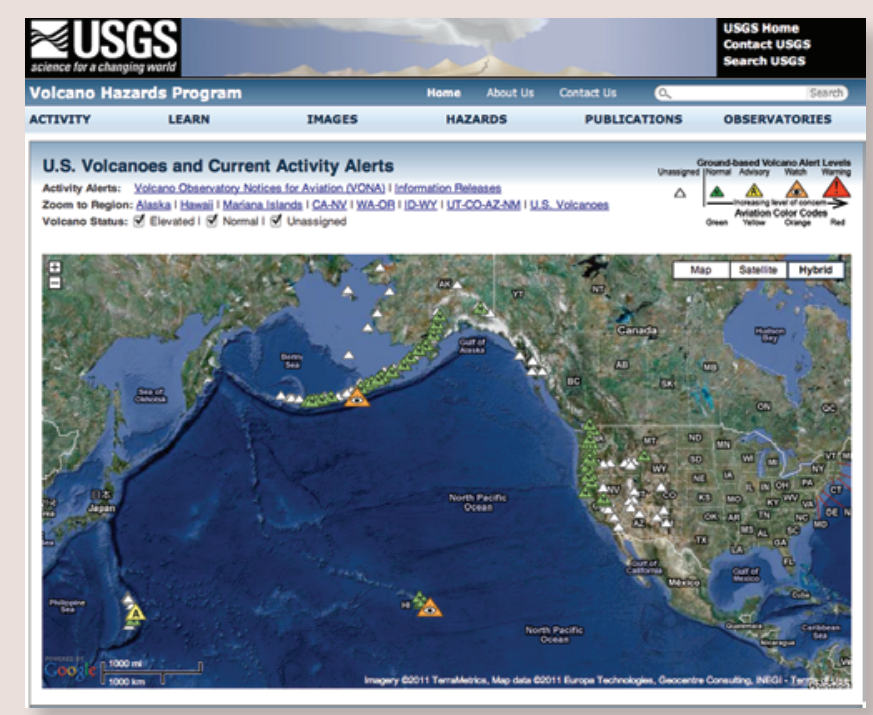

Figure 23. Screenshot of the U.S. Geological Survey's Volcano Hazards Program Web page. 
b. Partner to validate the accuracy of forecast, warning and assessment products.

c. Develop a repository of "lessons learned."

d. Involve the whole community in the evaluation of the response products so as to increase the reach of the products to all members of the community.

Path left by debris flow moving down a channel. The debris flow was generated in response to a rainstorm on November 12, 2009 in Arroyo Seco, southern California.

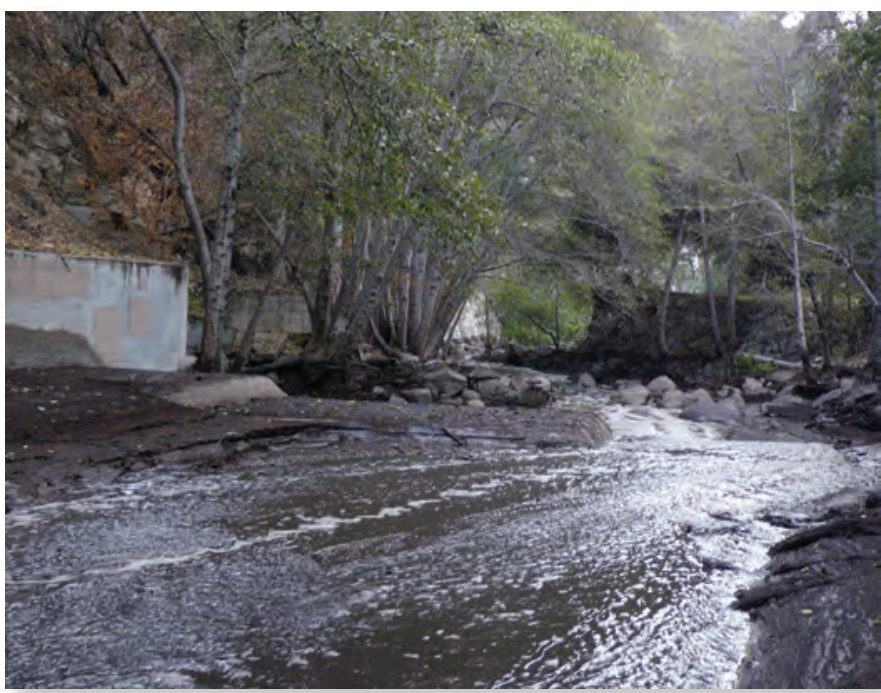

\section{Continuing Lessons in Managing Volcano Hazards: Mount St. Helens, Washington}

The dramatic May 18, 1980, explosive eruption of Mount St. Helens prompted a quantum leap in understanding volcanic processes and hazards. The event and its aftermath underscored the importance of adequate monitoring, detailed understanding of a volcano's eruptive history, and working with first responders and communities at risk well in advance of a crisis.

These lessons from the 1980s helped prepare for Mount St. Helens' reawakening in 2004. On September 23, instruments on the volcano detected increased seismicity. In early October, following a series of explosions, lava broke the surface. U.S. Geological Survey (USGS) changed alert levels and issued warnings as conditions changed, participated in response coordination under the National Incident Management System, and worked with the Mount St. Helens National Volcanic Monument to manage public access. In addition, with 2,000 flights over the Cascade Range daily, USGS worked closely with the Federal Aviation Administration to ensure safety of the aviation corridor.

Thoughout the nearly 4-year eruption, the USGS maintained constant vigilance, monitoring the volcano, providing status reports, assessing changing hazards, and responding to rumors. The 2004-2008 activity further strengthened ties between USGS and the first responder community, facilitated development of innovative monitoring technologies, and provided new insights into how volcanoes work.

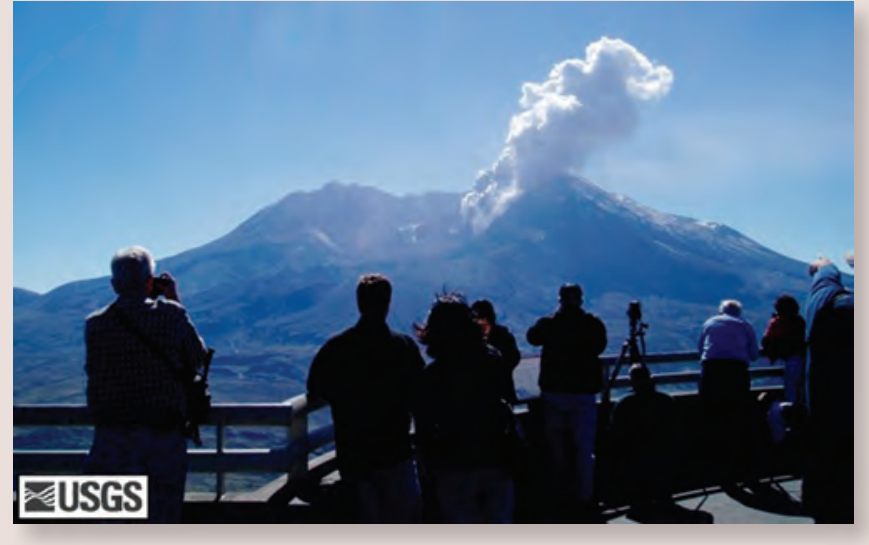

Figure 24. The public views Mount St. Helens from Johnston Ridge on October 1, 2004.

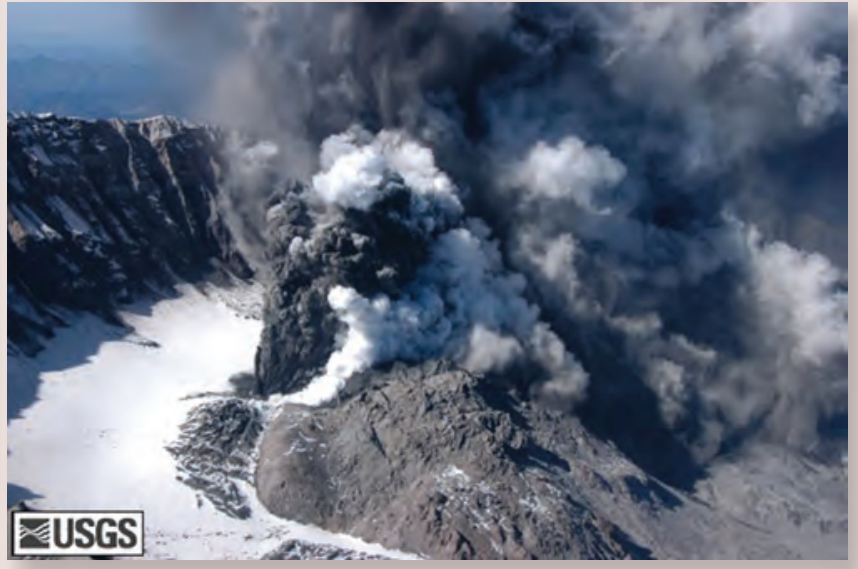

Figure 25. Explosive activity at Mount St. Helens, October 1, 2004. 


\section{A Vision of the Future}

\section{A Safer Nation Thanks to USGS Hazards Science}

This plan lays out core responsibilities that the USGS must continue to do to fulfill its basic mission in natural hazards and a variety of strategic actions that should be taken to enhance the USGS mission in hazards science, a mission that will directly result in a more resilient Nation in 2022 than today.

In our vision of 2022 and beyond, the USGS operates a robust, comprehensive network of instruments that monitor hazardous conditions. The Advanced National Seismic System is complete. A dense network of stream gauges monitors all high-risk flood areas. All 169 geologically young volcanoes in the United States are monitored in real time. USGS creates real-time estimates of wildfire perimeters. Coastal lidar to monitor coastal erosion is updated monthly. Many of the most at-risk landslide areas are being monitored and we have a global real-time geomagnetic network to track the impact of solar storms. A USGS $24 \times 7$ operations center monitors network health on all real-time hazards data, with the ability to call in crucial scientific personnel during times of hazards crises.

In this future, the USGS still has the capability to lead in hazards science because it has a diverse staff of scientists of different ages and disciplines who are experts in hazards science fields. Seismologists will have a better understanding of why one earthquake grows to be a damaging event while another one stays small. We will have the scientific understanding to be able to predict the duration and evolution of many hazards, including floods and geomagnetic storms. USGS science is enriched and informed by the effective interaction and communication among the hazard scientists and with the many important academic partners around the world needed to tackle difficult problems.

In this future, USGS scientists create and facilitate easily understood assessments and this information is used by emergency managers, land-use planners, and the general public to make decisions that minimize their risk. Scientific information is objectively incorporated into decision making using assessment tools and collaborative processes. Mature hazard vulnerability and risk assessments are automated and are interactive. Assessments are dynamic - they can be updated with new understanding or new information from events and they are responsive to decision needs during post-event recovery. Hazard assessments are comprehensive enough to include multiple hazards, environmental impacts, and projected change such as land use or climate. Hazard science is conveyed in ways that help people to comprehend uncertainties and despite them, manage risk.
In this future, the USGS has developed effective software tools to access and interpret the data from these networks and interpret them with a physical understanding of the hazards, and emergency managers and others use these tools to better manage natural disasters. Earthquake early warning will be implemented, giving some locations alerts that strong earthquake shaking will be arriving in seconds. Aftershock warnings will be routine across the country. ShakeMaps, describing the distribution of shaking, will be produced across the Nation from solid observational data and will be used by emergency managers, both public and private, to make decisions for a better response. Real-time inundation mapping will be regularly used to understand how floods are developing and fewer people will be caught unaware. With continuous $24 \times 7$ monitoring of our observational systems, we will never be surprised by a volcanic eruption or a geomagnetic storm. All these data are effectively served to decisionmakers through appropriate data portals.

\section{A Vision of USGS Hazard Science Successes of the Future}

\section{Floods}

In the Midwest, several days of severe storms threaten to flood large areas. Detailed, real-time inundation maps for both present and future flood levels are available and utilized by emergency managers and local citizens for all urban areas in the threatened area. These maps are tied to USGS streamgage data and NWS flood forecasts. These maps provide information for the transfer of patients from a threatened hospital and the relocation of a communications center out of the floodprone area. The State of Illinois has pre-deployed pumps and sand bags for a floodfight to shore up the towns levee. Emergency management officials in Missouri are able to preplan their evacuation decisions and deploy limited resources for maximum benefit.

\section{Wildfires}

An intermountain West community watches as a wildfire burns across the landscape. But the residents and fire-fighting personnel are confident that the wildfire poses little threat to their community. This confidence is based on wildfire extent forecasts based on the previous decade of research and monitoring by USGS scientists and land management agency officials that have motivated proper preparations and mitigations for wildland fuels. These decisions and mitigations protect communities from wildfires and significantly reduce the threats to water quality, endangered species, cultural resources, and the likelihood of debris flows. 


\section{Earthquakes}

After decades of being called overdue, the magnitude-7.8 earthquake on the southern San Andreas fault finally happens. Because of improvements to the Advanced National Seismic System, the information that an earthquake has begun on the San Andreas fault is transmitted to Los Angeles 60 seconds before the strong shaking arrives. Automatic controls move elevators to the nearest floor and opens the doors, sends messages to cell phones and rings alarms in schools. Because of years of education campaigns with annual ShakeOut drills, schools quickly move students away from windows into protected locations, surgeons and dentists remove instruments from their patients, and in other locations a rapid shut down of sensitive manufacturing processes occurs. Utilities with lifelines crossing the fault activate shutoff valves and other measures to reduce disruption to the grids and prevent fires. Through all these activities, much damage has been prevented and the path to recovery for California and the Nation is smoother.

\section{Coastal Hazards}

A family has just moved to a coastal town and is sitting in a realtor's office considering possible locations to buy a home. In the same office, an older couple is making a similar decision. As different locations are inspected, the two groups are consulting their smart-phones for natural hazard assessment information, provided in part by the USGS, including the potential erosion of the coast and flooding due to storm surge. Each group would like to be as close to the beach as possible. The hazard assessment application indicates that the probability of damage due to these natural hazards increases with proximity to the coast and that there are isolated areas that are not near the coast but have higher potential for flooding. The smart-phone application shows realistic scenarios at each location indicating impacts from hazards of varying severity and the family chooses a location that is much farther from the beach than they would have otherwise preferred. The older couple chooses a location right on the beach. Two years later, a large storm strikes the area. There is plenty of warning for evacuation and there is no loss of life. The older couple's house is destroyed, but they immediately move in with family, who selected a house with an extra apartment should this situation occur. Aside from losing some family possessions, disruption to each group's life was minimal.

\section{Volcanoes}

In 2022, the Cascades Volcano Observatory successfully forewarned the Nation of renewed activity at a long-dormant Pacific Northwest volcano. Using satellite radar surveillance and ground-based gas, earthquake, and deformation sensors, unrest was noted almost 2 months before the eruption began. Such lead time enabled emergency managers and nearby communities to prepare for the expected hazards outlined in the long-term hazard assessment. USGS also accurately forecasts the start of the eruption 72 hours in advance permitting communities and industry time to implement response plans and move assets out of harm's way. Once the eruption began, USGS ash fall and lahar inundation models provided accurate maps to guide community response and evacuations. Repeated explosions were detected by lightning, satellite, and other alarms ensuring that aircraft were notified within minutes. Though some critical infrastructure was damaged, early detection, accurate forecasts, long-term planning, and a coordinated interagency response prevented massive disruptions.

\section{Geomagnetic Storms}

In 2020, a mass of solar plasma was ejected from an ominously large spot on the face of the Sun. Data from sentinel satellite, positioned in between the Earth and the Sun, indicate that a front of solar wind is headed straight for the Earth-estimated arrival within 15 minutes. Immediately, space-weather agencies of NOAA and the Air Force issue warnings to military command centers, airlines, and operators of satellites and electric power grids. And just as predicted, 15 minutes later, USGS scientists confirm that the integrated global network of ground-based magnetic observatories has measured the sudden commencement of a global-scale magnetic storm, with magnetic activity centered on North America. The Department of Homeland Security is notified, and a briefing is prepared for the President by representatives of the National Space Weather Program. Over the next few days, the magnetic storm grows to become the largest ever recorded. Beautiful night-time aurora are visible almost everywhere around the world, but military satellites are damaged, civilian trans-polar airplane flights are cancelled, geophysical surveys are disrupted, and over-the-horizon radio communication is lost. Fortunately, in response to storm-time status bulletins issued by the USGS, preventative measures avert major outages of electric power in the United States.

\section{Landslides}

A major hurricane is forecasted to hit the Appalachian region bringing record-breaking rainfall. Tools for simulating landslide initiation, mobilization, and inundation developed by the USGS are used by State and local emergency management personnel trained in their use to provide probabilistic estimates of the impact of landslides and debris flows. These estimates improve coordination and preparation in advance of the storm and improve the situational awareness of the public, potentially saving lives and property. 


\section{Tsunamis}

(From Online Pacific Science News, Friday, March 18th, 2022) As coastal communities clean up and assess their losses from the tsunami waves spawned by the magnitude 9.2 earthquake that occurred off the Alaska Peninsula early Monday morning, scientists and coastal state officials are beginning to consider the reasons why the reported loss of life and serious injury was so small compared to the large coastal flooding and economic losses. Scientists whom we interviewed today said that magnitude of this earthquake and extent of the tsunami inundation were widely anticipated because of sustained field studies of prehistoric tsunami sand deposits in Alaska, Hawai $i$, and California led by U.S. Geological Survey scientists and their state and university science partners. These studies enabled production of tsunami inundation extent maps with associated probability, which were used by planners and emergency officials to pre-plan evacuations, which in turn was so crucial keeping the loss of life to a minimum.

\section{Multihazard Assessment}

Sitting in their corporate office in Dallas, Genac is considering options for a power-generating facility in the United States. High definition computer screens allow for zooming in for a look at one potential location in Louisiana on the recently developed national hazard map developed by USGS, NOAA, FEMA and the State Geological Surveys. The company's insurer and chief engineer is briefing the board of directors on the pros and cons of this location in contrast to the other 9 potential locations. The maps not only list each hazard magnitude, but have information on probability of occurrence and speed of onset. Because of this national hazard assessment map, the company is confident that it will have good information as it goes forward to the Nuclear Regulatory Commission for permission to build its new plant.

\begin{abstract}
Magnetic storms can cause aurora and, at the same time, interfere with telecommunication systems. Photograph by Roman Krochuk, Dreamstime.com.
\end{abstract}




\section{Opportunities and Challenges}

Several key challenges and opportunities became clear during the listening process. These are important issues that cannot be addressed within this Strategy's structure of goals, ongoing core responsibilities, and future action items. The new, Natural Hazards Mission Area (NHMA) within the USGS provides an opportunity to support and extend hazard science and its application, meet the identified challenges, and take advantage of the opportunities. Under its scientific umbrella, NHMA can help to accomplish the following:

- Exchange new ideas and approaches.

- Bring a broader range of expertise and resources to bear on shared problems.

- Encourage innovative and productive collaboration.

- Address neglected and emerging natural hazards problems.

Under its administrative umbrella, NHMA can accomplish the following:

- Ensure that hazards without formal programmatic leadership are supported and coordinated effectively.

- Help to address special issues, which are shared by all the sciences of rapid onset events with societal consequences: all work with partners, all need to make their science usable by decisionmakers, and all face similar tensions between operational and research demands.

- Coordinate development of products across hazards to capitalize on shared and similar efforts.

- Develop effective communication of hazards products, including online distribution.

- Keep USGS hazard scientists apprised of needs in the risk assessment community, and complementary efforts in other hazards.

\section{Issue: Maintain leadership in hazard science. USGS} expertise is one of the most valuable "products" the Bureau provides to the Nation in reducing losses from natural hazards. The USGS faces a great challenge to maintain and renew its expertise, which determines its capacity to monitor, assess, understand, and provide situational awareness of natural hazards. Long-term funding limitations have eroded the ability of the Bureau to mentor and replace departing employees and invest in a diverse workforce that can pioneer critical work on new, emerging topics with new, cutting-edge approaches. In many areas, a critical expertise for crisis response may rest with only one expert. The evolution of the workforce provides an opportunity to develop and maintain a new, stable structure that can preserve the wealth of knowledge that exists within the USGS and build an environment in which new scientists are able to meet the demands of the coming decade.

\section{Recommendations:}

- The aging of the USGS workforce and the need for broader responsibilities described in this report require greater attention to staffing and facility needs. The USGS should start by performing a staffing "gap analysis" across the Mission Area.

- Acknowledge that many USGS staff profiles blend contributions to both research and operations, refine employee evaluation and reward systems to adequately reflect the value of this mix.

- Focus research and development to emphasize areas where the USGS has a clear mission and leadership; collaborate with partners in areas where this can speed progress and reduce costs; avoid investing time and effort in developments already accomplished elsewhere.

Issue: Coordination across agencies and departments. Many departments and agencies in the Federal and State governments - too numerous to list exhaustively - conduct hazard science and mitigate risk from natural hazards. Declining budgets underscore the need for effective intragovernmental coordination. Most prominently, USGS hazard science complements the State science agencies, especially the Geological Surveys, and numerous Federal programs at the National Oceanic and Atmospheric Administration (NOAA), the National Aeronautics and Space Administration (NASA), National Science Foundation (NSF), the Department of Homeland Security (DHS) and its entities the Federal Emergency Management Agency (FEMA), the U.S. Coast Guard (USCG), the Science and Technology Directorate, and the National Protection and Programs Directorate, U.S. Forest Service (USFS), U.S. Army Corps of Engineers (USACE), and the other Department of Interior (DOI) bureaus. Over the course of our listening sessions and during external agency review, the SSPT heard from several additional agencies and departments who noted potential for strengthened collaboration. This list included the Center for Disease Control, the National Institute of Environmental Health, National Geospatial Intelligence Agency, the Defense Advanced Research Projects Agency, and the Department of Agriculture. Maintaining awareness of other agency programs and developing cooperative work requires time and personnel. Decisions to pursue active collaboration must be made with care to focus on high-value, high-return investments. NHMA leadership can help facilitate effective collaboration in a number of ways. 


\section{Recommendations:}

- Promote awareness of other agency programs and develop formal agreements, working groups, and response protocols to enhance cross-agency coordination and collaboration.

- Support active involvement in initiatives at NSF related to disaster resilience.

- Ensure that USGS hazard science supports the mission of State Geological Surveys.

- Work with other Mission Areas to create a formal USGS liaison process with FEMA and other key Federal agencies to coordinate efforts and share information.
- Work with FEMA to ensure the best science, data, and models are used in FEMA Regions' hazard mitigation plans and are incorporated into national efforts such as the software Hazus-MH and other FEMA-sponsored vulnerability and risk analysis tools.

- Work through international organizations and direct agreements with foreign partners to share experience, methods, and technologies.

- Seek ways to better utilize and leverage other agency data, expertise, and infrastructure to save money and support USGS hazard mission objectives.

Issues: Hazards without programs. The USGS role regarding different hazards varies because of differences in the Stafford Act mandates and because of shared roles and partnerships with other Federal agencies. In particular, some USGS

\section{MHDP Scenarios for Building Networks and Doing Research}

ShakeOut (2008) and ARkStorm (2010) scenarios, produced by the Multi-Hazards Demonstration Project (MHDP), were respectively based on consensus models for a major earthquake on the southern San Andreas fault and for a California statewide storm emulating winter, 1861-62. Throughout scenario development, a collaborative process engaged partners and stakeholders, and tapped the expertise of hundreds. These interdisciplinary scenarios applied state-of-theart science for the benefit of policy discussion and risk-wise decision making; and stimulated research in more than a dozen fields to estimate natural hazard processes, physical damages, and societal consequences. Fundamental research results have appeared in over 20 scientific publications and merited a special issue of Earthquake Spectra. In addition, U.S. Geological Survey scientists created customized distillations of scenario results at the request of individual counties and cities. The scenarios continue to contribute to disaster planning and mitigation long after initial drills and exercises conclude. As just a few examples, FEMA adopted the ShakeOut scenario as the basis of a Catastrophic Plan for Southern California, Bank of America changed their emergency plans because of ShakeOut, and the California Water Agency Response Network organized and practiced mutual aid for water systems, then applied this practice during response to the 2010 El Major Cucapah earthquake. The Commander, Navy Region Southwest, leveraged ARkStorm for the 2011 Citadel Rumble emergency response and recovery exercise in California and Nevada.

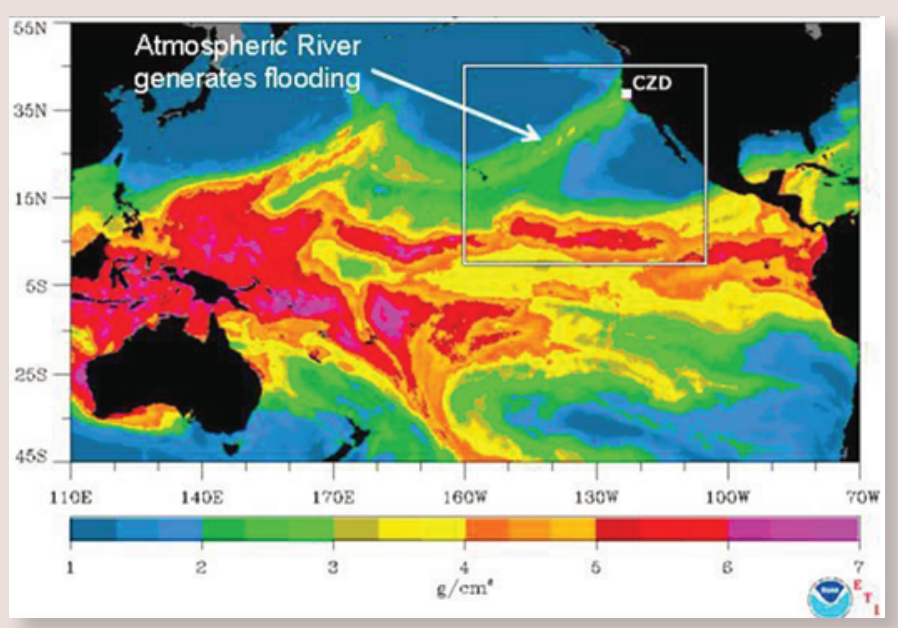

Figure 26. Researchers on the ARkStorm scenario modeled an atmospheric river storm similar to this one. An atmospheric river is a relatively narrow region in the atmosphere that transports large amounts of water vapor outside of the tropics. ArkStorm brought greater recognition of the importance of atmospheric rivers, and of limitations in local and State preparations for storms of this size. An ARkStorm is just about as likely as a large earthquake on the southern San Andreas fault. The storm's flooding would require evacuations of hundreds of thousands of people, far exceeding the capabilities of emergency responders. It would cause fewer casualties that a southern San Andreas earthquake, but have four times the economic consequences, generating long-term business interruption in many business sectors. 
hazard science is funded through a specific program, whereas other hazard science is not. Regardless of where a hazard lies within the USGS organizational structure, every hazard benefits from the advocacy of a coordinator. The NHMA Associate Director needs a point of contact for each hazard, particularly during crises.

\section{Recommendations:}

- The NHMA should work with relevant Mission Areas and Regional Executives to define the USGS science role for hazards without existing program structure.
- The USGS should have coordinators for each hazard who are knowledgeable about the full spectrum of natural hazards research (including tsunami and wildfire).

\section{Issue: Evolution of the Multi-Hazards Demonstration} Project (MHDP). In 2012, the MHDP concludes a 5-year demonstration of ways that hazards science can improve a community's resilience to natural disasters, with a focus on risk assessment products, and on innovative partnerships to communicate scientific results. MHDP successes include 7.9 million participants in ShakeOut earthquake drills,

\section{Lidar and InSAR: Powerful Tools for Assessments and Forecasts}

Lidar technology collects images from ground, air, and space, and has profoundly changed the way earth scientists visualize and understand the surface of our planet. Lidar data reveal landforms hidden by vegetation and enable geologists to identify previously unrecognized landslides, faults, volcanic landforms, and old stream channels. This knowledge can vastly improve the accuracy of hazard assessments, thus strategic acquisition of lidar is a critical objective in the coming decade.

InSAR maps ground deformation using radar images from Earth-orbiting satellites. InSAR greatly extends the ability of scientists to detect subtle and dramatic changes in the earth's surface and shows great promise in improving forecasts of many natural hazards. The USGS is a leader in many applications of InSAR and works closely with academics and other government agencies to acquire, process, and analyze images. Focused investment in InSAR expertise and support is a USGS priority in the coming decade.

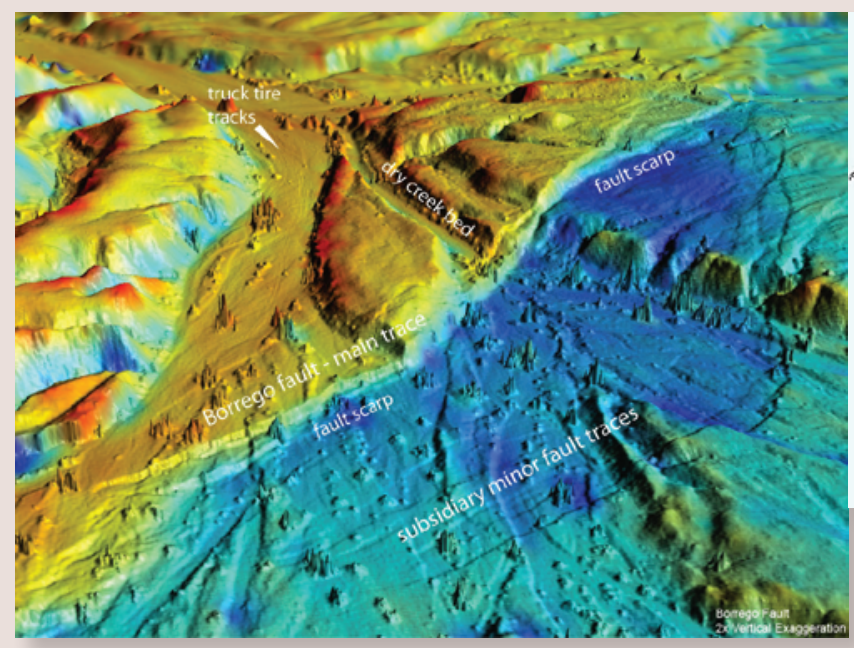

Figure 27. Lidar image revealed an intricate pattern of surface ruptures along the Borrego fault following the April 4, 2010, El Mayor-Cucapah earthquake (M 7.2) in Baja California, Mexico. Such distributed faulting-here more than 50 meters wide-presents special design challenges to housing developers or critical lifeline infrastructure planners in urban settings. Detection and interpretation of this rupture pattern was possible only because of strategic and timely Lidar image acquisition before and after the earthquake. Image courtesy of M. Oskin and K. Hudnut.

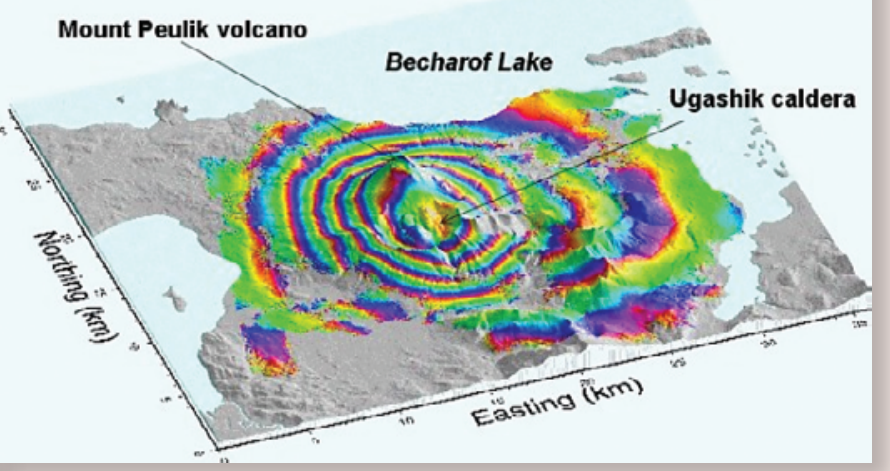

Figure 28. InSAR interferogram of Mount Peulik, a stratovolcano located about 550 kilometers $(\mathrm{km})$ southwest of Anchorage, Alaska. The striking bull's-eye fringe pattern centered on the southwest flank of the volcano represents about 17 centimeters $(\mathrm{cm})$ of uplift between October 1996 and September 1997. Other interferograms for September 1997 to September 1998 indicated about $3 \mathrm{~cm}$ of additional uplift. Model results suggest a magmatic intrusion of 50 million cubic meters at $6.6 \mathrm{~km}$ depth. InSAR tracking of volcano deformation is a powerful tool for early detection of volcanic unrest. Image courtesy of Z. Lu. 
landslide warning systems joint with the National Weather Service, scenarios used by emergency management, and increased visibility for USGS hazard science.

\section{Recommendations:}

- Use the national reach and perspective of the NHMA to strategically initiate and support such projects as needed throughout the Nation.

- Continue to develop MHDP-style scenarios and other products focused on resilience.

- Make available to other USGS missions, the MHDP experience in the use of scenarios as science application, assessment, and communication tools.

Issue: Interagency coordination between NOAA and USGS in hazard science and public warning products. The USGS has a long-term partnership with NOAA and NOAA's National Weather Service to investigate hazard processes and operate hazard warning systems for floods, fires, volcanic eruptions, tsunamis, and space-weather events. NOAA issues more hazard-related warnings than any other Federal agency; thus the USGS/NOAA coordination is critically important. In the coming decade, the USGS should strengthen its existing partnership with NOAA through increased collaboration in fundamental research, operation, maintenance, and delivery of reliable monitoring and decision-support tools, and effective public education.

\section{Recommendations:}

- Collaborate in modeling floods, tsunamis, ash cloud dispersion, geomagnetic storms, and other hazard processes to develop new and improved operational forecast tools.

- Take advantage of NOAA's training programs to develop geological hazard training for the emergency management community and for NWS forecasters who issue public warning.

\section{LANDFIRE: Geospatial Information for Strategic and Tactical Wildfire Planning}

Throughout the Nation, wildfire hazards have a major impact on people, homes, businesses, and the natural resources we depend on. Wildfire planning is vitally important and LANDFIRE (Landscape Fire and Resource Management Planning Tools) is a critical component of strategic and tactical planning for fire operations.

LANDFIRE is an interagency vegetation, fire, and fuel characteristics mapping program, sponsored by the U.S. Departments of the Interior and Agriculture, and executed by U.S. Geological Survey (USGS) and the U.S. Forest Service. LANDFIRE produces a comprehensive, consistent, scientifically credible suite of spatial data layers for the United States. The program is a long-range initiative that periodically updates LANDFIRE data to sustain the value of the project and to ensure the timeliness, quality, and improvement of future data products.

LANDFIRE fuel data describe the composition and characteristics of surface fuel and canopy fuel. Specific products include fire behavior fuel models, canopy bulk density, canopy base height, canopy cover, canopy height, the Fuel Characteristic Classification System fuelbeds, and fuel loading models. LANDFIRE data are in GIS-ready format as required for many fire behavior and effects models.

LANDFIRE provides key geospatial inputs to the Wildland Fire Decision Support System and its tools such as FSPro (Fire Spread Probability), a spatial model that calculates the probability of fire spread from a current fire perimeter or ignition point for a specified time period.

The USGS Earth Resources Observation and Science Center distributes LANDFIRE information.

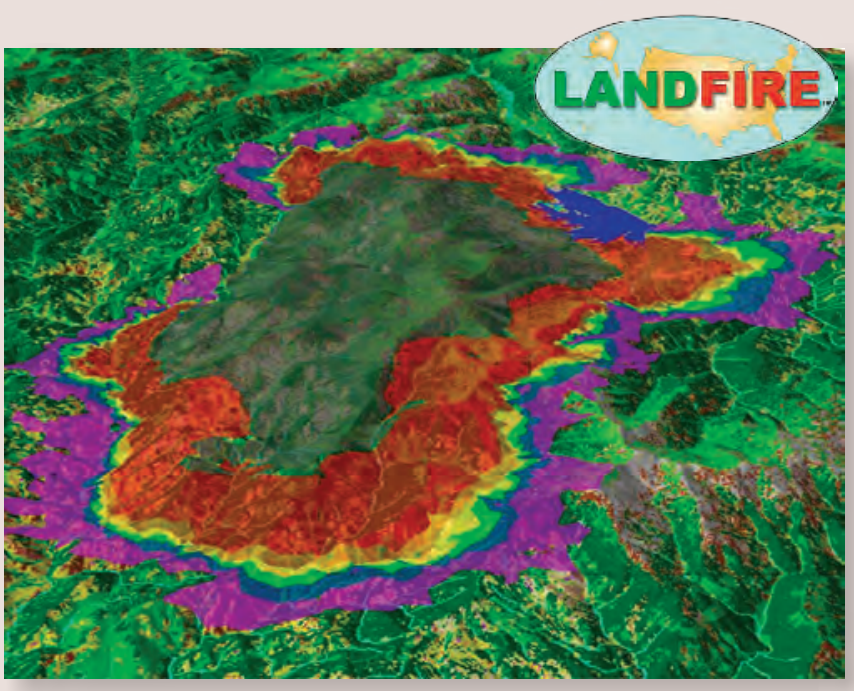

Figure 29. The 10-day burn probability perimeters derived from the FSPro analysis were used to develop probability zones and the associated acres and values within these perimeters. LANDFIRE geospatial data from U.S. Geological Survey were used to establish existing vegetation and fire fuel conditions for the 2007 Middle Fork Complex fire in Idaho. 
- Share information technology, data analysis, and visualization expertise to assist forecasters and the public in understanding hazardous processes and vulnerability.

- Pursue cross-agency collaboration in marine geohazard investigations involving NOAA ships and USGS marine geoscientists.

- Share lessons learned from assessment of public outreach and warning systems to inform and improve hazard messaging strategy and increase public understanding of hazards.

- Institute joint messaging where appropriate.

Issue: Fire science. Wildland fire science faces some particular challenges within the USGS. First, the science issues are complex and involve the biophysical properties of landscapes, the role of climate and weather affecting the risk, situational awareness and resources for firefighters, and the consequences of wildland fires for landslide potential, water quality, invasive species and ecosystem resilience. Thus, most of the Mission Areas have some stake in fire science, yet there is no formal fire science program. Second, the scientists are widely distributed through the USGS and include ecologists, hydrologists, remote-sensing specialists, and landslide geologists spread across dozens of science centers. Third, there are many other organizations with roles in fire science and response much larger than the roles of the USGS. A consequence of this complexity has been a fragmented approach to the problems, which can reduce the effectiveness of USGS products.

\section{Recommendations:}

- These problems could be reduced through more effective coordination between scientists and programs across the USGS. Establishment of a USGS Fire Science Council, with representation from all pertinent Mission Areas, could provide this internal coordination and also help the USGS define and clarify its interaction with other agencies involved in wildfire science and response. The Fire Science Council could set research objectives and help coordinate products and response tools to support USGS fire science efforts.

- USGS should develop a protocol for soliciting, supporting, and assigning USGS fire scientists to Burned Area Emergency Response teams.

Issue: Public interest in hazards. The general public has a high level of interest in the research activities of the hazards mission, and NHMA scientists are often the public face of the USGS. Furthermore, the hazards Web pages are some of the most read Web pages in the Federal Government. This high level of public interest puts a greater responsibility of NHMA scientists to strive for excellence in their public interactions.
Recognizing that informing the public about natural hazards and their potential impacts is one of the core responsibilities of the USGS, the NHMA must invest in supporting activities that facilitate this communication.

Recommendations: The NHMA should encourage public interactions with the Hazards Programs by doing the following:

- Increasing professional development of Web pages and social media.

- Promoting citizen science activities such as "Did You Feel It?" (earthquakes), "Did You See It?" (landslides), and "Did it Fall?" (volcanoes).

- Engaging fundamental science practices to ensure scientific integrity in its social media and citizen science activities.

- Providing training to scientists in improving interaction with the media and working with Science Centers to provide professional recognition to scientists who devote the time and resources to effective interactions.

- Working with the Office of Communications to create partnerships with the Science Centers to improve public products and media interactions.

Issues: Technological and other crises. USGS expertise with natural hazards enables us to make important contributions when the event involves similar processes, but is human caused. A recent example is the important USGS role in response to the Deepwater Horizon oil spill where USGS scientists were central to the interdisciplinary and multiagency scientific and emergency response. This capacity must be maintained by ensuring a diverse, creative, and enthusiastic workforce of natural scientists who are ready and able to respond to the Nation's emerging needs even if they transcend USGS statutory boundaries. It will be a challenge to leadership and the scientific staff to effectively manage these tactical scientific responses without taxing core programs across the Mission Areas.

Recommendation: NHMA should work with DOI and HREC to build and maintain ability to rapidly deploy USGS experts and equipment during nonnatural crises, as well as natural crises.

Issue: International role of USGS hazard science. Natural hazards must be considered in a global context. USGS hazard scientists make valuable contributions to saving lives and preventing suffering abroad. Many USGS hazard programs use globally dispersed monitoring networks to produce situational awareness and assessment products. Many of the rare, large hazardous events have not occurred in the United States during historical times; investigating such events worldwide returns critical knowledge and experience to the United States. 
Expertise in hazards is international, and strategically chosen collaborations with foreign partners can accelerate and reduce costs of needed research and development. Finally, the USGS is increasingly called upon to advise the U.S. Government and others on potential and actual hazardous events overseas.

\section{Recommendations:}

- The Bureau must support continued USGS engagement with the global hazard science community.

- In particular, close cooperation with our neighboring nations to ensure seamless monitoring and understanding of hazards to the North American continent and adjacent regions will require ongoing collaboration.
- Department of Defense and USAID have requested assistance identifying potential global disaster "hot spots' and in remaining informed during disasters and hazardous events overseas; the NHMA can spearhead common tools and approaches to provide appropriate global hazard situational awareness.

Issue: Critical evaluation of predictions of natural hazards. Because natural hazards pose a risk to society, predictions of the occurrence of hazards are sought by many decisionmakers even when those predictions are not scientifically verifiable. The Nation often needs critical, scientific evaluation of prediction methods that have raised public concern. Experience has shown that trying to ignore misinformation does not make it go away, but rather can allow the misinformation to spread.

\section{Volcanic Gas and Human Health: New Partnerships to Address Emerging Hazards}

Kîlauea Volcano emits noxious sulfur dioxide $\left(\mathrm{SO}_{2}\right)$ gas and other pollutants that produce acid rain and volcanic pollution known as vog (fig. 30). Acid rain damages crops and infrastructure and can leach lead into water supplies, while vog aggravates respiratory conditions. The USGS Hawai ian Volcano Observatory (HVO) monitors Kīlauea's emissions and works with health professionals, land managers, and others to better understand vog and enhance public awareness. In the early 1990s, HVO found that Federal gas and particle standards frequently were exceeded within populated areas of Hawai i Volcanoes National Park and brought attention to volcanic gas as a hazard. In partnership with the National Park Service, $\mathrm{HVO}$ developed an $\mathrm{SO}_{2}$ color-code advisory system and response plan to help protect visitors and staff. HVO is now involved in multidisciplinary, multiagency efforts to identify, track, and mitigate vog hazards. These include communitybased health studies, gas and particle monitoring, and research on agricultural impacts. USGS also worked with the University of Hawaii i and NOAA to develop a vog forecast system for the State. Ongoing collaboration with the USGS Crustal Imaging and Characterization Team has helped apply environmental geochemistry to address environmental and public health impacts of volcanic pollution.

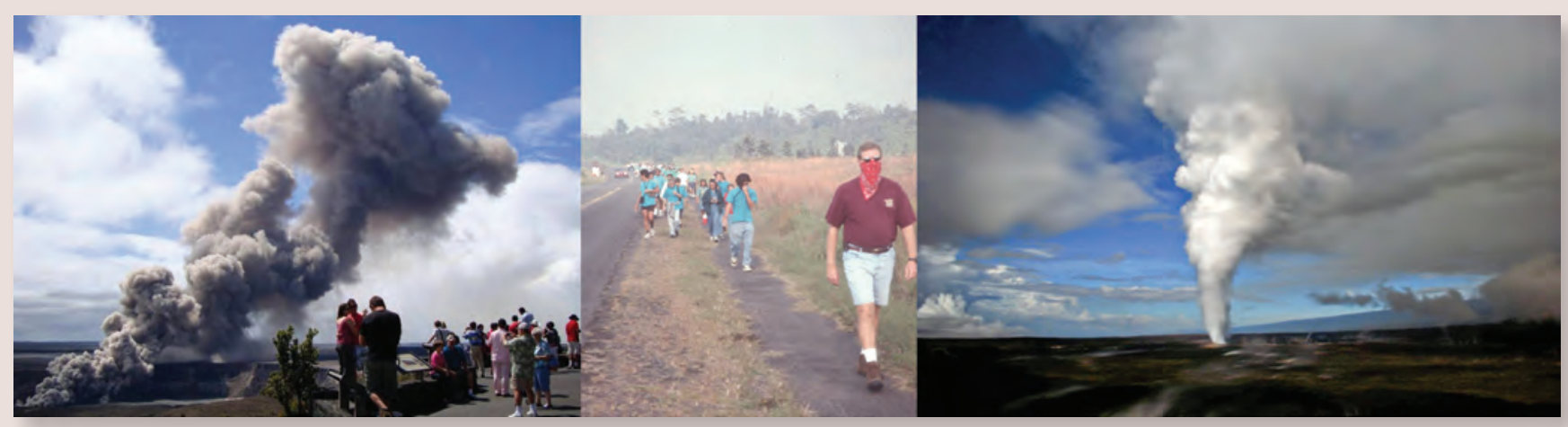

Figure 30. Kīlauea is the largest stationary source of $\mathrm{SO}_{2}$ in the United States causing effects to human health, agriculture, and business. Studies show increased emergency room visits for respiratory complaints since the onset of the 2008 summit eruption. In July 2008, the U.S. Department of Agriculture declared Hawaii i Island a disaster area because of agricultural losses. Local effects of Kīlauea's eruptive plume include potential fluoride toxicity in livestock, rapid corrosion of infrastructure such as fencing, roofing and other galvanized metal, and crop loss by farmers. There was an average 43 percent loss of total family income by Protea flower growers since 2008 due to volcanic gas and particles. 
Given its expertise, mission, and delegated responsibilities, the USGS has an obligation to be the authority about these predictions, which can cause significant social disruption. Evaluation of such predictions takes considerable effort, which is likely to increase.

Recommendation: The NHMA needs to be proactive in providing scientifically verified information about natural hazards and especially predictions when needed for public policy.

\section{Issue: Necessity of in-house Information Technology (IT)} capabilities. Information technology infrastructure and expertise are critical to fulfillment of the USGS mission related to natural hazards, in order to maintain and broaden $24 \times 7$ monitoring and warning capabilities and in order to make ad hoc situational awareness products needed during crises.
Recommendations: The NHMA should do the following:

- Convene occasional workshops where monitoring network operators can identify needed, near- and fartherfuture technologies and expertise.

- Use its position to increase awareness that local management of IT infrastructure is a necessity for monitoring and situational awareness.

Issue: Status of the USGS library. The USGS library has been an important resource for USGS research scientists. The USGS library has unique holdings not found elsewhere. In the new organization, the support systems for the library are not as clear.

Recommendation: The NHMA should advocate throughout the USGS for continuing support for the USGS library system.

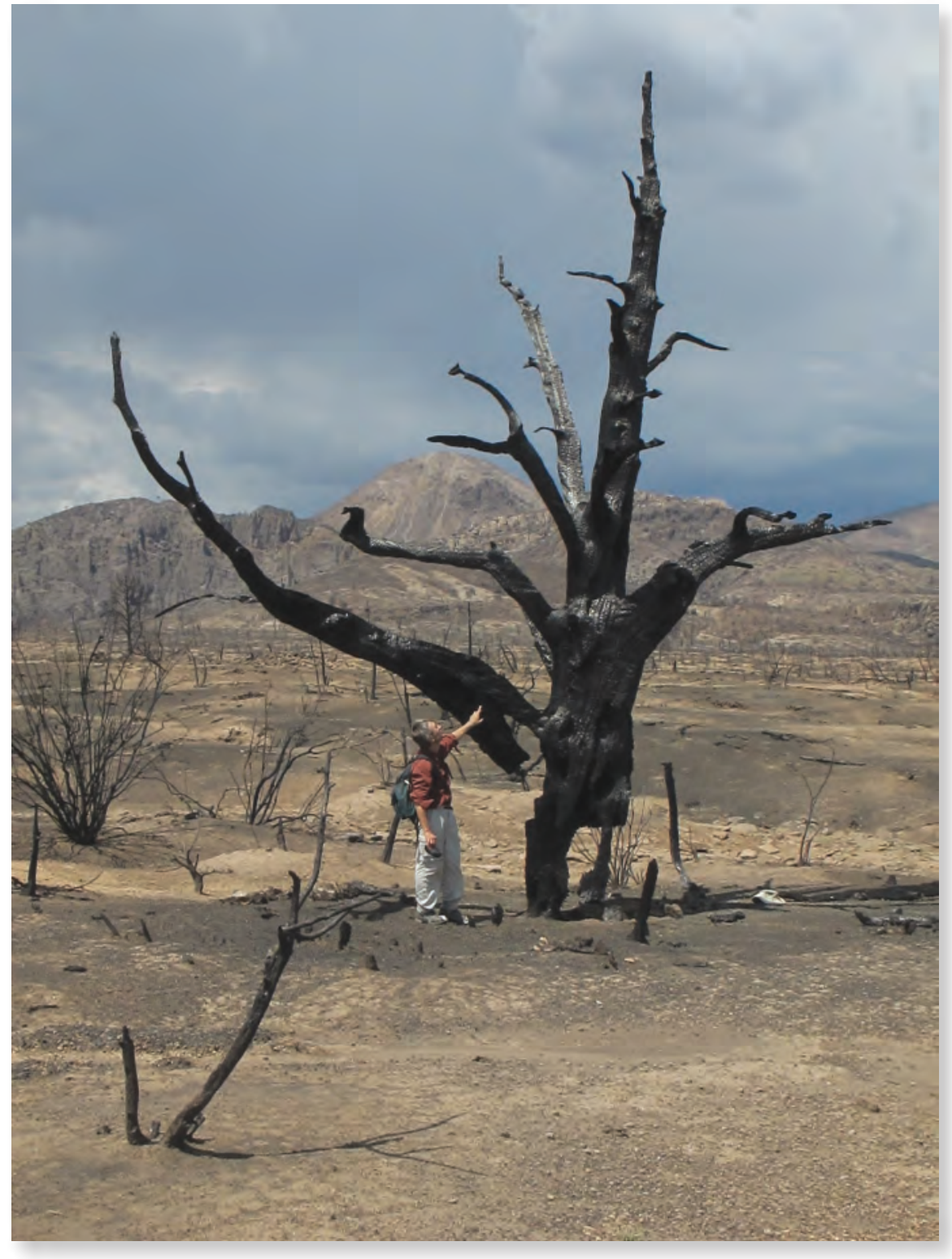

USGS scientist observes the results of the extensive, tree-killing fire that consumed almost all above-ground biomass in this part of the Las Conchas Fire burn area in the Jemez Mountains, New Mexico. Photograph taken by Craig D. Allen in late August 2011, 2 months post-fire. 


\section{Planning and Interconnections Across the USGS Mission Areas}

\section{Introduction}

The USGS is organized into seven Mission Areas: Hazards, Water, Climate and Land Use, Energy and Minerals, Environmental Health, Ecosystems, and Core Science Systems. The main focus of this report has been to address strategic science for the USGS mission in hazards, irrespective of organizational constructs of the USGS. Thus, science strategy outlined in this report may well be carried out by a USGS Mission Area other than the USGS Hazards Mission Area. Likewise, some science issues involving hazards have not been addressed in detail in this report because they are better addressed in one of the other six USGS strategic science plans. In addition, as USGS communicates its hazards data, science, assessments, and situational awareness to its stakeholders including the public, these activities may need to be coordinated with other USGS Mission Areas. An example of this would be communicating the impact on environmental health from hazards. The resulting interaction of science missions and the organizational construct of USGS Mission Areas requires extraordinary attention to coordination, collaboration, and communication among the USGS Mission Areas.

\section{Water and Hazards}

Water is a ubiquitous and crucial component to life on earth. Characterization of the amount, distribution, movement, and quality of the water on earth is an important mission of the USGS. The presence or absence of water plays an important role in the occurrence and severity of selected hazards and the occurrence of selected hazards can play an important role in the distribution, movement, and quality of water. As such, there are obvious interconnections and interdependencies between the USGS Water Mission Area (WMA) and the Natural Hazards Mission Area (NHMA) in carrying out the hazards mission of the USGS.

Floods: Floods are a major hazard occurring every year in the United States. The USGS real-time streamgage network, the centerpiece of the USGS flood science mission and activity, is the responsibility of the WMA, with the operational responsibility at the USGS Water Science Centers. Additionally, rapid deployment gages are deployed by WMA scientists and hydrographers to meet additional data needs during flooding and the WMA is taking a lead role in the development

\section{Magnetic Orientation for Directional Drilling}

The U.S. Geological Survey (USGS) Geomagnetism Program has begun a novel public-private cooperative relationship with the oil-services company Schlumberger to install and operate a new magnetic observatory near the town of Deadhorse, Prudhoe Bay, Alaska. These days, in order to minimize costs and environmental impact, multiple oil reservoirs are reached from a single platform by directional drilling — first drilling down and then out horizontally away from the surface platform. Like a compass can be used to estimate direction, a magnetometer in an instrument package that follows the drill bit is used to provide in situ orientation. Since the magnetic field at high latitudes can be very active, especially during magnetic storms caused by the interaction of the solar wind the with the Earth's magnetic field, simultaneous monitoring of the changing magnetic field at the surface also is required. The combination of data from a magnetic observatory and from the drill string enables accurate directional drilling. This is an application of USGS monitoring of the effects of space weather that is literally "down-to-earth"! As a condition of USGS involvement with the Deadhorse-observatory project, the data are freely available to the public.

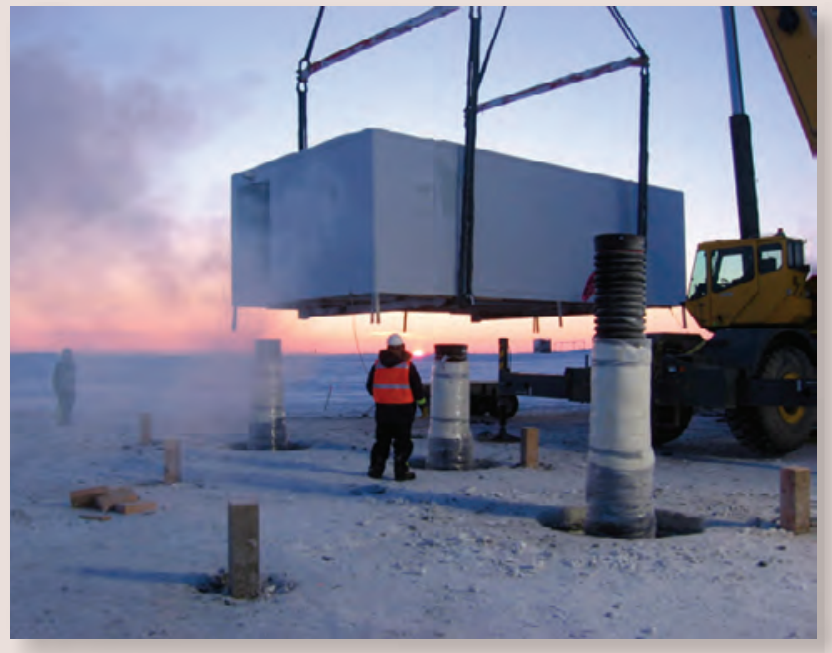

Figure 31. Installation of the Deadhorse, Prudhoe Bay, Alaska observatory, January 2010. 
of inundation mapping products. Although NSIP is designed to meet multiple needs, the most frequent justification for NSIP funding is related to flood monitoring and provision of information to the NOAA-NWS flood warning and forecast responsibilities. All five of the stated goals of NSIP (http://water.usgs.gov/nsip/goals9.html) are closely related to the USGS hazards mission.

Hurricane-induced coastal hazards: Landfalling hurricanes produce flooding and coastal damages. Storm-surge sensors, deployed by the WMA before landfall of Category III or greater hurricanes, provide important data to understanding coastal hazards, such as storm-surge flooding and shoreline erosion.

Landslides/debris flow: Landslides and debris flows are mass wasting processes that typically occur when a critical amount of water infiltrates or is entrained into the earth materials.

Wildfire: Following wildfires, the potential for floods, landslides, and debris flows is greatly enhanced. WMA hydrographers collect valuable rainfall and streamflow data in selected wildfire burn areas to provide data, both for warning and scientific process understanding.

Water-quality impacts from hazards: Following selected hazards such as floods, wildfire, and volcanic activity, the quality of water can be negatively impacted. WMA scientists and technicians collect data and conduct research into the impact of the hazards on water quality.

Drought: Worldwide, drought is a critical hazard that interplays with other hazards such as wildfire. The USGS is an important contributor to the Vegetation Drought Response Index and other drought information products in development by the multiagency National Drought Mitigation Center housed at the University of Nebraska. Expertise and resources from the Earth Resources Observation and Science Center (EROS) and streamflow information managed by the WMA contribute to this program. Although drought is recognized as a costly and serious hazard, most data collection and scientific research analysis is conducted by the WMA.

Tsunami: Although never used to date, the WMA could deploy storm-surge sensors and rapid deployment gages in anticipation of a tsunami.

To leverage programmatic overlap between hazards and water, the H-SPPT identifies the following priority areas of mutual interest:

- Flood science research in such areas as flood probability, regional flood-frequency analysis, paleoflood hydrology, rainfall-runoff processes, and riverine hydraulics are all carried out under the WMA oversight.

- Develop a sustainable program for the deployment and retrieval of sensors and analysis of storm-surge data.

- Enhance and foster further collaboration between scientists from WMA programs in rainfall-runoff processes, sediment transport, and geomporphology. Collaborate with scientists in the NHMA to conduct research into mass-wasting phenomena, such as landslides and debris flows.

\section{Hazardous Events and Ecosystem Dynamics}

Eruptions, fires, floods, and other hazardous events can have profound impacts on ecosystems, yet few studies document the recovery of plants and animals to such a devastating landscape 'reset'. On August 7, 2008, 3-kilometer-wide Kasatochi Volcano in the Aleutian Islands erupted violently, blanketing the island with volcanic debris (fig. 32). A long-term biological monitoring site of the U.S. Fish and Wildlife Service, Alaska Maritime National Wildlife Refuge (AMNWR), Kasatochi is now an ecosystem recovery experiment in progress. Geologists, botanists, ornithologists, and marine ecologists from the USGS, AMNWR, Universities of Alaska and Nevada-Las Vegas have returned to Kasatochi and nearby islands repeatedly to document impacts and collect post-eruption information to monitor the long-term recovery. This ongoing program is a unique opportunity to examine how volcanism and other processes that reshape the Earth's surface affect ecosystem dynamics. Results can provide insights into similar ecosystem perturbations elsewhere.
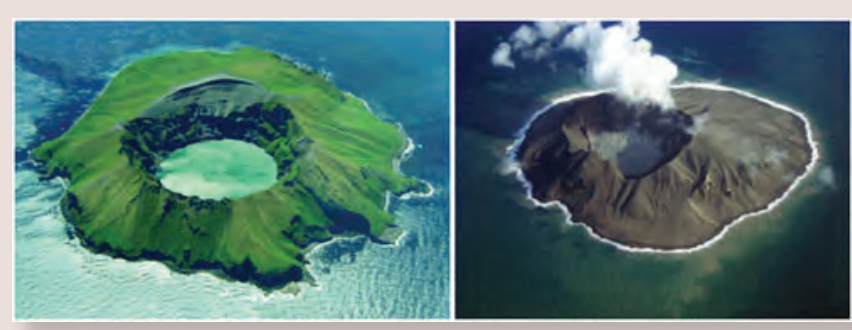

Figure 32. The island of Kasatochi, before and after eruption in 2008. 
- Enhance and foster further collaboration between WMA scientists with NHMA, Ecosystems, Core Science System scientists on the incidence of floods, landslides, and debris flows, along with assessing the impact on water quality in the burned watersheds.

- Foster collaboration between WMA scientist and NHMA in the study of the impacts of hazards on water quality.

- The NHMA should support WMA investigations of drought where possible.

- NHMA should fully utilize the capabilities in the WMA for deployment of long-term gages and rapidly deployable storm-surge sensors in coastal areas susceptible to tsunami.

\section{Climate and Land Use Change and Hazards}

Climate change has the potential to greatly affect the impact of many natural hazards. Extreme rainfall events can cause floods that exceed common thresholds and frequency; and can induce landslides. Drought can result in increased wildfire activity and can change hurricane frequency and severity, which affects coastal erosion processes. Climate change is expected to alter sea level, exacerbating the effects of coastal erosion and likely the damaging effects of tsunami events. Understanding the direct effects of climate change in relation to natural hazards is critical in order to identify and predict hazards, and estimate impacts for the development of adaptive management strategies.

Land-use change and projections, also the purview of the Climate and Land Use Change (CLU) Mission Area, ultimately contribute to the estimation of consequences of all natural hazards. Commercial, industrial, and residential development in seismic regions, in the shadows of volcanoes, along coastal reaches, in the flood plain, on steep slopes, and within the wildland urban interface compounds the risk and consequences of natural hazards.

The USGS also is directed in the Stafford Act to study and issue warnings for glacial processes that could impact infrastructure and public safety; however, the NHMA traditionally has not focused on this hazard as a priority. USGS work in glaciology, at present (2011), consists of maintenance of the Pacific Northwest and Alaska Benchmark Glacier Program, and limited glacier dynamic studies. The current (2011) urgent global focus on the role of the cryosphere as the critical indicator of climate change lends new emphasis to the need to understand and monitor the national inventory of ice. Moreover, recent work illuminating the substantial volumetric contribution of Alaskan glacier ice, particularly from calving glaciers, to changing sea level points to an urgent need to increase systematic monitoring of ice budgets in the Arctic. Outburst floods caused by catastrophic draining of glacially dammed lakes have the potential to dramatically alter ecosystems and threaten critical infrastructure, yet are poorly understood. Current destruction of permafrost in Alaska also is rapid and leading to pronounced impacts on communities - especially transportation and energy infrastructure - and ecosystems. The USGS CLU along with the Water Mission Area is well positioned to play an important role in systematic monitoring and the study of glacier dynamics and permafrost degradation in support of adaptation to new and emerging hazards of a changing climate.

Another related element is the assessment of opportunities for geologic carbon sequestration, including the storage of carbon in suitable geologic structures. Carbon sequestration may induce earthquakes and have other unintended effects.

CLU is responsible for development and operation of the Landsat satellite and manages other land-imaging assets. Hazards Mission has specific requirements for satellite and aerial imagery in optical, thermal, and microwave spectral frequencies. An important outcome of the land-imaging activities of CLU is the International Charter on Space and Major Disasters, which provides for the charitable re-tasked acquisition of and transmission of space satellite data to relief organizations in the event of major disasters.

To leverage programmatic overlap between hazards and climate and land-use change the H-SSPT identifies the following priority areas of mutual interest:

- Initiate long-term, interdisciplinary projects focused on understanding the impact of climate change on sea level rise and coastal processes in order to better understand how sea level rise caused by climate change will affect the impacts of natural hazards such as tsunamis and coastal erosion.

- Initiate long-term, interdisciplinary studies focused on understanding the impact of hazardous events on climate change, specifically volcanic out-gassing and injection of ash into the atmosphere.

- Investigate use of remote-sensing capability to improve hazard identification and assessments. The acquisition and application of lidar data is a high priority among all elements of the Natural Hazards Mission.

- Evaluate the role of climate change in altering the wildfire frequency and severity to understand and assess the hazard to life and property in the wildland urban interface.

- Evaluate the potential contribution of climate change to hazard exposure, vulnerability, and risk.

- Evaluate the role of land-use and land-cover change to increase hazard exposure, vulnerability, and risk.

- Evaluate the seismic hazard associated with geologic carbon sequestration and gas reservoir stimulation.

- Understand the impact of solar activity, as measured by geomagnetic activity, on earth's climate. 
- Analysis of seismic noise associated over historical timescales associated with changing meteorological conditions and sea-ice concentration.

\section{Energy and Minerals and Hazards}

As a nation, there are vulnerabilities from energy and mineral development, exploration, and related industrial activities. Using best practices and risk management enables us to use mineral and energy resources safely in our society. Many types of expertise typically applied to natural hazards can be brought to bear when energy and mineral practices cause hazardous events. Moreover, when mining and energy resources lie within regions susceptible to natural hazards, the vulnerability to a natural disaster can radically increase. The Natural Hazards Mission Area can help understand geologic structure and processes. The mutual benefit implies a need to integrate energy and mineral resource exploitation with an understanding of vulnerability to a hazard.

Natural hazards such as earthquake, volcanic eruption, and tsunami can cause catastrophic damages to facilities and mining and energy operations that contain or produce harmful contaminants. Natural hazards such as flood and wildfire can result in exposure to contaminates in runoff and smoke, either immediately or over the longer term. Understanding the direct effects of energy and mineral development in relation to natural hazards is critical in order to identify and predict the hazard and develop adaptive management strategies.

The USGS Energy and Minerals Mission Area provide scientific information for objective resource assessments and unbiased research results on mineral and energy potential, production, consumption, and environmental effects.

To leverage programmatic overlap between hazards and energy and minerals the H-SSPT identifies the following priority areas of mutual interest:

- Seismic hazards associated with geologic carbon sequestration and geothermal exploitation.

- Ground-water contamination because of hydrofracking during natural-gas extraction.

- Sink holes associated with underground mine collapse, including seismic forensics of collapse.

- Climate-induced changes in the environments of marine gas hydrates, possibly generating landslides of tsunamigenic significance.

- Coordinated efforts to obtain geophysical survey data for priority energy, mineral, and hazard target areas.

- Geothermal energy associated with volcanic systems (and some earthquake faults).

- Explore opportunities that might arise from restoration of abandoned marine investigations in the exclusive economic zone; such abandoned investigations have left the Unites States vulnerable in not having sustainable in-house scientific expertise to evaluate oil and gas potential. Filling this gap would also increase in-house expertise to respond to offshore oil-field disasters like the Macondo Well disaster of 2010.

\section{Environmental Health and Hazards}

The linkage between natural hazards and environmental health are apparent and profound. Natural hazards, such as earthquakes, volcanic eruptions, and tsunamis can cause catastrophic damages to industrial facilities, in addition to mining and energy operations that contain or produce harmful contaminants. The Japan 2011 earthquake and tsunami caused major loss of life and a nuclear disaster. Natural hazards such as floods and wildfire can result in exposure to contaminates in runoff, dust, and smoke, either immediately or over the longer term. Flood and fire raging through industrial societies can have catastrophic impacts as well. Wherever humans and animals coexist with potential natural hazard, there should be concern for environmental health. Understanding the direct effects of hazards on environmental health is critical in order to identify and predict the impacts and develop adaptive management strategies.

To leverage programmatic overlap between hazards and environmental health the H-SSPT identifies the following priority areas of mutual interest:

- Impact of volcanic gas emissions and airborne ash on human and environmental health.

- Effects of increased radiation during magnetic storms for high-altitude pilots, passengers, and polar-cap-route airlines.

- Dust and pollution associated with landslides, wildfires and fires burning built-up areas, including water pollution.

- Waterborne diseases and the release of pollutants (pesticides and other chemicals) associated with floods.

- General impact of floods, hurricanes, and tsunamis with their encroachment on built-up areas and associated release of pollutants.

- Human-caused disasters causing pollution (for example, the World Trade Center disaster).

- Collection of ephemeral data during and after an event.

\section{Ecosystems and Hazards}

At short time scales associated with hazardous events, understanding the direct effects of natural hazards on ecological systems is critical in order to identify and predict risks, develop adaptive management strategies, and address wildlife 
issues during response. Natural hazards can affect ecosystem resiliency by impacting wildlife and their habitat, marine mammals, threatened and endangered species, pollinators and plants. The frequency or severity of earthquakes, volcanic activity, tsunamis, floods, wildfire, and other natural hazards can have far-reaching impacts on ecosystems. During an event, hazard information is needed to forecast and respond to wildlife issues. Among the direct effects are changes in environmental factors such as topographic/bathymetric changes, vegetation, habitat function, and water quality and availability.

At longer time scales associated with ecosystem evolution, ecosystems can modulate the frequency and severity of hazards. The adaptive nature of ecosystems implies that resilience to natural hazards is a characteristic of the ecosystem. Understanding the processes of natural hazards will be necessary to develop models to predict future changes to ecosystems, to model how external stressors such as natural hazards will affect ecosystem resiliency, and to develop management alternatives in the face of stressors.

To enhance understanding of the relation between hazards and ecological systems, the H-SSPT recommends feedback between natural hazard and ecosystem processes be considered by both hazard and ecosystem studies. The emphasis of the hazard studies is to include relevant ecosystem processes in understanding hazard frequency and severity.

Wildfires are a clear example of a hazard that has a strong interaction with ecosystems. Wildfires are a major hazard in the United States leading to large annual losses, but also are a fundamental process in the functioning of many ecosystems. Many of the types of research questions addressed in the Hazards Mission for other hazards are addressed in the Ecosystem Mission Area for wildfire. The Fire Science Coordinator is also in the Ecosystem Mission Area connecting the wide range of research in the USGS. The Fire Science Coordinator needs to work closely with the Associate Director for Hazards to ensure that the USGS fills the Nation's requirements, especially when fires are occurring. To leverage programmatic overlap between Hazards and Ecosystems pertaining to wildfire, the H-SSPT identifies the following priority areas of mutual interest:

- Frequency of wildfires in different ecosystems.

- Impact of invasive species in changing the fire cycle.

- Changes in fire risk with climate change.

More generally, ecosystem studies should request that hazards include relevant hazard vulnerability assessments to enhance fundamental ecosystem understanding, as well as the understanding of more applied, adaptive management strategies. An important distinction between direct societal impacts and ecosystem impacts is that hazardous events may cause positive and negative changes in habitat. Just a few examples of these important ecosystem impacts attributable to natural hazards include disruptions of wildlife habitats because of volcanic events and processes, landslide disruptions, and permafrost degradations.

\section{Core Science Systems and Hazards}

The mission of the USGS Core Science Systems (CSS) is to create, manage and serve geospatial data about the earth. Hazards needs CSS to aid in processing and analyzing observations, and to provide access to geospatial data by scientists researching hazards and by outside users managing hazards. Integrated data management is a fundamental need of scientists studying hazards and of those who use USGS information, particularly emergency responders and planners.

The emergency-response and planning communities need trustworthy hazard data pulled together in one place and made easily accessible. Hazard preparation, response, and recovery planning require the development of models and interpretive maps of potential hazards that vary spatially throughout a region. USGS scientists need to be able to share scientific, built environment, and socioeconomic spatial data interoperably during product development and from one product to another.

An important responsibility of CSS is to support the scientific library of the USGS and to serve the science community. The USGS is considered a primary source of published geoscience and the USGS library holds many unique geoscience manuscripts.

The USGS also is directed in the Disaster Reduction Act to study, characterize, and issue warnings for land subsidence (carbonate karst and evaporite processes, sinkholes, and subsidence because of groundwater or hydrocarbon withdrawal). At present (2011), limited efforts in land-subsidence science are supported by Core Science Systems.

To leverage programmatic overlap between Hazards and Core Science Systems, the H-SSPT identifies the following priority areas of mutual interest:

- The geologic mapping under the National Cooperative Geologic Mapping Program in CSS is a basic tool for assessments in many of the hazards and must continue to be supported.

- Many hazards projects are creating geologic databases, such as the fault activity database. Hazards needs to interface with Core Science Systems to provide information into more general databases and to use CSS capabilities to create better databases and interfaces.

- Assessment of land-subsidence processes and impacts.

- Improve tools serving data and other products on line and integrated for users, specifically, enhancement of the Hazards Data Distribution System (HDDS), one of the most widely used dissemination portals for geospatial information and pre- and post-event satellite and aerial imagery.

- Improve tools for near-real-time monitoring for situational awareness, emergency and scientific response to disasters, potential disasters, and hazardous events. 
- Coordinate efforts to obtain geophysical monitoring and geophysical survey data for priority hazard target areas.

USGS geologist photographing a small rock fall from a road cut along the Blue Ridge Parkway north of Roanoke, Virginia. This is part of a study documenting landslides triggered from the 2011 magnitude 5.8 earthquake in Virginia. Green grass beneath the rock fragments indicates that the rock fall is fresh and probably was triggered by the earthquake. Photograph by Randall Jibson, USGS.

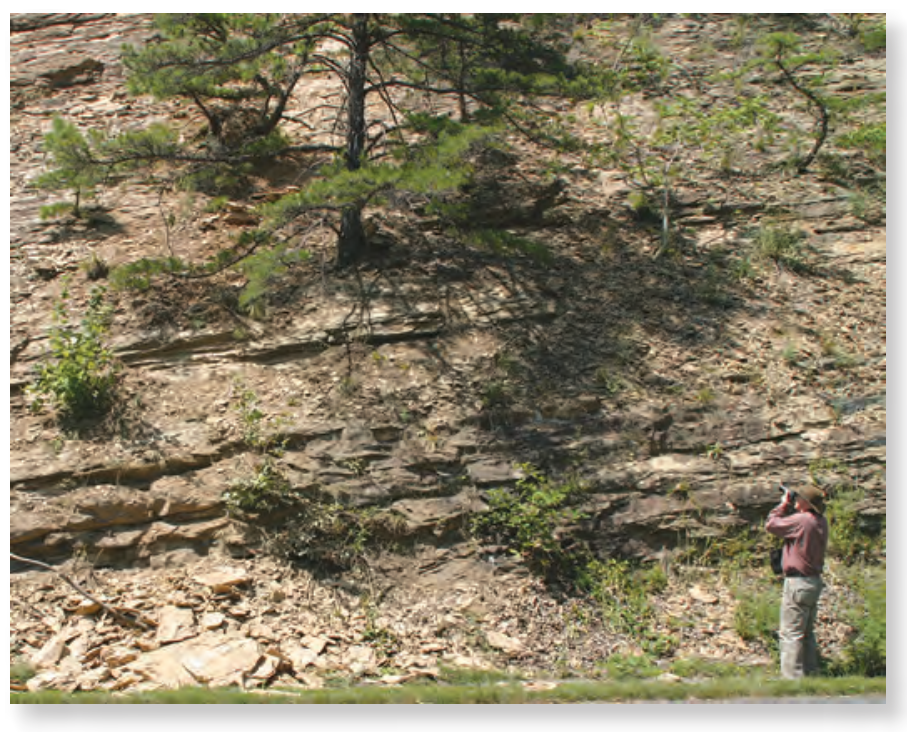

\section{Selected References}

Below are listed references that are cited in the text and other documents that were used by the H-SSPT in development of this report.

Aster, R., Bergantz, G., Carn, S., Serafino, G., Wilson, J., Yepes, H., and White, K., 2007, Review of the United States Geological Survey Volcano Hazards Program: American Association for the Advancement of Science Research Competitiveness Program, 37 p. (Also available at $h t t p: / /$ volcanoes.usgs.gov/publications/pdf/aaas2007.pdf.)

Baker, D.N., and others, 2008, Severe space weather eventsUnderstanding societal and economic impacts: A workshop report: The National Academies Press, Washington, D.C., $131 \mathrm{p}$.

California Integrated Seismic Network, available at $h t t p: / /$ www.cisn.org/docs.html.

Cohesive Wildfire Management Strategy Briefing Paper, August 6, 2010, 2 p.

Committee on Disaster Research in the Social Sciences, 2006, Facing hazards and disasters - Understanding human dimensions: The National Academies Press, Washington D.C., 24 p.

Committee on the Review of the National Landslide Hazards (Mitigation Strategy) Board on Earth Sciences and Resources, Division on Earth and Life Studies, National Research Council of the National Academies, 2004, Partnerships for reducing landslide risk-Assessment of the national landslide hazards mitigation strategy: The National Academies Press, Washington D.C., 144 p. (Also available at $h t t p: / / b o o k s . n a p . e d u / o p e n b o o k . p h p$ ?record_ $i d=10946 \&$ page $=R 1$.)
Committee on the Review of the USGS Volcano Hazards Program, 2007, Review of the U.S. Geological Survey's volcano hazards program: Washington D.C., National Academies Press, $37 \mathrm{p}$.

Committee on U.S. Geological Survey Water Resources Research, 1999, Hydrologic hazards science at the U.S. Geological Survey: Washington D.C., National Academies Press, $79 \mathrm{p}$.

East, J.W., Turco, M.J., and Mason, R.R., Jr., 2008, Monitoring inland storm surge and flooding from Hurricane Ike in Texas and Louisiana, September 2008: U.S. Geological Survey Open-File Report 2008-1365, 34 p. (Also available at $h t t p: / / p u b s . u s g s . g o v / o f / 2008 / 1365 /)$.

Ewert, J.W., Guffanti, M., and Murray, T.L., 2005, An assessment of volcanic threat and monitoring capabilities in the United States - Framework for a National Volcano Early Warning System: U.S. Geological Survey Open-File Report 2005-1164, 62 p. (Also available at http://pubs.usgs.gov/ of/2005/1164/.)

Fuis, G.S., and Wald, L.A., comps., 2003, Rupture in SouthCentral Alaska-The Denali Fault Earthquake of 2002: U.S. Geological Survey Fact Sheet 014-03, 4 p. (Also available at $h t t p: / / p u b s . u s g s . g o v / f s / 2003 / f s 014-03 /$.

Leith, W.S., Gee, L.S., and Hutt, C.R., 2009, U.S. Geological Survey Global Seismographic Network - Five-Year Plan 2006-2010: U.S. Geological Survey Open-File Report 2009-1013, $27 \mathrm{p}$. 
Highland, L.M., and Bobrowsky, Peter, 2008, The landslide handbook-A guide to understanding landslides: Reston, Virginia, U.S. Geological Survey Circular 1325, 129 p. (Also available at http://pubs.usgs.gov/circ/1325/.)

Kaufman, D., 2012, A Whole Community Approach to Emergency Management. (Also available at http://blog.fema. gov/2012/01/whole-community-approach-to-emergency. html.)

Lanzerotti, L.J., and others, 2006, Report of the assessment committee for the National Space Weather Program: Office of the Federal Coordinator for Meteorological Services and Supporting Research, FCM-R24-2006, Silver Spring, Md., $100 \mathrm{p}$.

Love, J.J., Applegate, D., and Townshend, J.B., 2008, Monitoring the Earth's dynamic magnetic field: U.S. Geological Survey Fact Sheet 2007-3092, 2 p. (Also available at http:// pubs.usgs.gov/fs/2007/3092/.)

Love, J.J., and Finn, C.A., 2011, The USGS Geomagnetism Program and its role in space weather monitoring: Space Weather, v. 9, S07001 (Also available at http://dx.doi. org/10.1029/2011SW000684.)

National Earthquake Hazards Reduction Program, 2008, Strategic plan for the National Earthquake Hazards Reduction Program-Fiscal years 2009-2013: National Institute of Standards and Technology, $66 \mathrm{p}$.

National Earthquake Hazards Reduction Program, 2010, White paper on achieving national disaster resilience-Advisory committee on earthquake hazards reduction: National Earthquake Hazards Reduction Program, 4 p. (Also available at http://www.nehrp.gov/pdf/ACEHRWhitePaperFeb2010.pdf.)

National Hydrologic Warning Council, 2006, Flood management benefits of USGS streamgaging program: National Hydrologic Warning Council, 48 p.

National Oceanic and Atmospheric Administration, 2008, NOAA's tsunami program 2008-2017 strategic plan, National Oceanic and Atmospheric Administration, 33 p.

National Research Council, 2004, Partnerships for reducing landslide risk - Assessment of the National Landslide Hazards Mitigation Strategy: Commitee on the Review of the National Landslide Hazards Mitigation Strategy, 144 p.

National Science and Technology Council, 2005, Grand challenges for disaster reduction: National and Science Technology Council, 28 p.

National Science and Technology Council, 2006, Grand Challenges Implementation Plan-Coastal Inundation: National Science and Technology Council, 4 p.
National Science and Technology Council, 2006, Grand Challenges Implementation Plan-Drought: National Science and Technology Council, 4 p.

National Science and Technology Council, 2006, Grand Challenges Implementation Plan-Earthquake: National Science and Technology Council, $4 \mathrm{p}$.

National Science and Technology Council, 2006, Grand Challenges Implementation Plan-Flood: National Science and Technology Council, 4 p.

National Science and Technology Council, 2006, Grand Challenges Implementation Plan-Heat wave: National Science and Technology Council, $4 \mathrm{p}$.

National Science and Technology Council, 2006, Grand Challenges Implementation Plan-Human and ecosystem health: National Science and Technology Council, 4 p.

National Science and Technology Council, 2006, Grand Challenges Implementation Plan-Hurricane: National Science and Technology Council, 4 p.

National Science and Technology Council, 2006, Grand Challenges Implementation Plan-Landslide and debris Flow: National Science and Technology Council, 4 p.

National Science and Technology Council, 2006, Grand Challenges Implementation Plan-Space weather: National Science and Technology Council, 4 p.

National Science and Technology Council, 2006, Grand Challenges Implementation Plan-Technological disasters: National Science and Technology Council, 4 p.

National Science and Technology Council, 2006, Grand Challenges Implementation Plan-Tornado: National Science and Technology Council, 4 p.

National Science and Technology Council, 2006, Grand Challenges Implementation Plan-Tsunami: National Science and Technology Council, 4 p.

National Science and Technology Council, 2006, Grand Challenges Implementation Plan-Volcano: National Science and Technology Council, $4 \mathrm{p}$.

National Science and Technology Council, 2006, Grand Challenges Implementation Plan-Wildland fire: National Science and Technology Council, 4 p.

National Science and Technology Council, 2006, Grand Challenges Implementation Plan-Winter storms: National Science and Technology Council, 4 p.

National Space Weather Program Council, 2010, Strategic plan: National Space Weather Program Council, 32 p.

National Wildland Fire Management Report to Congress and Cohesive Strategy, October 2010, 44 p. 


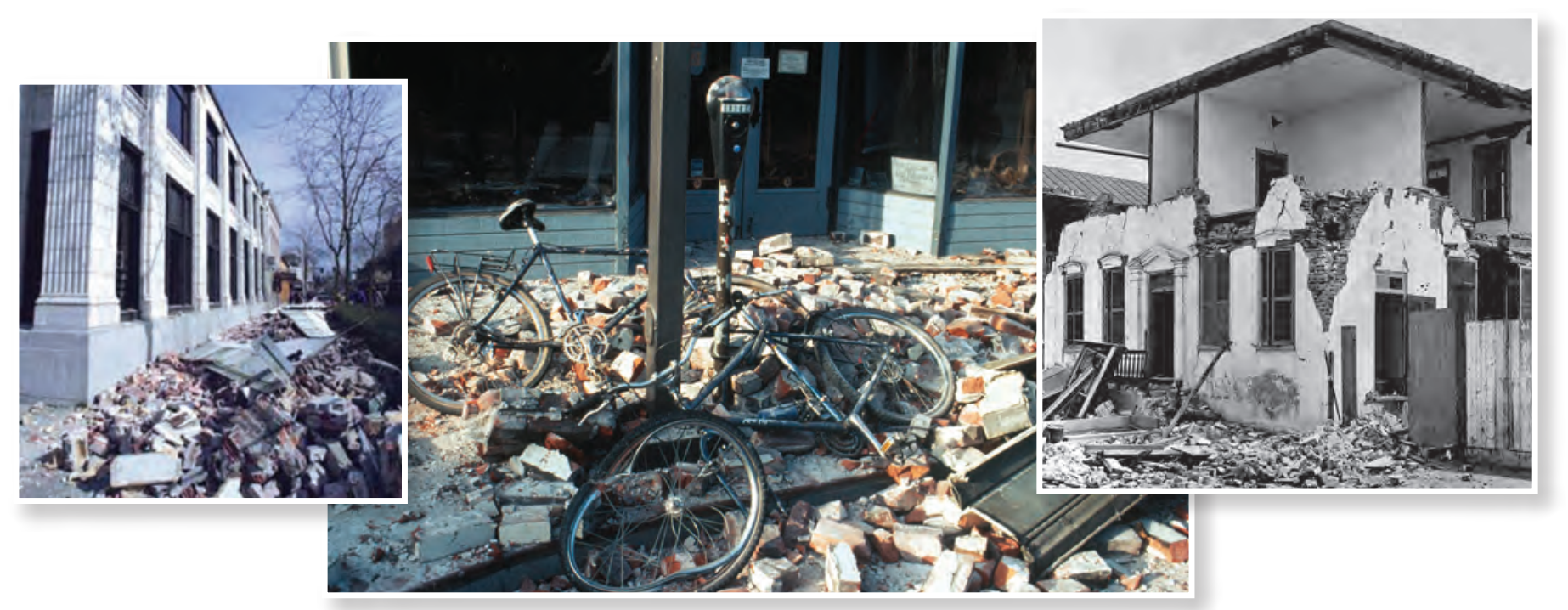

Left to right: Debris from the magnitude 6.8, 2001, Nisqually, Washington earthquake, the magnitude 7.1, 1989, Loma Prieta, California, earthquake, and the magnitude 7.0, 1886, Charleston, South Carolina earthquake. As these photographs show, collapse of materials from unreinforced masonry buildings is a persistent earthquake danger.

Neal, C.A., and Guffanti, M.C., 2010, Airborne volcanic ash-A global threat to aviation: U.S. Geological Survey Fact Sheet 2010-3116, 6 p. (Also available at $h t t p: / / p u b s$. usgs.gov/fs/2010/3116/.)

Peackock, W., Kunreuther, H., Hooke, W., Cutter, S., Chang, S., and Berke, P., 2008, Toward a resiliency and vulnerability observation network-RAVON: Hazard Reduction and Recovery Center reports $08-02 \mathrm{R}, 25 \mathrm{p}$.

Tsunami Warning and Education Act, Public Law 109-424, December 20, 2006, 9 p.

U.S. Department of the Interior, 2011, Strategic plan for fiscal years 2011-2016: U.S. Department of the Interior, 46 p.

U.S. Geological Survey, 1999, Requirement for an advanced national seismic system: U.S. Geological Survey Circular 1188,55 p. (Also available at http://pubs.usgs.gov/ circ/1999/c1188/.)

U.S. Geological Survey, 2004, Understand volcano hazards and preventing volcanic disasters-A science strategy for the volcano hazards program 2004-2008: U.S. Geological Survey, $71 \mathrm{p}$.

U.S. Geological Survey, 2005, Earthquake hazards program five-year plan-2005-2009: U.S. Geological Survey, 54 p.

U.S. Geological Survey, 2006, The U.S. Geological Survey landslide hazards program 5-year plan: U.S. Geological Survey, $26 \mathrm{p}$.

U.S. Geological Survey, 2007, Facing tomorrow's challenges-U.S. Geological Survey science in the decade 2007-2017: U.S. Geological Survey Circular 1309, 70 p. (Also available at $h t t p: / / p u b s . u s g s . g o v / c i r c / 2007 / 1309 /$.
U.S. Geological Survey, 2008, Strategic plan for the National Earthquake Hazards Reduction Program-Fiscal years 2009-2013: National Institute of Standards and Technology, 66 p. (Also available at http://nehrp.gov/pdf/ strategic_plan_ppt.pdf.)

U.S. Geological Survey, 2010, Volcano hazards programImplementation plan for the National Volcano Early Warning System, Pre-decisional draft 27, 46 p.

U.S. Group on Earth Observations, 2010, Achieving and sustaining Earth observations-A preliminary plan based on a strategic assessment: Office of Science and Technology, $34 \mathrm{p}$.

Wood, Nathan, 2007, Variations in city exposure and sensitivity to tsunami hazards in Oregon: U.S. Geological Survey Scientific Investigations Report 2007-5283, 37 p. (Also available at $h t t p: / / p u b s . u s g s . g o v /$ sir/2007/5283/.)

Wood, Nathan, Church, Alyssia, Frazier, Tim, and Yarnal, Brent, 2007, revised 2008, Variations in community exposure and sensitivity to tsunami hazards in the State of Hawai' i: U.S. Geological Survey Scientific Investigation Report 2007-5208, v. 1.1, 42 p. (Also available at http:// pubs.usgs.gov/sir/2007/5208/).

Wood, Nathan, and Soulard, Christopher, 2008, Variations in community exposure and sensitivity to tsunami hazards on the open-ocean and Strait of Juan de Fuca coasts of Washington: U.S. Geological Survey Scientific Investigations Report 2008-5004, 34 p. (Also available at http://pubs.usgs. gov/sir/2008/5004/.) 


\begin{tabular}{|c|c|c|}
\hline & \\
\hline \\
\hline
\end{tabular}

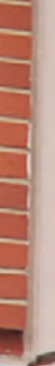

Floodwaters inundated streets in Cedar Rapids, lowa, June 13, 2008.

Photograph by Don Becker, USGS. 


\section{Definitions}

Hazard terminology often has different meanings and usage to different audiences. This glossary defines the terms as used in this report. Many of these are taken or modified from the United Nation's International Strategy for Disaster Reduction and the Intergovernmental Panel on Climate Change. In the text of this report, the first usage of each term appears in bold text.

Adaptive management Adaptive management focuses on learning and adapting, through partnerships of managers, scientists, and other stakeholders.

Catastrophe A disaster that causes disruption so great that the resilience of a community is far exceeded and impacts are evident for years to decades.

Core responsibilities Activities that the USGS must continue in order to uphold its mission. In many cases, these are mandated activities that help to protect lives and assets.

Crisis A potentially dangerous time or situation when hazardous events are occurring or threaten to occur.

Disaster Disruption of the functioning of a community or a society involving widespread human, material, economic or environmental losses and impacts that exceed the ability of the affected community or society to cope using its own resources.

Early warning Capacities needed to generate and disseminate timely and meaningful warning information about an impending hazard.

Emergency manager, management The people and organizations who manage resources and responsibilities that address all aspects of emergencies, in particular, preparedness, response and initial recovery steps.

Ephemeral data Data lasting for a very short time, especially data about a natural hazard that will be cleaned up by society seeking to repair damages.

Exposure People, property, infrastructure, or other societal or valued natural elements that are present in hazard zones and, thus, subject to potential losses.

Extreme event An event that is statistically unusual for its large size or magnitude, putting it in the tail of a statistical distribution.

Forecast Definite statement or statistical estimate of the likelihood of occurrence of a future event or conditions for a specific area. See prediction and warning.

Hazard A dangerous process, phenomenon, substance, activity or condition that may cause loss of life, injury or other health impacts, property damage, loss of livelihoods and services, social and economic disruption, or environmental damage.

Hazard Assessment Estimation of the characteristics (historical frequency, future probability, magnitude, duration, speed of onset, and spatial extent) of a hazardous natural process.

Hazard chronology Enumeration of the sequence and magnitude of hazardous events in the geologic and historic record.

Hazard science An aggregate of a wide range of disciplines in the natural, social and behavioral sciences that address hazards.

Hazardous event The specific occurrence of a hazard, which may or may not have negative effects (disaster and catastrophe are hazardous events with substantial negative effects).

Mitigation Action, including education, that eliminates or reduces the potential effects of a hazard.

Natural hazard Natural process or phenomenon that may cause loss of life, injury or other health impacts, property damage, loss of livelihoods and services, social and economic disruption, or environmental damage.

Nowcast Statement of current conditions.

Paleo A modifier indicating prehistoric, that is, before written records based on eyewitness accounts. A paleo-hazard is a hazard that existed in prehistory. Paleo-hazard studies investigate the geologic record of hazardous events in prehistory. 
Partner An organization or individual that works with the USGS to produce or provide information or other products. One category of stakeholder.

Prediction A specific statement that identifies a particular outcome at a certain time; predictions are a testable result based on a model or an understanding of process.

Resilience The ability of a system, community or society exposed to hazards to resist, absorb, accommodate and recover from the effects of a hazardous event.

Risk The likelihood of a hazard causing losses. Risk is a combination of the probability of a hazard occurring and the value of assets in harm's way.

Risk assessment A product describing the nature and extent of risk by analyzing potential hazards and vulnerability that together potentially could harm people, property, services, livelihoods and the environment on which they depend.

Scenario A study that posits the occurrence of a single disaster and estimates a single set of realistic outcomes from that event; components typically include hazard, risk and vulnerability assessments.

Situational awareness Information about what is happening, where and how big. Extensively used by emergency management to encompass the maps, facts, and first person accounts that they use to understand the scope of an unfolding disaster and make decisions about response.
Stakeholder A person, organization, agency, or industry that needs or benefits from USGS information.

Statutory Required by law or regulation.

Strategic actions High-value potential efforts that will reduce uncertainties about hazards and improve communication, and thus enhance the ability to provide accurate, effective assessments and situational awareness.

Uncertainty An expression of the degree to which a value is not known, whether because of limited information, disagreement, or inherent variation. The expressions may be put in terms of ranges of values, percentages, or more qualitative statements.

Urban Area where a hazard holds special importance because of the density of people, buildings, or infrastructure at risk.

User Someone who makes use of information or products. One category of stakeholder.

Vulnerability The degree to which a system (such as a social system, a built environment, or an economic system) is susceptible to damaging effects of a hazard.

Warning A statement about the elevated probability of a potentially dangerous, hazardous event in the near future.

Whole Community A FEMA approach that recognizes the importance of engaging the entire community to better prepare for, respond to, recover from, and mitigate against natural disasters. 


\section{Appendix 1. Hazard Science in the USGS}

\section{Earthquake Hazards Program}

The U.S. Geological Survey (USGS) Earthquake Hazards Program monitors the Nation's earthquakes, studies why they occur and how they shake the ground, provides quantitative earthquake-hazard assessments, helps promote loss-reduction measures using these results, and provides crucial scientific information to assist emergency responders when earthquakes occur. The USGS Earthquake Hazards Program operates under the National Earthquake Hazards Reduction Program (NEHRP), created by Congress in 1977. To meet the challenges and potential of NEHRP, activities supported by the USGS Earthquake Hazards Program are managed under four broad interrelated objectives:

- Improve quantification of seismic hazards - The USGS produces quantitative hazard-assessment products that enable the public and private sectors to assess earthquake hazards and implement effective mitigation strategies.

- Complete the modernization and expansion of nearreal-time earthquake notification and monitoring systems - The USGS is tasked with collecting, interpreting, and disseminating information on earthquakes that occur throughout the United States and on significant quakes worldwide for disaster response, earthquake preparedness, national security, scientific research, and public hazard awareness.

- Achieve better scientific understanding of earthquake processes and effects-The USGS pursues research on earthquake occurrence and effects for the purpose of developing and improving hazard-assessment methods and loss-reduction strategies.

- Provide national and local leadership to engage communities in earthquake safety practices - The USGS works with user communities to ensure that its products are readily available, easily understood, and appropriately used for earthquake mitigation and response.

The USGS is the only Federal agency with responsibility for recording and reporting earthquake activity nationwide. The USGS Earthquake Hazards Program focuses both on the Nation as a whole and on particular regional needs and problems in areas where earthquake risk is the greatest. Citizens, emergency responders, and engineers rely on the USGS for accurate and timely information on where an earthquake occurred, how much the ground shook in different locations, and what the likelihood is of future significant ground shaking.

The USGS is working to improve its earthquake monitoring and reporting capabilities through the Advanced National Seismic System (ANSS). Full implementation of ANSS will result in 6,000 new instruments on the ground and in structures in at-risk urban areas, as well as a backbone of modern seismic instruments for the Nation. Once in place, the ANSS will provide emergency response personnel with nearreal-time (within 5-10 minutes of an event) information on the intensity and distribution of ground shaking that can be used to guide emergency-response efforts. Similarly, information on building "shaking" will equip engineers with the data they need to improve building designs in the future.

\section{Global Seismographic Network}

The Global Seismographic Network (GSN) is a permanent digital network of state-of-the-art seismological and geophysical sensors connected by a telecommunications network. The GNS serves as a multiuse scientific facility and societal resource for monitoring, research, and education. Formed in partnership among the USGS, the National Science Foundation (NSF), and the Incorporated Research Institutions for Seismology (IRIS), the GSN provides near-uniform, worldwide monitoring of the Earth, with over 150 modern seismic stations distributed globally. The USGS Albuquerque Seismological Laboratory, the International Deployment of Seismometers group at University of California, San Diego, and other affiliate organizations cooperate in operating the GSN. The IRIS Data Management Center archives the data from the GSN.

The central focus in creating the GSN was for seismological needs, but the infrastructure is inherently multiuse and can be extended to other disciplines. GSN instrumentation is capable of measuring and recording with high fidelity all seismic vibrations from high-frequency, strong ground motions near an earthquake to the slowest global Earth oscillations excited by great earthquakes. Several GSN stations currently incorporate microbarographs, GPS, geomagnetic, and meteorological packages.

Together with the USGS National Earthquake Information Center operated by ANSS, the GSN are principal global sources of data and information for earthquake locations and earthquake emergency response. The GSN provides essential data for tsunami warning response globally and collaborates closely with National Oceanic and Atmospheric Administration Tsunami Warning Centers, Japanese Meteorological Agency, and the Australian Tsunami Warning System. The International Monitoring System for the Comprehensive Nuclear-Test-Ban Treaty Organization (CTBTO) works closely with GSN and about 30 GSN stations are linked directly to the CTBTO International Data Centre.

The Albuquerque Seismological Laboratory (ASL) is one of the more unique facilities within the USGS. Established in 1961, the lab initially served as a quiet site for testing seismometers, but quickly became the installation, maintenance depot, and data collection center for earlier global seismic networks. The ASL occupies a 160-acre site located in a 
remote area of the Isleta Pueblo adjacent to the south boundary of Kirtland Air Force Base, about 15 miles southeast of Albuquerque, New Mexico. The laboratory's remote location in the Manzanito Hills allows operation and testing of seismograph instruments without major disturbance from human noise sources. The ASL has two subsurface vaults mined into a granite hill, five boreholes, and several surface vaults. The extremely low-noise seismometer test facilities at ASL are quite important.

\section{Geomagnetism Program}

The USGS Geomagnetism Program monitors the Earth's magnetic field at 14 ground-based observatories that are situated across the United States and its territories. Several of the Program's observatories have been in continuous operation for over a century. Today, each observatory produces 1-second resolution data, and these are available in real-time for purposes of magnetic-storm monitoring. The Program has, recently (2011), begun to produce standard magnetic indices that measure magnetic-storm and magnetic-disturbance intensity. These are used for operational diagnosis of changing space-weather conditions and as inputs to physics-based models of the magnetosphere and ionosphere. Program staff conducts research on observatory data for purposes of mitigating geomagnetic hazards (Love and others, 2008). Recent projects include (1) mapping storm-time magnetic disturbance and inverting for crustal electrical conductivity in order to mitigate hazards for electric-power grids, (2) investigating claims that large earthquakes are sometimes preceded by anomalous magnetic activity, (3) investing possible correlations between geomagnetic activity, solar activity, and global climate change, and (4) establishing credible error estimates on the occurrence frequency of rare but extreme geophysical events.

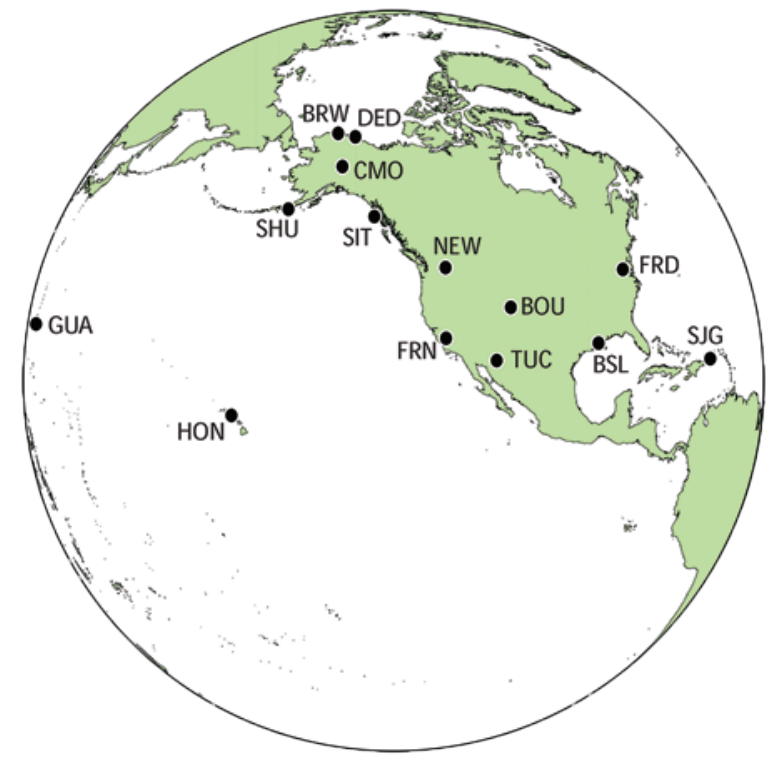

Figure 1-1. Locations of USGS geomagnetic observatories.
The USGS Geomagnetism Program is part of the U.S. Government's National Space Weather Program (NSWP), which coordinates space-weather responsibilities across a diversity of Federal agencies. The USGS is part of a Unified Space Weather Capability, as defined by a Memo of Understanding with NOAA, NASA, the U.S. Air Force, and the National Science Foundation. The USGS observatory network was identified as a "critical ground-based asset" in a recent review of NSWP (Lanzerotti and others, 2006). Internationally, the work of the USGS Geomagnetism Program is coordinated with foreign national geomagnetism institutes through the INTERMAGNET organization, a voluntary consortium dedicated to promoting the operation of observatories according to modern standards. Long-term archives of observatory data are maintained in the World Data System.

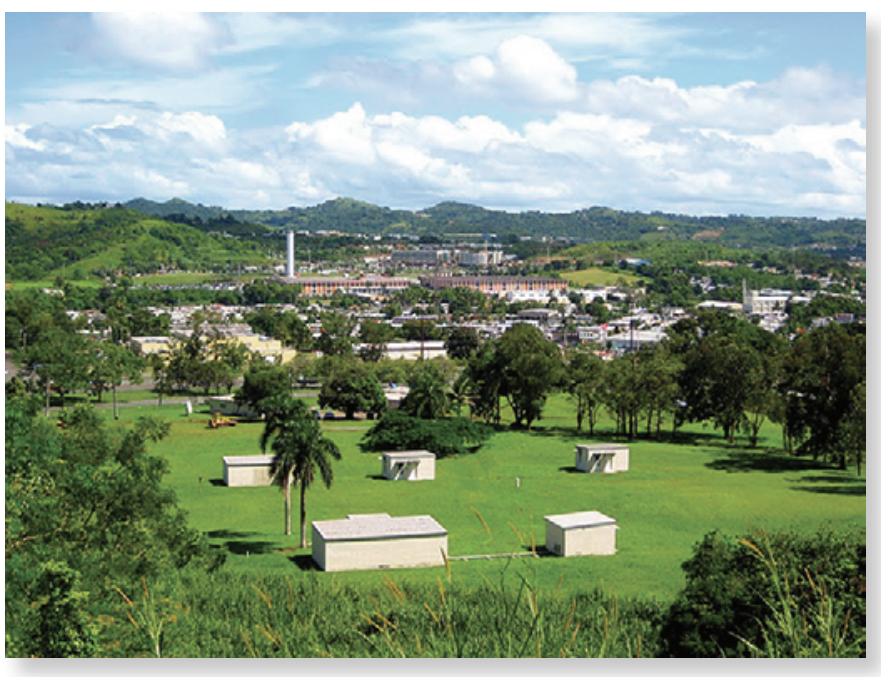

Figure 1-2. Panoramic view of the San Juan, Puerto Rico geomagnetic observatory.

\section{Tsunami Investigations}

Tsunamis share an important feature with giant cyclonic storms - Distant sources can raise huge waves that threaten U.S. shorelines. This fact makes tsunami hazards and risks to the United States shorelines a global matter. Over the last decade, global deaths and destruction caused by tsunamis have exceeded those caused by all other geohazards. Official USGS priorities in tsunami hazards are (1) identify and quantify tsunami sources, such as earthquake faults, volcanoes, and landslides, (2) assess tsunami sources and hazards and model tsunami generation, (3) improve understanding of how tsunamis are generated and incorporate this information into probabilities of tsunami hazards in different areas, and (4) assess tsunami inundations by interpreting tsunami effects. Tsunami investigations by the USGS span five different USGS Programs and six different Science Centers.

Destructive tsunami waves depend on three factors: the nature of the tsunami source that moves the seafloor and displaces the sea surface, the propagation of tsunami waves in the deep ocean that depends largely on the deep-water bathymetry 
between the source and the receiving coastline segment, and the detailed shape of the shallow seafloor bathymetry and near-shore topography and the geologic framework at the receiving shoreline. The USGS contributes at varying levels to all of these components of tsunami science.

Many important components of tsunami warnings and risk assessments are led by NOAA and the Federal Emergency Management Agency. Vital USGS contributions to the interagency effort include (1) Geologic investigations of pre-historic tsunamis based on field investigations of prehistoric tsunami deposits and paleoseismic investigations in subduction zones that supplement and extend the historical and instrumental records (for example, Cascadia). (2) Inputs to tsunami models, including the locations of likely offshore sources, the instrumental record and the historical records of offshore earthquakes and submarine volcanoes, as well as, the historic record. (3) Advanced models of near-shore tsunami inundation that include edge waves and other phenomena that conventional far-field models do not consider.

(4) Investigations sediment transport by tsunamis that inform us about where to look for and how to interpret paleotsunamic deposits based on sediment transport models and recent posttsunami surveys. Distinguishing between tsunami deposits and storm-surge deposits continues to be an ongoing challenge. (5) Probabilistic tsunami hazard assessments that depend on where, how big, and how often these tsunami events occur based on the above observations.

\section{Landslide Science}

Landslide and related hazards occur in every State in the United States. Landslides are part of the erosion process in mountainous regions and along river, valley, and coastal bluffs in areas with more subdued topography. Losses from landslides are increasing rapidly as landslide-prone environments are developed for transportation corridors, housing, industry, and recreation. USGS landslide hazard science focuses on landslides that occur in association with other natural hazards such as earthquakes, volcanic eruptions, floods and heavy rainfall, hurricanes, and wildfire.

Landslide science in the USGS is supported primarily by the Landslide Hazards Program (LHP); however, substantial work is supported by the Earthquake and Volcano Hazards Programs, and the Coastal and Marine Geology Program. The LHP and its predecessor have operated since the mid-1970s as a Congressionally authorized program dedicated to the reduction of damages and avoidance of hazards from landslides. The focus of the program is national, but it also responds to requests for assistance in foreign countries from the Department of State, as well as from international organizations such as the World Bank and the United Nations. As the only Federal program dedicated to landslide science, the LHP provides results of investigations for use by private consultants in geology and geotechnical engineering and by planners and decisionmakers at all levels of government and the private sector.
The results of USGS landslide science efforts have led to noteworthy improvement in understanding the nature and scope of landslide processes, hazards, and problems. Research on landslide hazards addresses fundamental questions of where and under what conditions landslides are likely to occur, as well as their size, speed, and impacts. Such research is essential if the Natural Hazards Mission Area is to make good progress in protecting the people and assets exposed to landslide hazards triggered by severe storms, earthquakes, volcanic activity, coastal processes, wildfire, and climate change in the United States.

The USGS currently (2011) maintains several Natural Landslide Observatories in the Pacific Coast and Rocky Mountain regions. These observatories collect near-real-time information on precipitation, hydrology, and landslide movement for specific landslide-prone areas. These monitoring observations are critical to advance the understanding of landslide processes, perform hazard assessments, respond to landslide emergencies, and forecast landslide activity in changing environments. Maintaining and expanding this network through the use of emerging observation and monitoring technology is critical for landslide and debris-flow warnings issued by the National Weather Service and to advance the understanding of the role of climate change on landslide hazards.

The state-of-the-art understanding of landslide and debris-flow processes is generally inadequate to make reliable forecasts of landslide timing, frequency, or magnitude for most areas of the Nation. Predictive tools are not mature and gaps in the understanding of debris-flow, bedrock and submarine landslide processes exist. USGS landslide science goals are to perform directed, topical research to improve this understanding. This requires maintaining the efforts and facilities to examine debris-flow and landslide mechanics and the development of new computational tools.

Assessing the hazard posed by landslides requires applying and conveying the combined experience and knowledge of the USGS by means of developing tools for hazard assessments. Hazard assessments are provided for demonstration areas and where the USGS has a clear role. The USGS also develops tools for landslide hazard forecasting, provides information for post-fire debris-flow warnings issued by the National Weather Service, responds to landslide emergencies, and increases public awareness of landslide hazards. Effective progress in these areas requires working with partners to provide landslide information for assessing risk, documenting damaging landslide events, and expanding the ability of the USGS to use ground, aerial-, and space-based remote-sensing data.

\section{Floods}

Although the USGS does not have a formal flood program, USGS scientists and engineers conduct numerous research and investigative studies on flooding and hydrographers collect streamflow and stage data at over 
7,800 streamgages, 4,000 of which are crucial to the flood forecasting statutory responsibility of the NOAA's National Weather Service.

USGS flood science can be loosely categorized into the following categories, with acknowledgement of overlap: monitoring methods, flood documentation, stochastic flood hydrology (probability, uncertainty, and trends), paleoflood hydrology, process understanding and modeling, and flood impacts on natural and built environments. Stochastic flood hydrology involves the study of the probability and frequency of floods and their linkage to the topographic, vegetative, geologic, land-use and climatic characteristics of the stream basin. Using stochastic techniques, the USGS has developed equations for estimating the magnitude of floods for selected frequencies in each State and many of the U.S. territories. Flood process understanding and modeling includes hydrologic research into, and development of models that simulate the physical processes of rainfall-runoff, snowmelt-runoff, open-channel hydrodynamics, river mechanics, and morphological change. This research is conducted at various levels of the USGS organizational structure.

The USGS streamgage program, which is conducted by the USGS, state-based Water Science Centers, is funded by a number of sources including the National Streamflow Information Program, Water Cooperative Program, and other Federal, State, and local agencies. Data from the streamgage program has multiple purposes other than flood monitoring and science, such as the assessment of water availability; design of water-related infrastructure; regulation of in-stream flows for ecosystem sustainability and water quality; and operational support for management of navigation, recreation, and water supply and irrigation systems. As part of flood investigations, the USGS often conducts post-flood analysis at nongaged streams to estimate peak water levels, streamflow rates, depths, velocities and other useful information.

In addition to research and investigative studies on flooding and collection of streamflow data, the USGS is actively involved in research efforts aimed at improving monitoring methods, along with continued emphasis on improving data dissemination during floods. In recent years, the USGS has partnered with the NWS in an effort to standardize realtime inundation mapping products that will be a noteworthy improvement over the real-time stage and flood forecast products that have traditionally been delivered by the two agencies during flood events.

\section{Hazard, Vulnerability, and Risk Study, and Decision Support}

Natural disaster consequences are less the result of nature than the actions and inactions of people before, during, and after an event. The USGS Geographical Analysis and Monitoring (GAM) program has extended hazard science with the stated goals of (1) vulnerability and risk assessment studies, and method development to improve the scientific basis for these assessments, as well as, disaster mitigation, response, and recovery activities, and (2) tool development to aid decision making about resource allocations. In the past, additional seed funding for some vulnerability and risk activities has originated from venture capital and headquarters and regional funds. Hazard programs (for example, earthquake, volcano, and landslide) also have supported development and implementation of vulnerability and risk assessments pre- and post-event. Finally, USGS vulnerability and risk assessment activities have been enabled by partners (for example, FEMA, NOAA, Environmental Protection Agency). Whereas vulnerability assessments have been multi-hazard and hazard specific, risk assessments primarily have been conducted in the domain of a hazard.

The Multi-Hazards Demonstration Project produced a comprehensive vulnerability assessment for the southern California ShakeOut and California ARkStorm scenarios that included infrastructure/building and content damages, health and safety implications, agricultural damages and losses, disruptions to goods and people movement, sector exposure, lifeline services, economic impacts, and environmental impacts. These assessments were accomplished with USGS geographical expertise supplemented by collaborations with social and behavioral science experts. Also, demographic and socioeconomic exposure, and sensitivity analyses have been conducted for tsunami, volcano, earthquake and coastal change hazards in Oregon, Washington, and Hawai i. These vulnerability assessments have influenced hazard mapping and mitigation priorities, mitigation planning, disaster response and recovery planning, and policy recommendations.

Vulnerability assessments of specific hazards include (1) DOI resource vulnerability to wildfire, (2) vulnerability of homes to wildfire in the Wildland Urban Interface, (3) realtime potential earthquake facility damage assessment (that is, ShakeCast), (4) fatality and economic loss impact estimates following significant earthquakes worldwide (that is, PAGER), and, (5) estimation of landslide losses post-event.

Risk assessments include (1) with FEMA, developing vulnerability and risk assessments from flood inundation maps tied to USGS real-time streamgage data and NWS flood forecast sites, (2) Google Earth viewable "risk maps" for selected building types, probabilities, and planning horizons across the conterminous United States, (3) forecasting fire risk in the Wildland Urban Interface, and (4) with NPS, a ground-breaking study of rockfall hazard and risk assessment in Yosemite Valley, California. Increasingly, vulnerability and risk assessments are being served through web-based geospatial tools to allow users to interact with hazard information and create their own assessments.

\section{Volcano Hazards}

The USGS has a long and rich tradition of exploring the world's volcanic landscapes and deriving critical insights into how volcanoes work. The mission of the Volcano Hazard 
Program (VHP) is to minimize social and economic disruption by understanding volcanic processes in order to detect unrest and deliver timely, accurate warnings. The United States and its Territories host 169 geologically young volcanoes including Novarupta, the source of Earth's largest eruption of the 20 th century. Of these, 55 are considered high or very high threat due to eruption frequency and style and the population and infrastructure in harm's way. To enhance public safety and deliver helpful hazard information to the Nation, the VHP devotes resources to four mutually supportive areas of focus: volcano monitoring and observation, fundamental process research, hazard assessment, and communication of critical hazard information.

The VHP maintains a workforce of about 120 research and operational geologists, geophysicists, engineers, and support staff housed primarily at its five volcano observatories in Hawaii, Alaska, Washington, California, and Yellowstone. A number of geoscientists from universities and State surveys are partners in these observatories through formal cooperative agreements. The U.S. Agency for International Development co-funds the Volcano Disaster Assistance Program, an international volcano crisis response and mitigation team that has saved thousands of lives and built local capacity in dozens of nations around the world since its founding in 1986.

Volcano monitoring is most effective when multiple data streams are combined. VHP employs seismic and geodetic networks to detect unrest and selectively uses satellite surveillance, gas surveys, infrasound, pressure sensors, lightning, web cameras, thermal cameras, water and spring sampling to track activity at the nation's volcanoes. The VHP portfolio of fundamental research into volcanic and related earth processes involves field investigations of volcanic deposits and eruptive histories, laboratory simulations and experiments, and
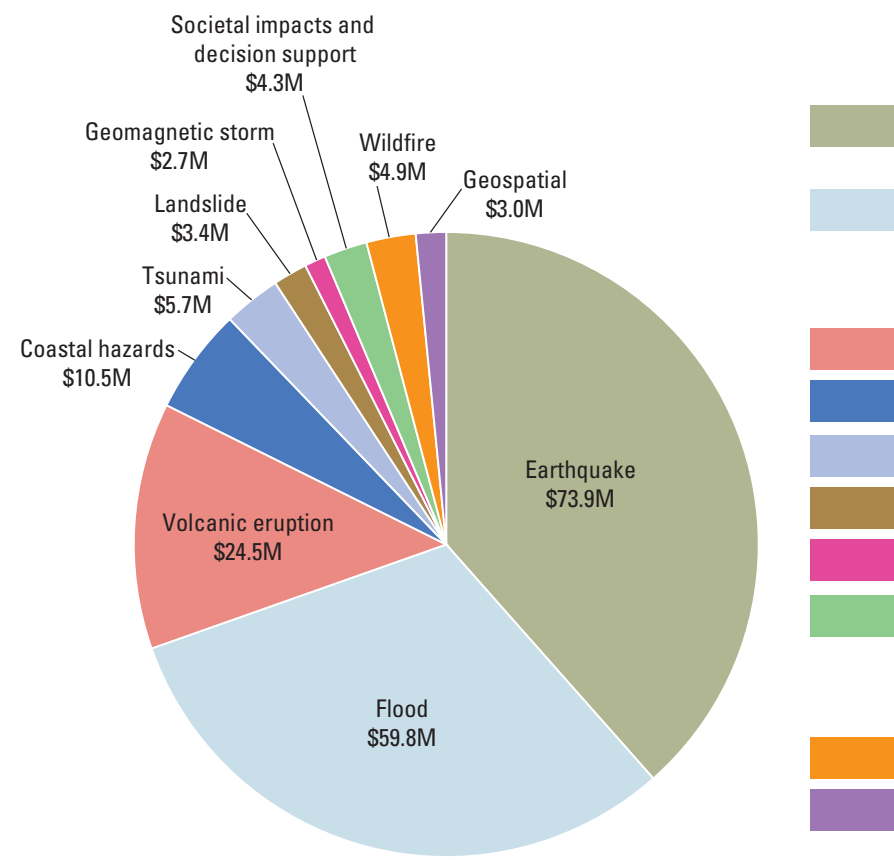

Figure 1-3. Approximate U.S. Geological Survey appropriated and reimbursable hazard funding levels. development of models to explain how volcanoes work. Volcano hazard assessments integrate understanding of volcanic systems, eruptive history, and processes to portray areas vulnerable to volcanic phenomena. Additional assessments done in partnership evaluate elements of vulnerability to support risk assessment and planning. Volcanic events are relatively rare but may unfold rapidly; thus, practiced eruption response plans must be in place before unrest occurs. VHP scientists work with Federal, State, and local agencies and the private sector to promote preparedness and develop effective communication strategies. Additionally, VHP works both domestically and internationally to educate and inform the public, emergency and critical infrastructure managers regarding the nature and potential impacts of volcanic events.

VHP partners with USGS scientists from the Earthquake, Landslide, Coastal and Marine Programs, the Water Mission Area, the Earth Materials and Human Health project, EROS data center, and the Advanced Systems Center on collaborative research and operational activities. Externally, VHP has strong ties with NOAA, NASA, FAA, the Smithsonian Institution, and other DOI agencies. VHP scientists and observatories collaborate with domestic and international academic colleagues. Finally, to ensure that volcano science is well applied to the support of public safety and preparedness, VHP scientists nurture strong partnerships with emergency management at multiple levels.

In 2005, Ewert and others completed a systematic evaluation and ranking of the Nation's volcanoes according to threat and current level of monitoring. Based on the results, the VHP and its partners prepared a plan to close critical gaps in monitoring and eruption response capability for the U.S. This plan, the National Volcano Early Warning System or NVEWS, is currently (2011) before Congress for authorization.

\section{EXPLANATION}

Hazard type - funding is in millions of dollars (M)

Earthquake - Includes Earthquake Hazards and Global Seismographic Network (GSN) programs

Flood-Includes reimbursable funding and appropriated funding in the following: National Streamflow Information Program, Cooperative Water Program, National Water Quality Assessment Program, and National Stream Quality Accounting Network (Note: This is both streamflow and water quality.)

Volcanic eruption-Includes Volcano Hazards Program

Coastal hazards (storm and erosion)—Includes Coastal and Marine Geology Program

Tsunami-Includes multihazards program

Landslide-Includes Landslide Hazards Program

Geomagnetic storm — Includes Geomagnetism Program and Air Force support

Societal impacts and decision support-Includes Geographic Analysis and Monitoring Program (Note: Reimbursable funds are for famine early warning project at EROS. If drought was considered under hazards, then we would have a significant additional reimbursable contribution.)

Wildfire

Geospatial-Includes National Geospatial Program and Land Remote Sensing Program (these products and activities cross all hazards and serve internal and external partners) 


\section{Appendix 2. The Domestic Value of USGS International Efforts in Hazard Science}

Many hazards need to be considered in a global context. In our ever-shrinking global context, the USGS is increasingly called upon to advise the U.S. Government and other interests on hazard events overseas. Expertise and experience in hazard science is international and to remain on the cutting edge of understanding, continued USGS involvement in global hazard science activities is critical. Hazard events that occur in other countries, such as large earthquakes and volcanic eruptions, affect the global economy, and therefore affect the United States. Very large events factor into our national security. Furthermore, some hazards are inherently global in scale: hurricanes migrate across oceans, tsunamis that affect the United States are usually initiated by earthquakes on the other side of the world, and geomagnetic storms encompass the whole Earth. Finally, many of the largest events are very rare and may not have occurred in the United States during historical times. Investigating such events wherever they occur worldwide brings back knowledge and benefits to the United States that are inestimable.

International work cross cuts all four hazards missions goals:

Observation. Some hazard programs, such as those of Earthquake and Geomagnetism, use global datasets to provide worldwide event notification and elements of hazard and risk assessments. Engagement with the global community in deploying monitoring networks, developing tools and methodologies to observe hazard processes and issue forecasts, and conduct geological and chronological studies of hazard sources and events is vital to a comprehensive understanding of our Nation's risk. Close cooperation with our international neighbors to ensure seamless monitoring and understanding of hazards to the North American continent and adjacent regions will require ongoing collaboration.

Fundamental understanding. Because of commonalities among hazards worldwide, USGS hazard science for the United States is critically informed by direct study of and response to hazard events overseas. Moreover, the frequency of natural hazard events in other countries provide superb and often unmatched opportunities to further USGS research into natural hazard processes and impacts. Exceptionally large hazard events are rare and may not have occurred in the United States in recent historical times. Studying their occurrence and effects outside the United States adds to the fund of knowledge and helps to assess U.S. hazards and their associated risks. Scientific insights from responding to hazard events around the planet provide direct lessons learned that are of benefit to domestic risk reduction.

Assessments and reducing global losses. As in the United States, global vulnerability and risk are increasing dramatically as growth and development occur in hazardous areas of the planet. Natural hazard events and disasters are increasingly global in scope and impact as economies become more and more interdependent. Diplomatic and humanitarian concerns alone should motivate appropriate USGS involvement in mitigation and response activities abroad, carefully done in cooperation with local organizations and with funding from other U.S. Government agencies or foreign governments. The successes of the USAID-supported Volcano Disaster Assistance Program and Natural Hazards Participating Agency Services Agreement are powerful examples of applying USGS expertise to save lives and reduce suffering abroad while promoting the interests of the Nation.

Situational awareness. The USGS provides expert guidance and information to the U.S. Government and other interests regarding hazards and hazard events around the world. The USGS is in a unique position to provide a global perspective on hazard 'hot spots' to facilitate planning and preparedness activities of Department of Defense and other U.S. Government agencies. While mindful not to tax the focus on domestic hazard science and response or undermine authority of local response agencies abroad, the USGS can and should play an important role in tracking and communicating global hazard events. 


\section{Appendix 3. Hazards Science Strategy Planning Team: Composition, Charge, Philosophy, and Process}

\section{Our Team}

In every USGS Mission Area, a Science Strategy Planning Team has been appointed to develop a long term, 10-year Science Strategy. The Hazards Science Strategy Planning Team (H-SSPT) comprises two co-chairs, and a seat for each of the hazards within USGS purview, plus a seat for the societal consequences that play a pivotal role in resilience. The initial team make-up is as follows:

\section{The Co-Chairs:}

- Robert Holmes, National Flood Coordinator

- Lucile Jones, Chief Scientist, Multi-Hazards Demonstration Project

\section{The Seats:}

- Coastal Processes-Nathaniel Plant, Oceanographer, St. Petersberg Coastal and Marine Science Center

- Earthquake-Craig Weaver, Pacific Northwest Regional Coordinator, Earthquake Hazard Program

- Flood-Mickey Plunkett, Director, Mississippi Water Science Center

- Geomagnetism \& Space Weather-Jeffrey Love, USGS Advisor for Geomagnetic Research

- Landslide-Jonathan Godt, Research Physical Scientist, Geologic Hazards Science Center

- Societal Consequences-Anne Wein, Operations Research Analyst, Western Geographic Science Center

- Tsunami-Steve Kirby, Research Geophysicist and Senior Scientist, Earthquake Science Center, Chair, USGS Tsunami Source Working Group

- Volcano-Tina Neal, Geologist, Volcano Science Center

- Wildfire-Jeff Eidenshink, Deputy Director, Earth Resources Observation and Science Center

\section{Team Facilitator:}

- Sue Perry, Staff Scientist, Multi-Hazards Demonstration Project

\section{Our Charge:}

The charge to the H-SSPT, by design, is very similar to the SSPT charges for other Mission Areas. The H-SSPT paid close attention to its charge, which was given by the Director at the start of the strategic planning process and is here reproduced verbatim:

"Charge to USGS Science Strategy Planning Team

"Natural Hazards

"Purpose. The Natural Hazards Science Strategy Planning Team (SSPT) is charged with developing a long-term (10-year) Strategic Science Plan for the U.S. Geological Survey (USGS) Natural Hazards mission area and the programs that support it. The strategic science vision and articulation of priorities developed by this Team will be used by USGS leadership in the development of guidance, implementation planning, and accountability reporting.

"Background. The USGS Science Strategy, "Facing Tomorrow's Challenges, U.S. Geological Survey Science in the Decade 2007-2017," sets forth six bold new strategic science directions and one cross-cutting science direction. These strategic science directions are interrelated and have been used to design the new USGS organization and define our new mission areas. This charter pertains to the Natural Hazards mission area.

"Team Leadership. The Team will have two co-chairs nominated by the USGS Executive Leadership Team (ELT) and appointed by the Director. The co-chairs serve for a term of 4 years and report directly to the USGS Associate Director (AD) for Natural Hazards, who will serve as the ELT lead for this effort. As an "executive champion" for the Team, the ELT lead will ensure regular interactions with the Director and the ELT. Co-chairs will also comprise an SSPT Advisory Team which will have as its primary goal to ensure cross-mission area coordination. It is estimated the time commitment for cochairs will be $35-40$ percent.

"Team Composition. The Team will consist of approximately 10 scientists and managers recommended by bureau leadership through both a nomination process and a call for interest. The final Team composition is approved by the Director. Team members are selected from throughout the USGS for their scientific expertise in the mission area and leadership skills. One member will be from the Office of Budget and Performance to provide technical assistance with respect to budget formulation, the appropriations process, and management analysis. Membership on the SSPT is rotational with time limited to a maximum of 3 years; Team membership will be staggered, with members serving between one and three years. It is estimated that the time commitment for Team members will be 20-25 percent.

"Outcomes and Products. The co-chairs will lead the SSPT in the development of a 10-year Strategic Science Plan and high-level budget, ensuring coordination and input from USGS scientists, managers, and stakeholders. The Natural Hazards Strategic Science Plan will begin with the framework provided in the USGS Science Strategy and build on, update, and expand upon it with actions the USGS can undertake over 
the next 10 years. The Natural Hazards Strategic Science Plan and other work products will be reviewed by USGS leadership and others as appropriate, and delivered to the USGS Director by the ELT lead. The ELT lead will ensure the ELT is actively engaged by seeking feedback and input at appropriate junctures, and will similarly facilitate interaction of the Team with USGS scientists, managers, and stakeholders.

"The primary product of the Team is a 10-year Natural Hazards Strategic Science Plan that encompasses the portfolio of USGS science under the $\mathrm{AD}$, as well as other relevant USGS science. The Plan should be succinct and include a summary of USGS goals and planned outcomes. The Plan should serve as a strategic framework that articulates priorities and primary activities to assist leadership in determining actions to be taken in the short-term. It will serve as a key guiding document for USGS leader-ship in science planning and execution, but will not explicitly address annual activities or short-term actions. Bureau leaders expect to use it as a basis for budget initiatives, national guidance, and regional implementation strategies. Accordingly, while the Plan should be long-term, strategic and visionary, its goals should be carefully crafted so that they can be used by management. Careful attention should be paid to the linkages to other mission areas and opportunities for collaboration."

\section{Our Process:}

The H-SSPT proceeded under an aggressive schedule. On December 1, 2010, the team members were appointed by the Bureau Director, and on August 1, 2011, the team delivered a first draft plan to the Associate Director of the Hazards Mission Area. In the intervening 8 months, the team met its charge through these activities, in roughly chronological order (although most steps were iterative):

- Selected hazards to be considered. This SSPT has been inclusive in considering a broad portfolio of natural hazards, including those outside mandated responsibilities under the USGS and other Federal programs, but for which the Nation is underserved.

- Identified USGS activities essential to fulfilling the hazards mission. These became the four overlapping goals discussed throughout this Strategy:

- Goal 1: OBSERVATIONS. The USGS acquires comprehensive observations important to natural hazards to improve fundamental understanding, assessments, and situational awareness.

- Goal 2: UNDERSTANDING. The USGS advances and applies fundamental understanding of natural hazards to improve assessments, and situational awareness.

- Goal 3: ASSESSMENTS. The USGS develops assessments of natural hazards, vulnerability and risk to inform decisions that can mitigate adverse consequences.
- Goal 4: SITUATIONAL AWARENESS. The USGS provides situational awareness to improve emergency response, inform the public, and minimize societal disruption.

- Determined key stakeholders to reach in listening sessions. Stakeholders is a broad designation that includes partners and collaborators within and outside the USGS, and users of USGS information, including decisionmakers at all levels of government, in the public and private sectors, as well as, in the media and the general public.

- Met with as many stakeholders as we could reach. Before composing this Strategy, team members held more than 60 formal listening sessions and informal discussions, in person, by webinar, and by conference call, at USGS offices, professional meetings of natural scientists, social scientists, engineers, and emergency managers, and the offices of other agencies including the Federal Aviation Agency, Federal Emergency Management Agency, National Oceanic and Atmospheric Ad-ministration, and National Weather Service. We worked top down and bottom up, talking to upper management and the regional workforce. Attending team members briefed the others about each session. Appendix 4 lists the formal sessions. Informal discussions were too numerous to list.

- Sought input from USGS leadership. The H-SSPT held meetings with the executive leadership team, the regional executives, and program coordinators. In addition, the H-SSPT interviewed hazard-related program coordinators by way of questionnaires. See appendix 3 for the list of contributors for these meetings.

- Incorporated input from electronic submissions. In addition, the team read and discussed electronic submissions made through email and browser-based questionnaires.

- Held biweekly team meetings by phone conference. The first of these meetings included a briefing from each team member as a representative of that seat, to inform the others about the work within and makeup of each team member's "world' within the USGS.

- Held six face to face meetings, each 2-3 days long. These in-person sessions were used to debate the focus of the Strategy, its goals and action items.

- Actively used email and the confluence blog-based technology to shared ideas and materials. 


\section{Selection Approach and Criteria for Strategic Actions}

Before we wrote a single word of this Strategy, we spent months talking with stakeholders within and outside the USGS, and engaging in discussions as a team. During this process, a large number of worthy actions and ideas were either developed by the team or proposed by stakeholders. Early in deliberations the team realized it needed a set of criteria and methodology for action item screening and selection. These criteria and methodology were necessary for the team to absorb the range of ideas, to distill the number down to a manageable set, and to explain or defend decisions regarding the final action items included in this report.

Some programs and activities automatically rose to the top and received special consideration. These are USGS programs and activities that are crucial to the basic mission of the USGS, either through federally mandated responsibility or because they provide essential earth and biological science characterization. These are programs and activities that were judged by USGS stakeholders and this team as pivotal to USGS hazard science activities, and thus, must be protected and preserved. Examples of these programs include the streamgage network, seismographic networks, and geomagnetic observatories.

Some action items carried additional weight because they have great potential to improve the effectiveness and broaden the use of USGS science, and thus maximize benefit to society. However, the team also strongly felt that the USGS must not simply pursue the latest "hot" science topic driven simply by the inertia of societal interest or "topic du jour". There are important elements to our science that may have no quick payoff or societal appreciation, and that might take years to mature and become relevant. Such science should be supported, but also repeatedly evaluated to ensure that we are holding to the spirit of science in the public interest.

A recurring theme in stakeholder sessions was that the USGS risks becoming "a mile wide and an inch deep" in its scientific undertakings and abilities. The team also tried to balance the need to focus collective hazards science activities around mission and societal needs, while remaining agile and open to the new directions that will be essential to fulfilling that mission in the future. Individual creativity and science opportunities that are not yet foreseen will always be crucial.

The team needed a Strategy that had substance and detail, without being prescriptive or encroaching in the domain of program plans. The team tried to balance big ideas and grand vision with actions that could proceed in varied budget climates.

With its initial charge and all these considerations in mind, the team developed a quantitative ranking scheme to form the final action items for this Strategy. Every candidate action item was ranked based on each of the following criteria. (Scores in each category could vary as indicated in parentheses.)

- Does it fit the USGS hazards mission? (1-5)

- Is it a fundamental and crucial USGS national capability, such as basic data and information networks or a function on which others depend? (1-5)

- Would achieving this item have a large effect on economy, human health, or national security of the United States? (each 0-2)

- Does it address large gaps in hazards scientific knowledge? (0-2)

- Is it a scientific endeavor where there is a lack of others doing this work? (0-1)

- Is it fundamental research that has a high likelihood of being of substantial relevance within 20 years? (0-2)

- Does it have a component that allows for better assessment and quantification of risk? (0-2)

- Does it involve multiple hazards? (0-1)

- Does this utilize new or existing partnerships? (0-2)

- Does this represent a USGS targeted hazard that is underrepresented in the action items for this report (such as wildfire)? (0-1)

- Are there synergies with other Mission Areas? (0-2)

- Does this improve use of USGS information to better societal decision making? (0-2)

This quantification took the team about 75 percent of the way to the final action items in this Strategy; additional team thought and discussion completed the journey. The action items in this Strategy distill, merge, and organize the individual actions into more broadly encompassing efforts that span more hazards, over longer time frames, than the individual suggestions. 


\section{Appendix 4. Listening Sessions}

Table D-1. Stakeholder sessions.

[MHDP, Multi-Hazards Demonstration Project for Southern California; USGS, United States Geological Survey; EHP, Earthquake Hazards Program; AVO, Alaska Volcano Observatory; SC, Science Center; JPL, Jet Propulsion Laboratory; NSF, National Science Foundation; AGU, American Geophysical Union; NWS, National Weather Service; NEIC, National Earthquake Information Center; NOAA, National Oceanic and Atmospheric Administration; ESRL, Earth System Research Laboratory; NEMA, National Emergency Managers Association; USAID, United States Agency for International Development; EM, Emergency Management; FEMA, Federal Emergency Management Agency; CVO, Cascades Volcano Observatory; DOGAMI, Oregon Department of Geology and Mineral Industries; USACE, U.S. Army Corps of Engineers; METOC, U.S. Navy Meteorologic and Oceanographic Command; NORTHCOM, United States Northern Command]

\begin{tabular}{|c|c|c|}
\hline Date & Location & Meeting (M) or Organization (0) \\
\hline $1 / 11 / 2011$ & Los Angeles, Calif. & M: MHDP Tsunami Scenario Kickoff Meeting \\
\hline $1 / 12 / 2011$ & Pasadena, Calif. & O: USGS EHP \\
\hline $1 / 20 / 2011$ & Anchorage, Alaska & O: USGS-AVO \\
\hline $1 / 2011$ & Golden, Colo. & O: USGS EHP \\
\hline $1 / 2011$ & Albuquerque, N. Mex. & O: USGS Seismographic Laboratory \\
\hline $1 / 2011$ & Urbana, Ill. & O: USGS Water SC \\
\hline $1 / 23 / 2011$ & Seattle, Wash. & M: American Meteorological Society \\
\hline $1 / 31 / 2011$ & Pasadena, Calif. & O: JPL-Caltech remote sensing \\
\hline $1 / 5-7 / 2011$ & Austin, Tex. & M: NSF Geoprisms Implementation Workshop \\
\hline $12 / 2010$ & San Francisco, Calif. & M: AGU listening session \\
\hline $2 / 1-3 / 2011$ & Portland, Oreg. & M: National Tsunami Hazard Mitigation Program Coordinators \\
\hline $2 / 2011$ & Kansas City, Mo. & O: NWS River Forecast Center \\
\hline $2 / 7-8 / 2011$ & Menlo Park, Calif. & M: USGS Six listening sessions \\
\hline $2 / 7 / 2011$ & Menlo Park, Calif. & O: USGS Landslides \\
\hline $2 / 7 / 2011$ & Menlo Park, Calif. & O: USGS-Gump \\
\hline 2/9/2011 & Sacramento, Calif. & O: USGS Water SC \\
\hline $3 / 1-3 / 2011$ & Menlo Park, Calif. & M: USGS National Marine Geohazards Workshop \\
\hline $3 / 1 / 2011$ & Minneapolis, Minn. & M: Advisory Council on Water Information \\
\hline $3 / 14 / 2011$ & Denver, Colo. & O: Crustal Geophysics \& Geochemistry SC \\
\hline $3 / 14 / 2011$ & Denver, Colo. & O: USGS Potential Field \\
\hline $3 / 14 / 2011$ & Golden, Colo. & O: USGS Landslide \\
\hline $3 / 14 / 2011$ & Golden, Colo. & O: USGS NEIC \\
\hline $3 / 15 / 2011$ & Denver, Colo. & M: USGS listening session \\
\hline $3 / 16 / 2011$ & Golden, Colo. & M: USGS listening session \\
\hline $3 / 17 / 2011$ & Boulder, Colo. & O: NOAA Space Weather Prediction Center \\
\hline $3 / 17 / 2011$ & Boulder, Colo. & O: NOAA ESRL \\
\hline $3 / 17 / 2011$ & Boulder, Colo. & O: NOAA NWS \\
\hline $3 / 17 / 2011$ & Boulder, Colo. & O: NOAA National Geophysical Data Center \\
\hline $3 / 17 / 2011$ & Boulder, Colo. & O: University of Colorado Hazards Center \\
\hline $3 / 20-23 / 2011$ & Alexandria, Va. & M: NEMA listening session \\
\hline $3 / 2011$ & Boise, Idaho & M: National Interagency Fire Center \\
\hline $3 / 21 / 2011$ & Reston, Va. & O: NWS Aviation Service Branch \\
\hline $3 / 21 / 2011$ & Silver Springs, Md. & O: NOAA NWS \\
\hline $3 / 21 / 2011$ & Washington, D.C. & O: USAID Office of Foreign Disaster Assistance \\
\hline $3 / 22 / 2011$ & Iowa City, Iowa & O: USGS Water SC \\
\hline
\end{tabular}


Table D-1. Stakeholder sessions.-Continued

[MHDP, Multi-Hazards Demonstration Project for Southern California; USGS, United States Geological Survey; EHP, Earthquake Hazards Program; AVO, Alaska Volcano Observatory; SC, Science Center; JPL, Jet Propulsion Laboratory; NSF, National Science Foundation; AGU, American Geophysical Union; NWS, National Weather Service; NEIC, National Earthquake Information Center; NOAA, National Oceanic and Atmospheric Administration; ESRL, Earth System Research Laboratory; NEMA, National Emergency Managers Association; USAID, United States Agency for International Development; EM, Emergency Management; FEMA, Federal Emergency Management Agency; CVO, Cascades Volcano Observatory; DOGAMI, Oregon Department of Geology and Mineral Industries; USACE, Army Corps of Engineers; METOC, U.S. Navy Meteorologic and Oceanographic Command; NORTHCOM, United States Northern Command]

\begin{tabular}{|c|c|c|}
\hline Date & Location & Meeting (M) or Organization (0) \\
\hline $3 / 22 / 2011$ & Vancouver, Wash. & O: USGS Societal Impacts \\
\hline $3 / 22 / 2011$ & Washington, D.C. & M: FEMA listening session at NEMA meeting \\
\hline $3 / 22 / 2011$ & Reston, Va. & M: NWS listening session at NEMA meeting \\
\hline $3 / 24 / 2011$ & Reston, Va. & O: FEMA \\
\hline $3 / 28 / 2011$ & Tampa, Fla. & M: National Surface Water listening session \\
\hline $3 / 31 / 2011$ & St. Petersburg, Fla. & M: USGS listening session \\
\hline $3 / 4 / 2011$ & By phone & O: USGS Hawai ian Volcano Observatory \\
\hline $4 / 12-16 / 2011$ & Seattle, Wash. & M: American Association of Geographers \\
\hline $4 / 14 / 2011$ & Memphis, Tenn. & M: Seismological Society of America listening session \\
\hline $4 / 19 / 2011$ & Anchorage, Alaska & M: USGS AVO listening session \\
\hline $4 / 2011$ & Hawaii & O: USGS Hawai`i Volcano Observatory \\
\hline $4 / 21 / 2011$ & Vancouver, Wash. & M: USGS CVO listening session \\
\hline $4 / 22 / 2011$ & Portland, Oreg. & O: Oregon State Geologist \\
\hline $4 / 22 / 2011$ & Portland, Oreg. & O: DOGAMI landslide staff \\
\hline $4 / 22 / 2011$ & Denver, Colo. and phone & M: USGS Wildfire listening session \\
\hline $4 / 25 / 2011$ & Boulder, Colo. & M: electric power grid industry at NOAA workshop \\
\hline $4 / 26 / 2011$ & Webinar & M: USGS listening session \\
\hline $5 / 10 / 2011$ & San Diego, Calif. & M: National Hydrologic Warning Council \\
\hline $5 / 18 / 2011$ & Louisville, Ky. & M: National Association of Floodplain Managers \\
\hline $5 / 2-6 / 2011$ & Miami, Fla. & M: USGS Coastal sediments \\
\hline $5 / 2011$ & by phone & O: Nuclear Regulatory Commission \\
\hline $5 / 25 / 2011$ & Web based & M: emergency managers forum and poll \\
\hline $5 / 5 / 2011$ & Mo. & O: USACE, NOAA/NWS, USGS flood \\
\hline $6 / 11 / 2011$ & Alaska & O: Alaska State EM \\
\hline $6 / 14 / 2011$ & Dubuque, Iowa & M: Association of American State Geologists listening session \\
\hline $6 / 8 / 2011$ & Washington, D.C. & M: Space Weather Enterprise Forum \\
\hline $7 / 6 / 2011$ & Colorado Springs, Colo. & O: METOC, NORTHCOM \\
\hline $8 / 2011$ & Minn. & M: USGS Water Mission Area \\
\hline
\end{tabular}

\section{Meetings with USGS Leadership}

In addition, the team also had multiple telephone and face to face discussions with USGS program coordinators regional executives; and hazard program coordinators contributed written questionnaires. Individual team members had one-on-one meetings too numerous to list. 


\section{Appendix 5. Disaster Relief Act of 1974}

Date: $\quad$ August 16, 2001

To: $\quad$ ChjpGroat, Pat Leahy, Bob Hirsch, Barbara Wainman, Tim West, Carla Burzyk. Suban Collier, John Pallister, Marianne Guffanti, John Filson, Lipdx Gunderson, Jipa Devine.

From: $\quad$ Patl Beauchemin, Office of Communications

Subject: $\quad$ USGS Authority to issue Geologic Hazards Warnings

In recent months the question has arisen regarding the origin of USGS's authority to issue geologic-related hazards warnings. Broad authority for Federal agencies is provided by the Disaster Relief Act of 1974 (P.L. 93-288) more commonly referred to as the Stafford Act. The specific connection to the USGS was made in 1977 via issuance of a Federal Register Notice which detailed the procedures to be implemented related to "warning and preparedness for geologic-related hazards". Thanks to the good memories and well kept files of Jim Devine and Joyce Costello, a somewhat yellowed but intact copy of this Federal Register notice has been unearthed (copy attached). Please replicate this notice and distribute it widely so that the next generation of the Survey will be more readily aware of this important authority.

\section{Attachment}


10-11-83

Vol. 48 No. 197

Pages 46005-46258

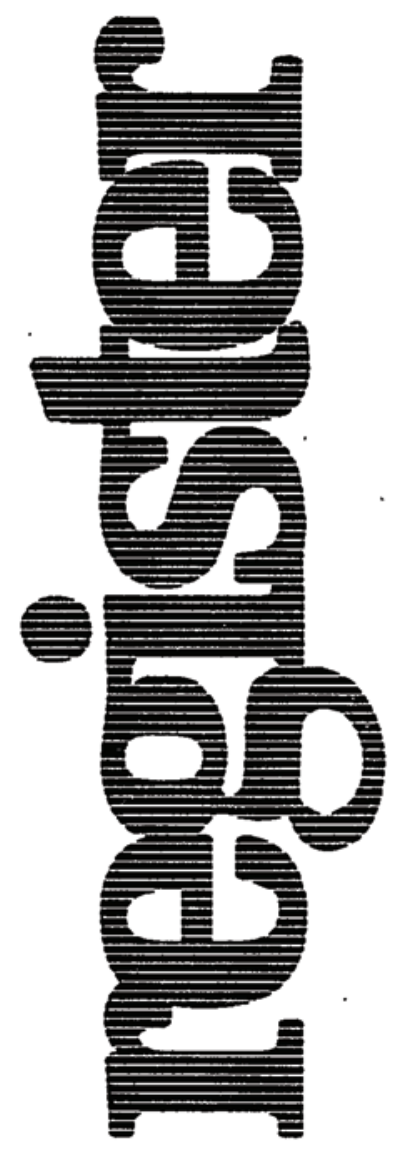

\section{Selected Subjects}

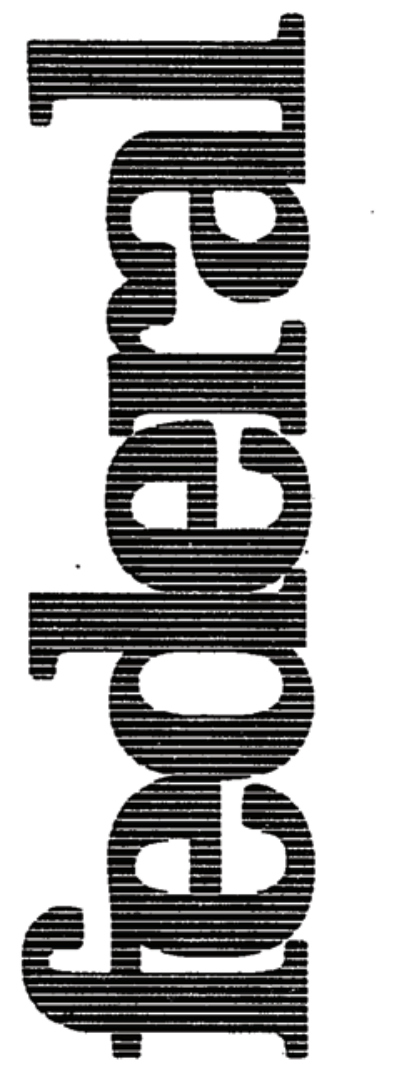

Tuesday

October 11, 1983

\section{Air Pollution Control \\ Environmental Protection Agency \\ Animal Drugs \\ Food and Drug Administration \\ Aviation Safety \\ Federal Aviation Administration}

Banks, Banking

Federal Reserve System

Crop Insurance

Federal Crop Insurance Corporation

Electric Power Rates

Federal Energy Regulatory Commission

Endangered and Threatened Wildilfe

Fish and Wildlife Service

\section{Fisheries}

National Oceanic and Atmospheric Administration

Flood Insurance

Federal Emergency Management Agency

National Credit Union Administration

Food Additives

Food and Drug Administration

Foreign Investments in U.S.

Agricultural Stabilization and Conservation Service

Freedom of Information

Commodity Futures Trading Commission

CONTINUED INSIDE 
involved. There are no closed portions for the meetings announced in this notice. The dates and times reserved for the open portions of each committee meeting are listed above.

The open public hearing portion of each meeting shall be at least 1 hour long unless public participation does not last that long. It is emphasized, however. that the 1 hour time limit for an open public hearing represents a minimum rather than a maximum time for public participation, and an open public hearing may last for whatever longer period the committee chairman determines will facilitate the committee's work.

Meetings of advisory committees shall be conducted, insofar as is practical, in accordance with the agenda published in this Federal Register notice. Changes in the agenda will be announced at the beginning of the open portion of a meeting.

Any interested person who wishes to be assured of the right to make an oral presentation at the open public hearing portion of a meeting shall inform the contact person listed above, either orally or in writing, prior to the meeting. Any person attending the heating who does not in advance of the meeting request an opportunity to speak will be allowed to make an oral presentation at the hearing's conclusion, if time permits. at the chairman's discretion.

Persons interested in specific agenda items to be discussed in open session may ascertain from the contact person the approximate time of discussion.

$A$ list of committee members and summary minutes of meetings may be requested from the Dockets Management Branch (HFA-305), Food and Drug Administration, Rm. 4-62, 5600 Fishers Lane, Rockville, MD 20857. between 9 a.m. and 4 p.m.; Monday through Friday. The FDA regulations relating to public advisory committees may be found in 21 CFR Part 14.

Dated: October 4, 1983.

William F. Randolph,

Acting Associate Commissioner for Regulatory Affairs.

|FR Doc. 83-27504 Filed 10-7-83; 8:45 am| BILLING CODE 4160-01-1

\section{Public Health Service}

National Toxicology Program Board of Scientific Counselors Meeting

Pursuant to Pub. L. 92-463, notice is hereby given of the meeting of the National Toxicology Program Board of Scientific Counselors, U.S. Public Health Service, in the Conference Center. Building 101, South Campus. National
Institute of Environmental Health Sciences, Research Triangle Park, North Carolina, on October 27, 1983.

The meeting will be open to the public from 10:00 a.m. until adjournment for the purpose of providing peer review of the data from the chronic carcinogenesis bioassay of FD\&C Red No. 3 in Charles River CD-1 rats of both sexes. The bioassay was sponsored by the Certified Color Manufacturers Association, conducted by International Research and Development Corporation (IRDC), and submitted to the Food and Drug Administration (FDA) in support of permanent listing of FD\&C Red No. 3. The review will be conducted by the Technical Reports Review

Subcommittee of the Board in conjunction with an ad hoc panel of experts.

The meeting will commence with a brief overview of the study. This will be followed with presentations by scientific staff from the Bureau of Foods, FDA. concerning the pathology findings. Sufficient time will be allowed for public comment.

The Executive Secretary, Dr. Larry G. Hart, Office of the Director, National Toxicology Program, P.O. Box 12233. Research Triangle Park, North Carolina 27709, telephone (919) 541-3971, FTS 629-3971, will furnish program information prior to the meeting and summary minutes subsequent to the meeting.

Dated: October 4, 1983.

David P. Rall,

Director, National Toxicology Program.

[FR Doc. 83-27374 Filed 10-7-83: 8:45 am]

BILLING CODE 4140-01-M

\section{DEPARTMENT OF THE INTERIOR}

Presidential Commission on Indian Reservation Economies; Meeting

October 6, 1983.

The Presidential Commission on Indian Reservation Economies, established pursuant to Executive Order 12401, as amended by Executive Order 12442 , will hold its first meetings on October 19, 1983, from 10 a.m. until 5 p.m.. and on October 20, 1983, from 9 a.m. until 5 p.m., in the GSA Auditorium at 18th and F Sts., NW., Washington. D.C.

The purpose of the meeting is to initiate the work of the Commission consistent with the Executive Orders and the Commission's charter, and to lay out workplans and a public hearing schedule, along with administrative and housekeeping chores.
The agenda of the meetings is summarized as follows:

The first meeting will open with the swearing in of the Commission and the delivery of opening remarks. There will then be an open discussion of the Commission's workplan for its first two months, and public hearings may be scheduled for that period. Subsequently, the Executive Director of the Commission will provide the Commissioners with an orientation on current issues in Indian affairs. The second day of the meetings will be devoted to items of business which members of the Commission wish to discuss, with the goal of dividing the work of the Commission among the Commissioners and staff.

This notice is being published slightly less than 15 days prior to the scheduled dates of the meetings due to delay in securing a suitable site for such a public meeting. Because of the busy schedules of the persons appointed to the Commission and the need for commencement of the business of the Commission, the 15-day notice requirement is hereby waived.

For further information, please contact Mr. Roy Sampsel at 202/343-3107.

William H. Coldiron,

Solicitor.

[FR Doc. 83-27689 Filed 10-7-83; 8:45 am]

BIUING CODE 4310-02-M

\section{Geological Survey}

Revision of Terminology for Geologic Hazard Warnings

AGENCY: U.S. Geological Survey. Interior.

ACTION: Notice.

SUMMARY: This notice describes proposed changes in the terms and criteria used by the U.S. Geological

Survey for issuing statements concerning geologic-related hazards to public officials and the public.

For the purpose of this statement, a geologic hazard is a geologic condition, process, or potential event, such as an earthquake, volcanic eruption, or landslide, that poses a threat to the health, safety, or welfare of the public or to the functions or economy of a community or larger governmental entity. In this context a Geologic Hazard Warning is a formal statement by the Director of the U.S. Geologic Survey that discusses a specific geologic condition, process, or potential event that poses a significant threat to the public, and for which some timely response would be expected. Directives or advisories to the 
public to take action, based on a Geologic Hazard Warning, may be issued by officials of State and local governments, and other Federal agencies, with authority and responsibility to issue such statements.

The term Hazard Warning is reserved for those situations posing a risk greater than normal and warranting considerations of a timely response in order to provide for public safety. Information regarding hazardous conditions that do not meet the criteria for a Hazard Warning may, however, also be sent to public officials as it becomes available. Transmittal of such information would not constitute a Hazard Warning.

1. The criteria for a Geologic Hazard Warning are:

a. a degree of risk greater than normal for the area; or a hazardous condition that has recently developed or has only been recently recognized; and

b. a threat that warrants consideration of a near-term public response.

2. A Geologic Hazard Warning consists of:

a. a description of the geologic or other pertinent conditions that cause the concern;

b. factors that indicate that such conditions constitute a potential hazard;

c. location or area that may be affected;

c. estimated severity and time or occurrence, if such estimates are justified by available information;

e. if possible, a quantitatively based probabilistic statement on the likelihood of a given event or events within a specified time period; and

f. a description of continued

Geological Survey involvement and estimate of what and when additional information might be available.

If a life or property-threatening event is thought to be imminent, and immediate response is warranted by the public and public officials, the emergency nature of the Hazard Warning will be stated clearly either in the heading or the first sentence of the text of the warning statement. If the immediate crisis.passes, either with or without the anticipated event, a revised statement will be issued to reflect the change conditions and a re-evaluation of the geologic hazard.

DATES: Comments on the revisions are welcomed and will be considered in the adoption of final hazard warning procedures. Comments are due within 30 days from the date of this notice. ADDRESS: Send.comments to: Office of the Assistant Director for Engineering
Geology, U.S. Geological Survey, 106 National Center, Reston, Virginia, 22092.

SUPPLEMENTARY INFORMATION: The Federal Register of April 12, 1977, Vol. 42, No. 70, pages 19292 to 19296 describes the current terminology as well as the U.S. Geological Survey's authority to issue warnings of geologicrelated hazards, capabilities to predict hazardous events, and provisional procedures to report hazardous conditions.

The change from the present threelevel system to that proposed here is based on past experience and is expected to result in a more effective warning procedure. These changes are only to the present hazard terminology and their criteria. They do not entail or imply any changes to the procedures the U.S. Geological Survey uses to notify State and local governments, other Federal agencies, the public, or the news agencies and services.

Dated: September 30, 1983.

James F. Devine,

Asșistant Director, Engineering Geology.

[FR Doc. 83-27542 Filed 10-7-83; 8:45 am]

BILLING CODE 4310-31-4

\section{Bureau of Land Management}

\section{[N-1005, N-1005A]}

\section{Nevada; Classification Vacated}

September 28, 1983.

1. Pursuant to the authority delegated by Bureau Order 701 and amendments thereto, the following Bureau of Land Management multiple use classifications were published in the Federal Register:

N-1005, date published: June 29, 1967 (FR Doc 67-7343

N-1005A, date published: December 22, 1970 (FR Doc 70-17012

Pursuant to the Classification and Multiple Use Act of September-19, 1964 (43 U.S.C. 1411-18) and the 43 CFR 2460 regulations; these actions classified approximately $4,334,000$ acres of public land in White Pine County, Nevada, for multiple use management. The land was segregated as follows:

\begin{tabular}{|c|c|c|}
\hline $\begin{array}{l}\text { Classifica- } \\
\text { tion }\end{array}$ & Acres & Segregated from \\
\hline 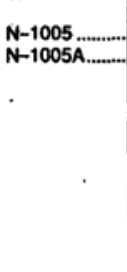 & $\begin{array}{r}4,334,000 \\
21,060\end{array}$ & $\begin{array}{l}\text { Apricultural land laws. } \\
13,940 \text { acres from all forms of } \\
\text { appropriation including mining } \\
\text { but not Recreation and Public } \\
\text { Purposes, mineral leasing and } \\
\text { material sales. } \\
7,120 \text { acres from all forms of } \\
\text { appropriation except Becrea- } \\
\text { tion and Public Purposes, } \\
\text { mining. mineral leasing or ma } \\
\text { terial sales. }\end{array}$ \\
\hline
\end{tabular}

2. Pursuant to 43 CFR 2461.5(c)(2), the classifications are hereby vacated with the exceptions listed below:

a. The following described land will remain segregated from all appropriation including the mining laws, but not the Recreation and Public Purposes Act nor the mineral leasing and material sale laws:

Mount Diablo Meridian, Nevada

Goshute Cave Geologic Area

T. 25 N., R. 63 E.

Sec. 1, E $1 \frac{1}{2}$ NE $1 / 4$.

T. 25 N., R. 64 E.,

Sec. 6, Lots 5, 12.

Goshute Canyon Natural Area

T. 25 N., R. 63 E., Unsurveyed.

Sec. 1, SW1/4SW1/4;

Sec. $2, S^{1 / 2}, S^{1 / 2 N 1 / 2, ~ N W 1 / 4 N W 1 / 4 ; ~}$

Sec. 3, All;

Sec. 4, All;

Sec. 5, All;

Sec. 8, NE1/4, SE1/4NW1/4, N1/2NW1/4, N1/2 $\mathrm{SE} 1 / 4$

Sec. $9, N 1 / 2$, SW1/4, W1/4SE1/4, NW1/4SE $1 / 4$ Sec. $10, N 1 / 2$;

Sec. $11, N 1 / 2, N 1 / 2 S^{1} 1 / 4, N E 1 / 2 S W 1 / 4 ;$

Sec. 12, N1/2SW1/4, S1/2NW1/4, NW11/4NW11/4 SW $1 / 4$ NE $1 / 4, N W 1 / 4 S^{2} 1 / 4, E 1 / 2 S^{1} 1 / 4$.

T. 26 N., R. 63 E.

Sec. 26 , SW $1 / 4$, SW $1 / 4$ NW $1 / 4$, SW $1 / 4$ SE $1 / 4$;

Sec. 27, SE $1 / 4, S^{1} 1 / 4 N^{1} 1 / 4, S^{1} / 2 S^{2} 1 / 4 ;$

Sec. 33, SE1/4, E1/2 SW1/4, S1/2NE1/4;

Sec. 34, N1/2, SW1/4, E1/2SE1/4;

Sec. 35, $W 1 \frac{1}{2}, W^{1} 1 / 2 E^{1} 1 / 2, E^{1} 1 / 2 S^{1 / 4}$

T. 25 N., R. 64 E.

Sec. 7, SW1/4, SW1/4SE $1 / 4$;

Sec. 17, SW $1 / 4$ NW $1 / 4$ :

Sec. 18, NE $1 / 4 N^{1} 1 / 4, N E 1 / 4$.

Blue Mass Canyon Scenic-Area

T. 21 N., R. 68 E.,

Sec. 1, Lots 1 and $2, S 1 / 2 N E 1 / 4$.

T. 21 N., R. 69 E.

Sec. 6, Lots 3, 4, and 5, SE1/4NW1/4.

T. 22 N., R. 68 B.,

Sec. 36, E1/2.

T. 22 N., R. 69 E.

Sec. 31, Lots 2, 3, and 4, E1/2SW1/4, B1/2

SW $1 \frac{1}{4}$, SE$^{1} 1 / 4$ NW $1 / 4$, W $1 / 2 N E 1 / 4$

Bat Cave and Guano Mine Historic Area

T. 15 N., R. 67 E.

Sec. 25, SE $1 / 4$ SE $1 / 4$.

North Creek Scenic Area

T. 10 N., R. 65 E.

Sec. 20, S1/2 S1/2.

Snake Creek Indian Burial Cave

Archaeological Site

T. 12 N., R. 70 E.

Sec. 13, SE $1 / 4$ NW $1 / 4$.

Rock Animal Corral Archaeological Site

T. 15 N., R. 70 E.

Sec. 23, SE1/4.

Baker Creek Archaeological Site

T. 13 N., R. 70 E.

Sec. 7, Lots 1 and 2. 


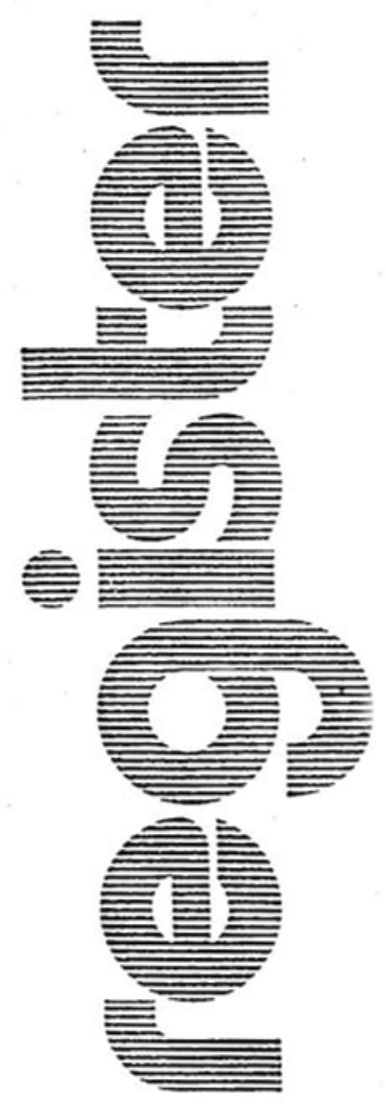

\title{
TUESDAY, APRIL 12, 1977 \\ PART III
}

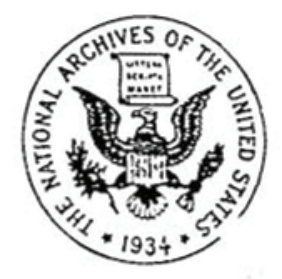

\section{DEPARTMENT OF THE INTERIOR}

Geological Survey

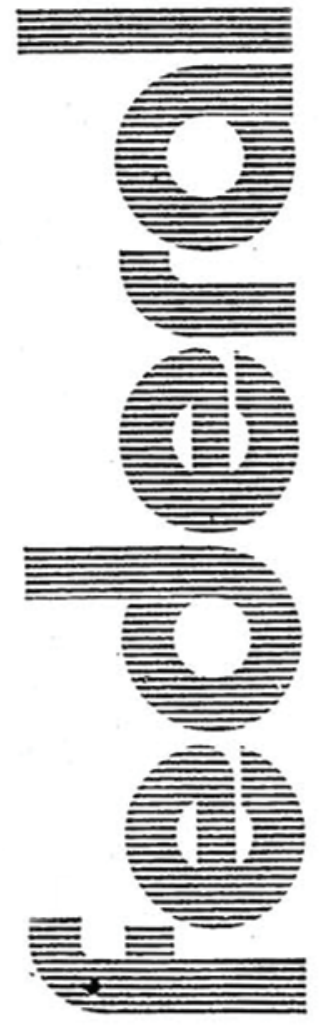

\author{
1. \\ WARNING AND \\ PREPAREDNESS FOR \\ GEOLOGIC-RELATED \\ HAZARDS
}

Proposed Procedures 
19292

\section{DEPARTMENT OF THE INTERIOR Geological Survey \\ WARNING AND PREPAREDNESS FOR GEOLOGIC.RELATED HAZARDS \\ Proposed Procedures}

Geological Survey authority for IsSUING Warnings of Geologic-Related Hazards

Under the broad responstbilities asslgned to the Geological Survey by Its Organlc Act of 1879 for the "examinatlon of the geological structure" of the United States, the Survey has for many decades undertaken studies of earthquakes, volcanoes, and other natural hazards. In recent years, as knowledge of these and related geologic phenomena has Increased, the Survey has also developed capabilities for predicting some potentially hazardous events in some areas, and has the implicit obligation to inform civil authorities and the public of such predictions.

On May 22, 1974. Congress enacted Public Law 93-288 (88 Stat. 143), which Is known as the "Disaster Relief Act of 1974" (hereinafter, "the Act") "to provide an orderly and continuing means of assistance by the Federal Government to State and local governments in carrying out their responsibilities to alleviate the suffering and damage which result from - * disasters - " Section 202 (a) of the Act states that "The President shall insure that all appropriate Federal agencies are prepared to issue warnings of disasters to State and local officials." In addition, Sect!on 202(b) states that "The President shall direct appropriate Federal agencies to provide technical assistance to State and local governments to insure that timely and effectlve disaster warning is provided." The disasters included aro "hurricane, tornado, storm, flood, high water, winddriven water, tidal wave, tsunami. earthquake, volcanic eruption, landslide, mudslide, snowstorm, drought, fire. explosion, or other catastrophe - "." The Act further states in Section 308 that "The Federal Government shall not be liable for any claim based upon the exercise or performance of or the failure to exercise or perform a discre tionary function or duty on the part of a Federal agency or an employee of the Federal Government in carrying out the provisions of this Act."

Executive Order 11795 entitled, "Delegating Disaster Relief Functions Pur suant to the Disaster Relief Act of 1974" (30 FR 25939, July 11. 1974) delegates to the Department of Housing and Ur. ban Development the authority to exercise certain of the powers and authorities of the President with respect to Federal disaster assistance. Pursuant to the authority conferred by Section 1 of E.O. 11795, the U.S. Department of Housing and Urban Development conferred iimited responsibility under the Act- to the Secretary of the Interior 140 FR 52927, November 13, 1975). This authority was, in turn, redelegated by the Secretary of the Interior (Departmental Mianual, 220 JM 8, Release 1883, May 3.

\section{NOTICES}

1976), "subject to the general policy guidance and coordination of the Assistant Secretary-Energy and Minerals," to the Director, Geological Survey, who is "empowered to exercise the authority. functions, and powers granted by Section 202 of the Disaster Relief Act of 1974 with respect to disaster warnings for an earthquake, volcanic eruption, landslide. mudslide, or other geological castastrophe."

\section{Purpose of Statement}

The purpose of this statement is to describe the Geological Survey's capabillties and limitations for advance recognition and warning of various kinds of geologic-related hazards and the procedures proposed to carry out the responsibilities delegated under the Act, and to elicit public comment on the proposed procedures. Application of these capabilities and procedures is largely limited to areas where Geological Survey research and field studies are ongoing. This statement should not be interpreted as indicating the existence of a nationwide operational capability to issue notifications, watches, and warnings of hazardous conditions wherever and whenever they may exist.

Comments regarding these proccdures and policies are invited. Comments received by June 30,1977 will be taken into account in subsequent revisions as appropriate. Comments should be addressed to:

DIrector, U.S. Geological Survey, Natlonal Center, 12201 Sunrise Valley Drlve, Reston, Virgln!a 22092.

\section{E. MCKelvey,} Director.

U.S. Geological Survey.

\section{Definitions}

For the purpose of this statement, a geologic hazard is a geological condition process, or potential event that poses a threat to the health, safety, or welfare of a group of citizens or to the function or economy of a community or large gcvernmental entity. A geological disaster or catastrophe is the occurrence of a severe hazardous event. In the context of this statement, the terms "Notice of Potential Hazard," "Hazard Watch," and "Hazard Warning" refer to the issuance of technical information to officials responsible for public safety and to the news media: recommendations or orders to take defensive actions are issued by officials of State and local governments. where the police and public safety authot:ity rests in our governmental system. These terms are defined as follows:

Notice of potential hazard.-The communication of information on the location and possible magnitude or geologic effects of a potentially hazardous geologic event, process, or condition.

Hazard watch. - The communication oi information, as it develops from a monitoring program or from observed precursor phenomena, that a potentially catastrophic event of generally predictabls magnitude may be imminent in a general area or region and within an indefinite time period (possibly months or years).
Hazard warning.-The communication of information (prediction) as to the time (possibly within days or hours), 10cation, and magnitude of a potentially disastrous geologic event or process.

\section{Capabilities to predict} Hazardous Events

(a) Geologic processes and conditions that could result in harm to people and property include earthquakes, volcanic eruptions, landslides, mudflows, subsidence, faulting and fissuring of the ground surface, and giacier-related phenomena such as release of glaciercammed lakes and rapid ice surges or retreats. Under certain conditions, these events may occur suddenly and affect large numbers of people and property over a wide area; in other instances. however, the processes involved occur slowly or affect very limited areas so that few if any people are endangered.

(b) The present capability of scientists to predict hazardous events varies greatly as to the type of event and as to knowledge of its time, place, and magnitude of effects.

(1) Earthquakes.

(a) Geographic distribution. Much of the United States is subject to some degree of earthquake hazard. The western states of Alaska, California, Hawali, Idaho, Montana, Nevada, New Mexico. Utah, Washington, and. Wyoming are particularly susceptible, but major earthquakes have also struck the eastern and central parts of the United States (Hadley and Devine, 1974), particularly Arkansas, Georgia, Kentucky, Indiana, Illinois, Massachusetts, Mississippi, Missouri, New York, Nc:th Carolina, South Carolina, and Tennessee.

(b) Effects. (i) Earthquake-generated ground shaking, in- many instances. causes the most widespread earthquake damage, principally through fallure of buildings. Earthquakes also give rise to various-geologic processes that may cause injuries and property damage, in cluding surface faulting, landsliding and associated ground failures, generation of large waves in water bodies, and regional vertical movements (downwarping and upwarping).

(ii) The surface effects of earthquakes have been evaluated on the basis of geologic and seismologic studies in parts of Alaska (Page, et al., 1972) $)^{-1}$ California (Borcherdt, 1975), Idaho (Witkind 1972). Nevada (Bingler, 1974), Utah (U.S. Geol. Suryey, 1976), Washingtor (Pitt. 1972; and U.S. Geol. Survey, 1975) and the eastern United States (Dutton. 1889 ). The results of regional studies underway in these and other states will be published as they are completed.

(c) Prediction capability. (i) Precictions of the precise location, time, and magnitude of specific earthquakes-cannot generally be made now. Certain p:ecursors. such as ground tilting anc changes in water levels in wells, the mag. netic field, and seismic wave velocity

'Re:ezences here and elsewhere in thris statement are representative rather than exhaus:lve of descriptions of the phenoment 
characteristics in rock, may be useful In predicting earthquakes. Experimental Instrumental arrays have been Installed in a few research areas, such as near Hollister, California, to evaluate these precursors and to help develop an earthquake prediction capabllity.

(ii) Locations of faults that may be the source of future damaging earthquakes have been determined in some regions of the country, particularly in parts of Alaska, Californla, Nevada, Idaho, Montana, and Utah. Geologic and seimologic studies in these regions. however, are not adequate to assure that all such faults have been delineated. Geologic studies of recurrence intervals of earthquakes have been made on only a few faults, principally in California. Some of these studies provide a basis for estimating the magnitudes of earthquakes that are like to be generated by movement along $a^{*}$ particular fault. Broad-scale estimates of the susceptibility of the various regions of the U.S. to earthquake hazards have been made and are published in earthquake hazard maps and reports (Algermissen and Perkins, 1976) which will be updated as new information is acquired. These maps. and the more detalled studies on which they are based, identify those regions known to be highly susceptible to earthquakes, even though they may not identify all faults along which movement may take place.

(iii) Regional earthquake hazard as sessments are also underway in parts of New Mexico, New York, South Carolina, and Washington, and in the lower Mississippi Valley.

(2) Volcanic eruptions. (a) Geographic distribution. At the present time. volcanoes are active in Alaska and $\mathrm{Ha}$ waii; volcanoes in California, Oregon, and Washington are dormant, but have erupted within the last 150 years. The likelihood of future eruptions damaging to man is greatest in the vicinity of volcanoes in these States. Geologic evidence indicates that volcanic activity could occur in other areas, such as Arizona, Nevada, New Mexico, Wyoming, and Idaho (Mullineaux, 1976), where eruptions have occurred as recently as 350 years ago: there is no current evidence, however, to suggest that volcanic activity may occur in these areas in the near future. Broad estimates have been made of regional susceptibility and types of volcanic hazards in the conterminous U.S and Hawaii and are being published (Crandell, 1976: Crandell and Mullineaux, 1975: Mullineaux, 1976: and Powers. 1948): these will be updated as new information is acquired.

(b) Effects. (i) Volcańic eruptions produce a wide variety of primary and secondary hazards to life and property, stemming mainly from hot avalanches. mudflows. ash falls, lava flows, volcanic gases, hot particle and gas clouds, and floods.

(ii) Studies of the products of past volcanic activity in the Cascade Range, including lava flows, ash falls, mudflows, and hot avalanches, have been completed on the volcanoes of MIt. Baker
(Hyde and Crandell, 1975), Lassen Peak (Crandell, et al, 1974), Mt. Rainler (Crandell, 1973), and Mt. St. Helens (Crandell and Mullineaux, 1976: Crandell, et al, 1975): simllar studies are planned or in progress for other major volcanoes in the Cascade Range, such as Mt. Hood and Mt. Shasta, and for Augustine Volcano in Alaska.

(iii) Detalled studies at Kilauea and Mauna Loa volcanoes in Hawail show that the products of most historic and prehistoric eruptions are lava flows: subordinate products include ash falls and hot particle and gas clouds. Eruptions issue from fissures and vents, both in the summit areas and along rift zones on the flanks of the volcanoes. Assessments of hazard-susceptible areas have been made for the islands of Hawaii (Mullineaux and Peterson, 1974) and Oahu (Crandell, 1975).

(c) Prediction capability. (i) Kilauea and Mauna Loa volcanoes are monitored by an array of instruments and by systematic measurements which permit assessing the likelihood of impending activity (Waesche and Peck, 1966; Kinoshita, et al, 1974). Physical precursors often permit predictions to be made within time frames of weeks or days, and sometimes highly specific signals precede eruptions by one to several hours (Swanson, et al, 1971: Fiske and Kinoshita, 1969).

(ii) A study of the historic cycles of activity on Mauna Loa indicates the possibility of long term prediction of the general locality and the general time frame (months or years) of the next eruptivc event (Lockwood, et a:, 1976).

(iii) Predictive capability has not been achieved for volcanoes in the Cascade Range or Alaska, although it is possible that the methods developed in Hawail might be modified and adapted to be useful in these regions. Detailed estimates of hazard-susceptible areas surrounding some of these and other volcanoes have been made as indicated in section (b) if and iii. Other studies are underway and will be published as completed.

(3) Landslides (including mudflows and mudslides). (a) Geographic distribution. Landslides and related hazards occur in every state in the United States. They occur largely in areas of steep terrain, but also along river, valley, and beach bluffs in otherwise flat country. The general distribution of landslide incidence and susceptibility has been assessed for the conterminous U.S. and published as a national overview map at $1: 7.500 .000$-scale (Radbruch-Hall, et a!.. 1976). This map will be updated as new information becomes available.

(b) Ef ects (i) Many landslides move slowly and commonly are not a great hazard to people. However, they are estimated to cause more than $\$ 1$ billion damage to property annually.

(ii) Mud and debris flows generated by intense rainfall or rapid snowmelt. large landslides that move abruptly, rockfalls, and landslides into large reservoirs may be hazardous to people and property. Similarly, landslides that dam streams inundate property upstream and can produce severe and dangerous flooding downstream if the barrier is breached suddenly.

(c) Prediction capability. (1) A capability to predict the tIme, place, and magnitude of landslides is possible, but is limited to very small individual landslide areas in which detailed geologic and engineering studies have been conducted, Including test borings and laboratory analysis. Consequently, general information on areas potentially susceptible to slope failures will be communicated as a Notice of Potentlal Hazard. Detection of precursors may allow prediction and warning of landslides in areas of special topical studies. as in the Santa Monica Mountains of outhern California (Campbell, 1975).

(ii) In addition to the national overview map of landslide incidence and susceptibility, maps that show landslide deposits at a scale of 1:500,000 have been prepared for the State of Colorado (e.g. Colton, et al.. 1976). Larger-scale $(1: 125,000,1: 62,500$, and $1: 24,000)$, more detailed assessments of landslide susceptibility have been made of a number of small areas and a few regions in varlous parts of the U.S. (Briggs, 1974; Nilsen, 1973; and Simpson, 1976). Such maps are published as they are completed.

(iii) Landslide hazards are evaluated incidental to regional mapping programs or as a part of general geologic hazards studies in selected areas. The Geological Survey is also attempting to delineate and reduce landslide hazards on a nationwide basis.

(4) Glacier-related phenomena. (a) Geographic distribution. Large glaciers that are most likely to be hazardous to people and property occur in Alaska and Washington. Smaller glaciers also occur in California, Colorado, Idaho, Montana. Oregon, and Wyoming. Although no regional or national overview of all gla cler-related hazards has been made, the distribution of potentially hazardous surging glaciers has been analyzed (Post. 1969), and the areas susceptible to outburst flood hazards have been determined in Alaska (Post and Mayo, 1971) and the Paciflc Northwest (Richardson. 1968).

(b) Effects. (i) The rate of advance and retreat of glaciers is generally so slow that there is little cause for concern except in the case of glacier surges and where glacier changes result in floods or icebergs. Rapidly advancin glaciers, and especially surging glaclers. may advance over transportation corridors or other works of man or may dam valleys, causing the formation of glacier-dammed lakes. Such lakes, which may also be formed by glacier retreac. may burst out periodically or sporadica! ly, resulting in downstream flooding Downstream flooding can also be caused by the periodic outbreak. of water-stored within or under glaciers.

(ii) Icebergs, which are formed by calving from the frorit of glaciers that end in the sea or large lakes, may be discharged at greatly increased rates when 


\section{NOTICES}

d. Hazard Watch. (1) If existing or new information indicates that a region, area, locality, or geologic condition is undergoing change that may be interpreted as a precursor to a potentially hazardous event within an unspecifled perlod of time (possibly months or years), such information will be evaluated and, if authenticated, the Director will assure that such information is transmitted promptly to civil authorities and the public as a Hazards Watch.

(2) Federal, State, and local officials responsible for public safety will be notified in advance of the intent to issue a Hazard Watch to enable them to inroke emergency preparedness plans for an orderly public response.

(3) Hazard Watches will be accompanied, to the extent possible, by a definition of the parameters of the expected event, including, in addition to the place, magnitude, and general time, the possible geologic or hydrologic effects and the uncertainties associated with each.

e. Hazard Warning. (1) When developIng information from precursory phenomena, which have been monitored through an experimental or operational hazard assessment program, appears to signal a potentially hazardous event within a specific period of time( possibly days or hours), the information will be conveyed promptly to the Director for evaluation and consideration as a hazard prediction.

(2) The Director or his designee will determine whether or not the prediction has a sound scientic basis and is authenticated by a comprehensive evaluation If a prediction is issued as a result of this review and authentication process, any uncertainties that may exist wi!l bc evaluated and,stated.

(3) The Director, upon authentication of a prediction of an event of possible catastrophic proportions, will assure that such information is promptly transmitted as a Hazard Warning. first to Federal, State, and local officials responsible for public safety, to enable them to invoke emergency preparedness plans for an orderly public response, and then to the news media.

(4) Hazard Warnings will be accom panied, to the extent possible, by a definition of the parameters of the expected event including, in addition to the time, place, and magnitude, the possible geologic or hydrologic effects, and the uncertainties associated with each.

f. Communication of Notices of Potential Hazard, Hazard Watches, and Haz ard Warnings. (1) Information leacing to a Notice of Potential Hazerd or a Haz ard Watch will generally be obtained well in advance of an crent and can be transmitted directl $\because$ to concerned offcials by letters and to the puolic b" p:ess releases to the news media.

(2) Where potentially hazardous conditions are monitored. local. State. and Federal authorities will be informec periodically of the results of such investigations and techrical assistane. to the extent possible, will be extended as re- quested by these officials to assist in developing possible mitigation measures.

(3) At the present time, a capability to predict a geologic event of possible catastrophic proportions within days or hours does not exist except in rare cases. In such cases, where the information becomes avallable that suggesis a potentially disastrous event may be imminent. public officials will be notified by telephone and such information will be transmitted directly to the public as a Hazard Warning. Public and existing Federal communication facilities, such as the Department of Commerce's Weather Radio System and the Department of Defense's National Warning System will be utilized whonever possible and appropriate.

(4) The Geological Survey will also communicate to responsible Federal Agencies and State and local governments, as soon as practicable, all available new knowledge as to geologic conditions or processes that may affect or alter public response to Notices of Potential Hazard, monitoring programs, Hazard Watches, or Hazard Warnings. This may result in the cancellation of the notice. watch, or warning, or a change in the hazard classification to better reflect an increased degree of uncertainty as to the time of occurrence of the event or a lessened sense of urgency.

(5) Notices of Potential Hazard, Hazard Watches, and Hazard Warnings to governmental agencies will also include:

(a) A statement of the authority of the U.S. Geological Survey for issuing the notice, watch, or warning:

(b) Copies of scientific uapers or authentication reports that form the basis of the notice, watch, or warning:

(c) An offer to consult with any reviewers that the Governor or Governors of affected States may wish to appoint:

(d) An offer to provide appropriate technical assistance within areas of expertise in the Geological Survey in evaluating possible geologic hazards, as they may affect people and property:

(e) A statement of what additional steps. if any, the U.S. Geological Survey proposes to take to better deflne the degree or area of hazard; and

(f) A list of all parties to whom the notice, watch, or warning is being transmitted.

g. Technical assistance. (1) As used in this stateinent, technical assistance pertains to:

(a) advice of available Gcological Survey personnel on subjects within their area of expertise-geclogy. hydrology. chemistry, and, to a limited extent, soil engineering. structura! engincering, and land-use planning: and

(b) Deploymen: of available instruments to better define hazardous conditions, processes, or events.

(2) Technical assistauce shoulc not be interpreted to refer to:

(a) Funding for public works or hazard mitigation projects for which funcis have not been allocated to the Geo!ogical Survey:

(b) Assignment of personnel or equipment to assess ! azardous conditions out- side geographical or topical areas of ongoing research or mapping programs except for unusual or compelling roasons. SELECTED RETERENCES

Alzermissen, S. T., and Perk!ns, D. M., 1976. A probabllstic estimate of maximum acceleration In rock in the centlguous Unlted States: U.S. Geol. Survey open-file rept. $76-416,45 \mathrm{p}$.

Bingler, E. C.. 1974, Earthquake hazard map of the Reno area, Nevada: Nev, Bur, of Atines and Geol. Environmental Map Serles, Reno follo.

Eorchierdt, R. D.. ed., 1975. Studies for selsnilc zonation of the San Franclsco Bay reGlo:1: U.S. Ceo!. Survey Prot, Paper 041-A, $102 \mathrm{p}$

Ertggs, R. P.. 1971. Map of overdip slopes that. can affect landslides in Allegheny County. Pe:unsylvanta: U.S. Geol. Survey Misc, Field Studies Map M?P-543, scale 1:125,000. Ditshncil. K. O.. 1975, Map showing areas that correlate with sustdence events due to unclezground nitning of the Pittsburgh and Upper Freeport coalbeds, Allegheny. WashIngton, and Westmoreland Countles, Pennsylvanla: U.S. Geol. Survey Misc. Fleld Studies Map MF-623-C. scale 1:125,000.

Campbell. R. H., 1975. Soll sllps, debris flows. and ratnstorms in the Santa Monica Nountalus and vlcixlty, southern Callforrla: U.S. Geol. Survey. Pror. Paper 851. $51 \mathrm{p}$.

Castle, R. O., and Yerkes, R, F, 1076, Recent surface movements in the Baldwin Hills. Los Angeles County. Californla: U.S. Geol. Surve; Prot. Paper 882, 125 p.

Colton. R. B., Holligan, J. I., Anderson, L. W.. and Patterson, P. E., 1976 Preliminary map o: landslida deposits in Colorado: U.S. Geol. Survey Misc. Inv. Map I-964, scale 1:500.000

Crandell, D. P., 1973. Map showlng potentlal l:azards from future eruptlons of Mount Ralnler, Washington: U.S. Geol. Survey Misc. Inv. Map I-836, scale 1:250,000.

- 1975. Assessment of volcanic risk on the island of Oahu, Hawall: U.S. Geol. Survey open-file rept.-75-287; 34 p.

1976. Prelliminary assessment of potentia! hazarcis from future volcaritc eruptlons in washington: U.S. Geol. Survey Mise. Field Studies Map MF-774, scale $1: 1.000,000$

Crjndeil. D. R., and Mullineaux, D. R., 1975 , Techniģt:e and rationale of volcanlc hazard3. appraisa:s in the Cascade Range. northwestern United 8tates: Environmental Geology, v. 1, p. 23-32,

1976. Potential hazerds from future ert:pitions of Mtouat St. Helens Volcano. Washington: U.S. Geol. Survey open-fle rept. $76-421,25 \mathrm{p}$

Crance:1; D: R., Mfutlineaux, D. R., and Rubln. Ne:er. 1975, Mount St. Helens Volcano. recent and future behav! ${ }^{2}$. Sclence; February, v, 187 , no: 4175 , p. 438-440.

Crance!!. D. R.. Mutulneaux, D. R., S!ga: $\infty$ s. R. S.. and Rubing Meyez. 1974. Chags:Crags eruptions and rockfall-avalanches, Lassen Vo:canic National Park, Callfornia: U.S. Gso!. Survey Jour. Research. v. 2, no. 1, p $49-59$

Da:ies. W. E., Simpson, J. H., Ohlmacner. G. C. Kirk, W. S., and Newton E. G 1376 Iap showing engineering aspects of kars: f: :is United States: U.S. Geol. Surve opa:!-file map 76-623. scale $1: 7.500,000$.

Dun:ud. C. R., 1975: Engineorting geology fac to:s controlling coal-mining subsidence th t'tali and Colorado:-U.S. Geol. Survey: Pro: Pajer $969.30 \mathrm{p}$

Diticn .C. E...1883, The Charleston earthquake of August 31, 1886; U.১. Geal survey Arntia! Repori 9. p. 203-528. 


\section{NOTICES}

Fiske, R. S., and Kinoshlta, W. T., 1969, In flation of Kllauea Volcano prior to 1ts 1967-1968 eruption: Sclence, v. 165, p. $341-$ 349 .

Gabrysch, R. K., 1969, Land-surface substdence in the Houston-Galveston reglon, Texás: in Land subsidence: Internat. Assn. Sclentinc Hydrology, Pub. 88 (IASHUNESCO), v. 1, p. 43-54.

Gabrysch, R. K., and Bonnet, C. W., 1976. Land-surface subsidence at Seabrook, Texas: U.S. Geol. Survey Water Rezources Int. 76-31.

Hadley, J. B., and Devine. J. F., 1974, Selsmotectonic map of the castern United States: U.S. Geol. Survey Misc. Fleld Studizs Miap MF-620, 8 p., 3 map sheets, scale 1:500,000.

Hyde, J. H., and Crandell, D. R., 1975, Origin and age of postglaclal depostts and assess. ment of potentlal hazards from future eruptlons of Mount Baker, Washington: U.S. Geol. Survey open-file report $75-286$, $22 \mathrm{p}$.

KInoshlta, W. T., Swanson, D. A., and Jack son, D. B., 1974. The measurement of crustal deformation related to volcanlc activity at Kllauea Volcano. Hawall: In Physlcal Volcanology, ed. Clvetta, L., Gasparinl, P., Luongo, G., and Rapolla, A., Elsevier Scientific Publishing Co., p. 87-115.

Lockwood, J. P., Koyanagl, R. Y., Tilling, R. I. Holcomb. R. T., and Peterson, D. W., 1976. Mauna Loa threatening: Geotimes, v. 21 no. 6. p. $12-15$.

Lofgren, B. E., 1969, land subsidence due to the application of water: in Revlews in Englneering Geology II: Geol. Scl. of Amer Ica, p. 271-303.

1975, Land subs!dence due to ground. water withdrawa!, Arvin-Marlcopa area, Callfornla: U.S. Geol. Survey Prof. Paper 437-D. p. D1-D55.

Mullineaux, D R.. 1976. Prellminary overvlew map of volcanic hazaras in ino $=n n$ terminous United States: U.S. Geol. Survey Misc. Fleld studies Map MF-78s, scale $1: 7,500,000$.
Mullineaux, D. R., and Peterson, D. W., 1974 Volcantc hazards on the Island of Hawall: U.S. Geol. Survey open-file report 74-239, $61 \mathrm{p}$.

Newton, J. G., 1976, Early detection and correction of sink hole problems in Alabama, with a prellminary evaluation of remote wensing applications: Alabama Highway Dept., Bur. Research and Develop., Research Rept. HPR-76, 83 p.

Nilsen, T. H., 1973, Prellminary photolnterpretation map of landslide and other surficial deposits of the Concord 15-minute quadrangle and the Oakland West, Richmond. and part of the San Quentin $71 / 4$ minute quadrangles, Contra Costa and Al ameda Countles, Callfornta: U.S. Geol. Survey Misc. Field Studles Map MF-493. scale $1: 62,500$.

Papadopulos. S. S., Wallace, R. H., Jr., Wesselman, J. B., and Taylor, R. E., 1975 Assessment of onshore geopressured-geo thermal resources in the northern Gulf of Mexico basin in Assessment of Geotherma: Resources of the United States-1975. White, D. E., and Williams, D. L., eds.: U.S. Geol. Survey Circ. 726, p. 125-141.

Page, R. A., Boore, D. M., Joyner, W. B., and Coulter. H. W., 1972, Ground motion values for use in the selsm!c design of the trans. Alaska plpeline system: U.S. Geol. Survey Clrc. 672, $23 \mathrm{p}$

Pitt, A. M., 1972, Seismic activity in the Hanford region, Washington, March 23, 1969 to Junc 30, 1971: U.S. Geol. Survey openfile report, 25 p.

Poland, J. F., 1971. Land subsidence in the Santa Clara Valley, Alameda, San Mateo. and Santa Clara Countles, Californta: U.S. Geol. Survey Misc. Field Studles Map MF 336. scale $1: 125,000$.

Poland, J. F., and Dav!s, G. H., 1969, Land subsidence due to withdrawal of flutds: Geol. Soc. Amertca, Revlews in Eng. Geol. II. p. 187-269.

Posi Austin, 1969. Distribution of surgtng glaciers in western North America: Jour. Glaclolo:v, vol. 8 , no. 53, p. 229-240.
1975. Preliminary hydrography and historle terminal changes of Columbla Glacter. Alaska: U S. Geol. Survey Hyd. Atlas, HP. 559,3 sheets.

Post, Alistin, and Mayo, L. R., 1971, Glacler dammed lakes and outburst foods in Alaska: U.S. Geol. Survey Hyd. Atlas HA 455,3 map sheets, 10 p.

Powers, H. A., 1948, A chronology of the exploslve eruptions of Kllauea: Paclac Sclence, v. 2. no. 4. p. 278-292.

Radbruch-Hill, D. H. Colton, R. B., Davles. W. E. Lucchitta, Ivo, Skipp, B. A., and Varnes, D. J., 1976. Preltminary landsltde overvle: map of the Conterminous Unlted States: U, S-Geol. Survey Misc. Fleld Studies Map MF-771, scale 1:7,500,000.

Richardson. Don, 1968. Glacler outburst floods in the Pacific Northwest: U.S. Geol. Survey P:of. Paper 600-D, p. D79-D86.

Simpson, H. E., 1976. Map showling landslides in the Golden quadrangle. Jefferson in the Golden quadrangle, Jefferson
County. Colorado: U.S. Geol. Survey Misc. Inv. Mip I-761-B, scale 1:24,000.

Swanson, D. A., Jackson, D. B., Duffeld, W. A., and Petezzon, D. W.. 1971. Mauns Ulu eruption, Kllauea, Volcano; Geotlmes, v. 16. no. 5, p. $12-16$

U.S. Geol. Survey, 1975, A study of earthquake losses in the Puget Sound area, Washington: U.S. Geol. Survey open-file report $75-375.298 \mathrm{p}$.

1976, A stud $;$ of earthquake losses in the Salt Lake Cits area, Utah: U.S. Geol. Survey open-file report $76-89,357 \mathrm{p}$.

Witk!nd. I. J, 1972, Earthquake hazard map of the Hen:ys Lake quadrangle, Idaho and Montana: U.S. Geol. Survey Misc. Inv. Map I-781-E, scale $1: 62,500$

Yerkes, R. F.. and Castle, R. O., 1969, Surface deformation assoclated with oll and gas field operations in the United States, in Land subs!cence: Internat. Assn. Sclentific Hydrolog:, Pub. 88 (IASH-UNESCO), v, 1 , p. $55-56$.

Waesche, H. H., and Peck, D. L., 1966, Volcanoes tell secrets in Hawall: Natural History. Ma:ch 1966, p. 21-29.

[FR Dos.77-10732 Filed 4-11-77;8:45 am] 
Car transported by the 2004 tsunami in Sri Lanka, Jan. 2005. Photograph by Robert Morton, USGS.

a)

$+2$

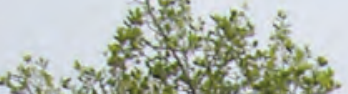

H.

Nin

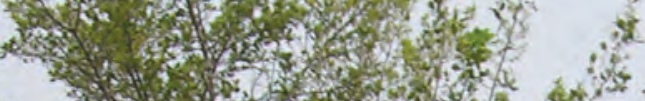

a

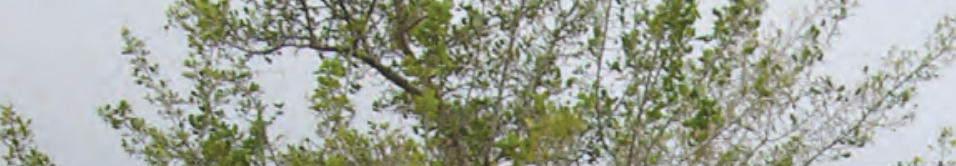




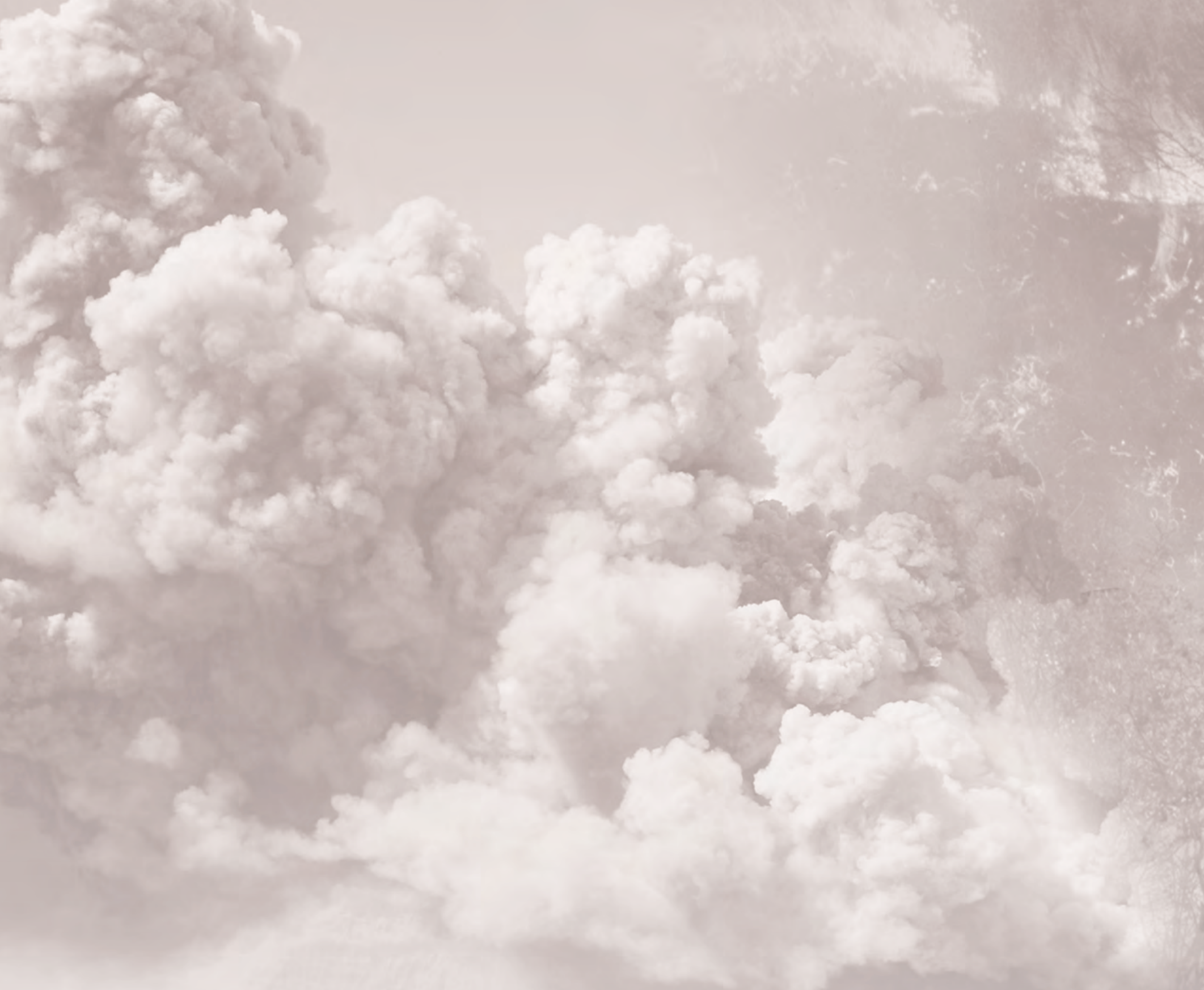



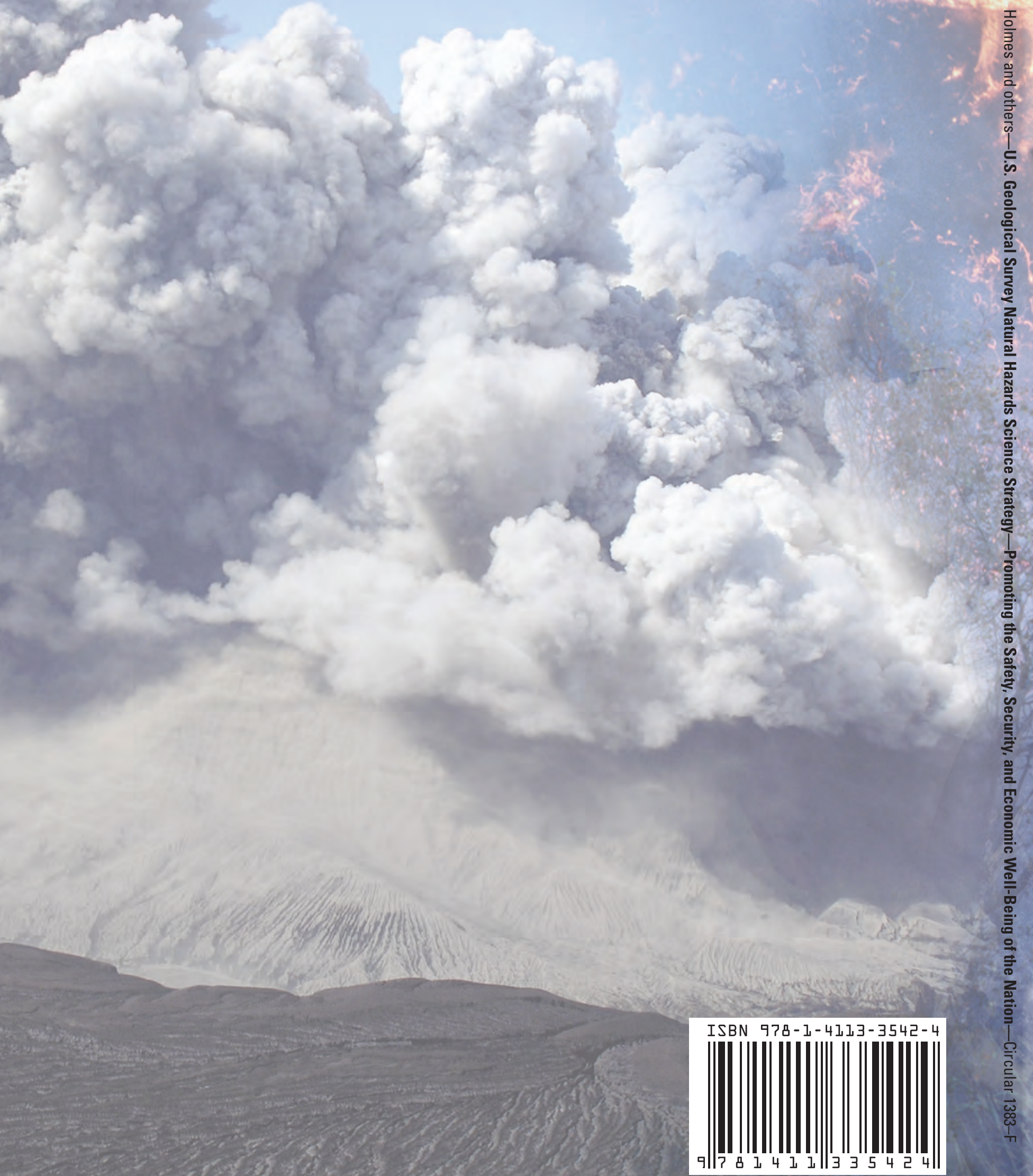